Universidade de São Paulo

Instituto de Medicina Tropical de São Paulo

Eduardo Evangelista

ESTUDO DAS VARIAÇÕES DAS ASSEMBLEIAS DE CULICÍDEOS (DIPTERA:

CULICIDAE) NOS DIFERENTES ESTRATOS DA VEGETAÇÃO E SUA

RELAÇÃO COM HÁBITOS ALIMENTARES

Dissertação apresentada ao Instituto de Medicina Tropical da Universidade de São Paulo para obtenção do título de Mestre em Ciências

Área de concentração Doenças Tropicais e Saúde Internacional

Orientador Prof. Dr. Mauro Toledo Marrelli

São Paulo 


\section{Eduardo Evangelista}

ESTUDO DAS VARIAÇÕES NAS ASSEMBLEIAS DE CULICÍDEOS (DIPTERA: CULICIDAE) NOS DIFERENTES ESTRATOS DA VEGETAÇÃO E SUA RELAÇÃO COM HÁBITOS ALIMENTARES

Dissertação apresentada ao Instituto de Medicina Tropical de São Paulo da Universidade de São Paulo para obtenção do título de Mestre em Ciências

Área de concentração Doenças Tropicais e Saúde Internacional

Orientador Prof. Dr. Mauro Toledo Marrelli

São Paulo 
Ficha catalográfica elaborada pela Biblioteca do Instituto de Medicina Tropical de São Paulo da Universidade de São Paulo - Bibliotecário Carlos José Quinteiro, CRB-8 5538

(c) Reprodução autorizada pelo autor

Evangelista, Eduardo

Estudo das variações das assembleias de culicídeos (Diptera: Culicidae) nos diferentes estratos da vegetação e sua relação com hábitos alimentares / Eduardo Evangelista. - São Paulo, 2018.

Dissertação (Mestrado) - Instituto de Medicina Tropical de São Paulo da Universidade de São Paulo, para obtenção do título de Mestre em Ciências.

Área de concentração: Doenças Tropicais e Saúde Internacional

Orientador: Mauro Toledo Marrelli

Descritores: 1. CULICIDAE. 2. BIODIVERSIDADE. 3. ANOPHELES. 4. REAÇÃO EM CADEIA POR POLIMERASE. 5. ENTOMOLOGIA MÉDICA. 6. ÁREAS DE CONSERVAÇÃO.

USP/IMTSP/BIB-11/2018. 


\section{Agradecimentos}

Nesse espaço gostaria de expressar o quanto sou grato a todas as pessoas que acompanharam minha jornada neste desafio do mestrado.

Agradeço ao meu orientador Dr. Mauro Toledo Marrelli pela amizade, respeito e pela proximidade com seus alunos (o que torna o ambiente agradável ao trabalho e estimula a busca pelo conhecimento) por me aceitar como seu aluno e acreditar que eu poderia seguir adiante com o desenvolvimento do meu trabalho, através de suas considerações e orientação sempre com agilidade, assertividade e precisão, desde o aprimoramento profissional em 2015 até o mestrado.

Agradeço a Agência de Fomento à Pesquisa do Estado de São Paulo - FAPESP pelo financiamento durante todas as ações de meu projeto de mestrado, processo n²015/25820-6 bolsa de mestrado. Ao financiamento do projeto Biota/FAPESP $n^{\circ}$ 2014/50444-5, (do qual surgiu o meu projeto) que custearam as campanhas para áreas de coleta, que proporcionaram elevação em meu enriquecimento profissional, pessoal e intelectual.

Agradeço ao Instituto de Medicina Tropical de São Paulo, Universidade de São Paulo - IMTUSP, por onde iniciei minha trajetória no mestrado pela aprovação em sua seleção. Agradeço ao Dr. Expedito José de Albuquerque Luna e a Dra Hiro Goto por me avaliarem e me aceitarem no programa de mestrado.

Agradeço a Eliane Araújo do Serviço de Pós-Graduação Programa de Medicina Tropical desse instituto pelo suporte a mim prestado, sempre com rapidez e assertividade. Ao Sr. Carlos José Quinteiro (Bibliotecário chefe do IMT) pelo suporte e conferência da bibliografia na versão final da dissertação.

Agradeço ao amigo Antônio Ralph Medeiros-Souza por estar sempre presente e disponível para receber e me ajudar com a estatística de meu trabalho, além de todas as discussões sobre o tema de estudo, que foram fundamentais e contribuíram para o enriquecimento e desenvolvimento do meu trabalho.

Ao taxonomista Aristides Fernandes pela simplicidade, respeito, atenção aos alunos do laboratório, ao seu trabalho minucioso na taxonomia de mosquitos que, sem seu trabalho outros não seriam possíveis.

Ao amigo Walter Ceretti-Jr pela presença, pelo companheirismo, repertório de músicas tocadas diariamente que descontraem o laboratório, pelas muitas trocas de ideias, dicas de leitura de artigos, idas a campo.

A Gabriela Carvalho pelos ensinamentos das técnicas moleculares e compartilhamento de suas experiências com o trabalho de hábito alimentar dos mosquitos. Ao Daniel Pagotto Vendrami pelos ensinamentos no laboratório de biologia molecular, pela solidariedade em um momento difícil e pela amizade. A Natasha França pela descontração nas conversas com o grupo. Ao Ramon Wilk pelos conselhos e troca de ideias sobre diversos assuntos. Ao Rafael Christe pelas conversas sobre variados assuntos, de vídeo game à metafísica. A Amanda Alves 
que esteve presente na jornada de estudo desde o aprimoramento. A Laura Sayão pela ajuda nas questões de biologia molecular e pela amizade. À todos os amigos do laboratório de Entomologia da sala 24 na FSP/USP, Karolina Morales, Ana Letícia, Laura Multini e André Wilke.

Agradeço ao Biólogo Dr. Delsio Natal pelo vasto conhecimento em Entomologia Médica - Ecologia de mosquitos transferidos à seus alunos e a instigar seus alunos sempre ao debate sobre os Culicidae em suas aulas, nos ambientes da FSP/USP e por fazer parte de minha banca de qualificação e defesa. A Dra. Tamara Nunes de Lima Camara pela participação na banca de defesa e suas considerações neste trabalho. A Dra. Regiane Tironi (SUCEN/SP) pela participação em minha banca de defesa, pelas aulas ministradas no curso de estatística para entomologia que pude participar, pelo prazer em ajudar seus alunos com as duvidas.

Aos amigos Ronan Coelho, Pâmela Andrade, Bruno Nakazato, Dr. Paulo Urbinatti, Dra. Márcia Bicudo, Dra. Leticia Marteis, pela amizade.

Dra. Maria Anice Mureb Sallum que me proporcionou nas aulas novos olhares sobre a epidemiologia das doenças e entomologia voltada aos Culicidae. À Tatiane, Sandra Nagaki, Ivy Luizi, Leonardo Suveges, pela amizade.

As meninas do programa de Mestrado Profissional em Entomologia da FSP/USP, Carole, Júlia Vono, Geane Andrade, Kelly Reis, Samanta Parisi.

À Joyce Montes, Renildo (CCZ) presentes nas coletas no Parque Estadual da Cantareira (PEC).

Aos colegas Dr. Luís Mucci, Luiz Bonafé SUCEN Taubaté, Paulo "Bilão", João SUCEN Caraguatatuba pela descontração e pelas conversas animadas durante as coletas. Ao Marcio Port Carvalho, Instituto Florestal pelo apoio durante as coletas no PEC.

Agradeço a pesquisadora Dra. Ana Maria de Castro Ribeiro Duarte pela simplicidade, disponibilidade e apoio.

Agradeço eternamente à minha mãe Vilma Elizabeth a mais resiliente e forte guerreira que já conheci que sempre teve muita consideração e acima de tudo Amor incondicional por mim e pelos seus netos. Ao meu pai Hélio por me ensinar experiências de vida. A minha irmã Vanessa Hampsher por estar presente.

À minha esposa amada, dedicada, amiga e companheira de sempre Fernanda Barreiro da Silva Evangelista, aos meus filhos Kauê lan (01), Hayra Elizabeth (02), Caio Hanry (03) e Yurik (04) meus bebês, alguns nem tanto bebês... Mas minhas alegrias e motivos para continuar perseguindo meus sonhos.

Á todos que fizeram parte dessa jornada de sucesso e realização.

Muito Obrigado!

Nam-myoho-renge-kyo. 
"Passei a vida inteira com medo, medo das coisas que poderiam acontecer e das que poderiam não acontecer. O que eu descobri foi que o medo, essa é a pior parte. Esse é o verdadeiro inimigo". 


\section{RESUMO}

Evangelista E. Estudo das variações nas assembleias de culicídeos (Diptera: Culicidae) nos diferentes estratos da vegetação e sua relação com hábitos alimentares (dissertação). São Paulo: Instituto de Medicina Tropical de São Paulo da Universidade de São Paulo; 2018

Estudo entomológico foi realizado nos limites extremos do município de São Paulo, que possuem cobertura vegetal significativa em forma de Unidades de Conservação representadas ao norte, pelo Parque Estadual da Cantareira (PEC), onde epizootias e casos humanos de febre amarela têm ocorrido nos últimos anos, e ao sul, pela Área de Proteção Ambiental (APA) Capivari Monos onde ocorrem casos assintomáticos de malária-bromélia. Mosquitos foram coletados no período de fevereiro de 2015 a abril de 2017, em sete ambientes com feições periurbana, intermediária e silvestre. Armadilhas CDC foram instaladas na copa e ao nível do solo, com objetivo de verificar a estratificação vertical das espécies de mosquitos. Aspiração e armadilha de Shannon complementaram as coletas de fêmeas ingurgitadas para verificação do comportamento alimentar por técnica de PCR. Nove oligonucleotídeos do citocromo $\mathrm{B}$ mitocondrial foram utilizados para este propósito. Riqueza, abundância, composição e equabilidade foram utilizados para verificar a diversidade dos ambientes. No total foram obtidos 10.070 espécimes de culicídeos adultos distribuídos em 95 espécies/categorias taxonômicas distribuídas em dezesseis gêneros. Na APA, foram identificadas 75 espécies/categorias taxonômicas e 7.472 espécimes e desse total $67 \%$ foram mais frequentes na copa. As espécies Culex (Culex) nigripalpus e Anopheles (Kerteszia) cruzii, ambas ocorrendo com maior frequência no estrato copa em todos os ambientes pesquisados. No PEC, 58 espécies/categorias taxonômicas e 2.598 espécimes foram coletados e $55 \%$ foi coletado no estrato solo. Wyeomyia (Prl.) confusa (solo), Culex (Mel.) vaxus (copa) e Limatus durhamii (solo) foram as mais abundantes. Com relação aos hábitos alimentares 386 amostras foram obtidas, Anopheles cruzii representou $70 \%$ (270), se alimentando principalmente em hospedeiro humano no estrato solo. A presença de culicídeos vetores evidenciam a alta importância epidemiológica dos ambientes estudados merecendo atenção das autoridades em saúde publica, dada a interação entre as espécies de mosquitos e suas fontes de repasto sanguíneo.

Palavras chave: Culicidae. Biodiversidade. Anopheles. Reação em cadeia por polimerase. Entomologia médica. Áreas de conservação. 


\begin{abstract}
Evangelista E. Study of the variations of the mosquitoes assemblages (Diptera: Culicidae) in different strata of the vegetation and its relation with eating habits. (dissertation). São Paulo: Instituto de Medicina Tropical de São Paulo da Universidade de São Paulo; 2018
\end{abstract}

An entomological study was carried out in the extreme limits of the municipality of São Paulo, which have significant vegetation cover in the form of Conservation Units, represented in the north, by the State Park of the Cantareira (PEC), where epizootics and cases human of Yellow Fever have been occurred in the last years, and in the South by the Environmentally Protected Area Capivari Monos, where asymptomatic cases of malaria-bromelia have been occurred. Mosquitoes were collected from February 2015 to April 2017 in seven environments with peri-urban, intermediate and wild features. CDC Traps were installed in the canopy and at ground level, with the objective of verifying the vertical stratification of mosquito species. Aspiration and Shannon traps complemented the collection of engorged females to verify the feeding behavior by PCR technique. Nine mitochondrial cytochrome B oligonucleotides were used to this propose. Richness, abundance, composition and equability were used to verify the diversity of environments. In total, 10,070 adult culicidis were collected, comprising 95 species / taxonomic categories distributed in sixteen genera. At APA, there were 75 species / taxonomic species and 7,472 specimens and a total of $67 \%$ were more frequent in the canopy. The species Culex (Culex) nigripalpus and Anopheles (Kerteszia) cruzii, occurred more frequently and canopy stratum in all the environments surveyed. In the PEC, 58 species / taxonomic categories and 2,598 specimes were collected and $55 \%$ were collected in the ground strata. Wyeomyia (Prl.) confusa (ground), Culex (Mel.) vaxus (canopy) and Limatus durhamii (ground) were more abundant. Regarding the feeding habits, 386 samples were obtained, Anopheles cruzii represented $70 \%$ (270), feeding mainly on human host in the ground strata. The presence of vector culicids evidences the high epidemiological importance of the studied environments, deserving attention of the Public Health Authorities due to the presence and interaction of mosquito species and their sources of blood feeding.

Keywords: Culicidae. Biodiversity. Anopheles. Polymerase chain reaction. Medical entomology. Areas of conservation. 


\section{Sumário}

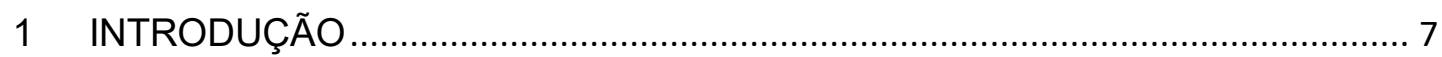

1.1 Família Culicidae: Diversidade e Bioecologia. ..................................................... 7

2.1 Estratificação Vertical e Acrodendrofilia de Mosquitos: ecologia e implicações

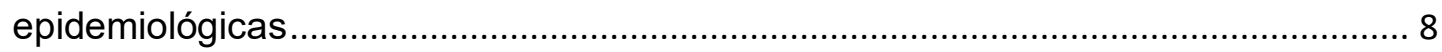

3.1 Comportamento Alimentar de Mosquitos ….....................................................

4.1 Técnicas para identificação de Hábitos Alimentares em mosquitos ....................13

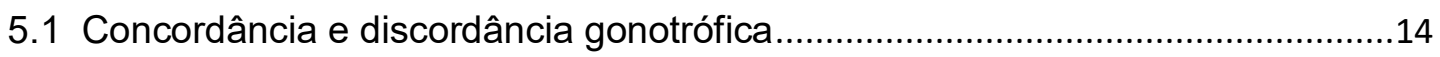

6.1 A Área de Proteção Ambiental Capivari Monos e o Parque Estadual da

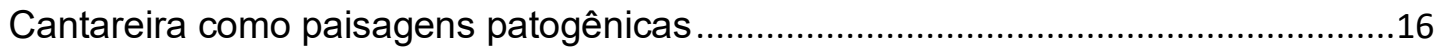

7.1 Mosquitos vetores do vírus da Febre Amarela em São Paulo............................19

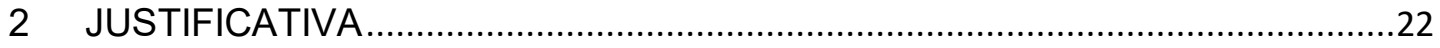

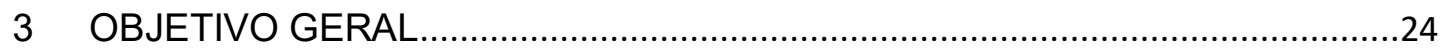

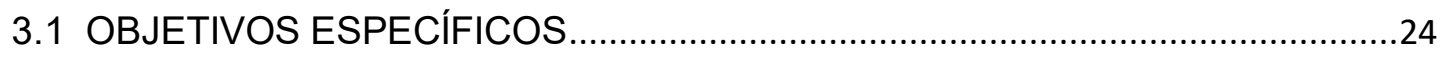

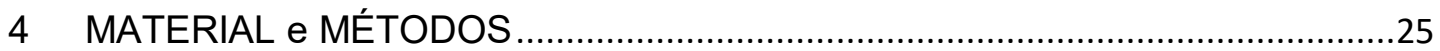

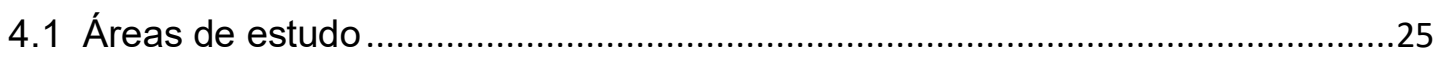

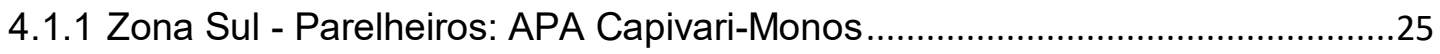

4.1.2 Zona Norte - Serra da Cantareira: Parque Estadual da Cantareira ..................29

4.2 Coleta de culicídeos: Estratificação Vertical.........................................................32

4.3 Coleta de mosquitos ingurgitados: Hábito Alimentar...........................................33

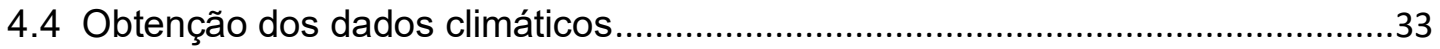

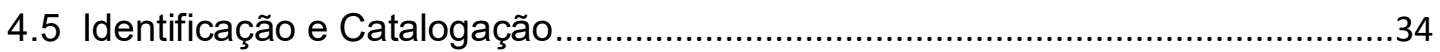

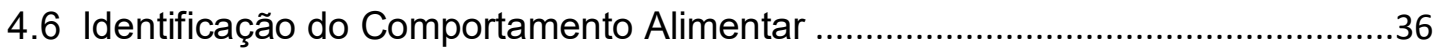

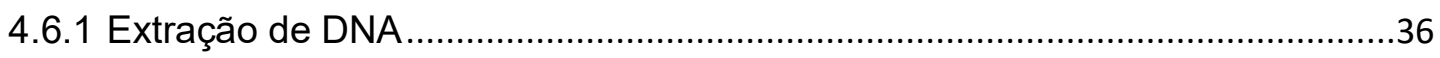

4.6.2 Reação em Cadeia da Polimerase (PCR).........................................................36

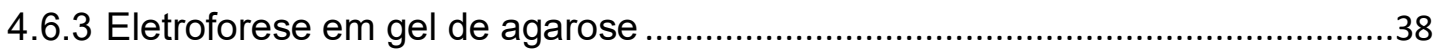

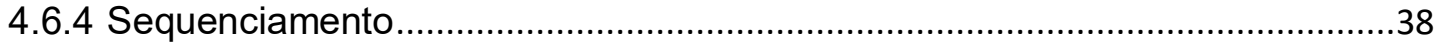

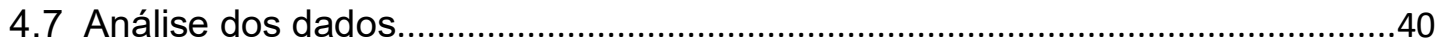

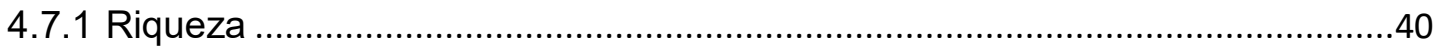

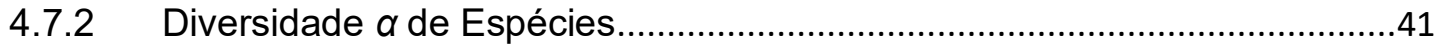

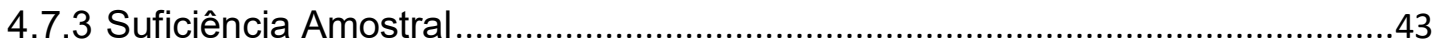

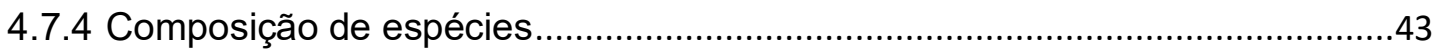


4.8 Estratificação Vertical: Frequência copa e solo . .44

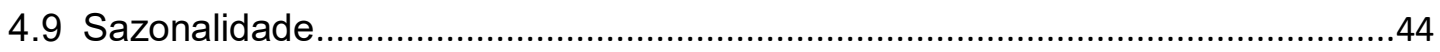

4.10 Comportamento Alimentar de mosquitos ........................................................45

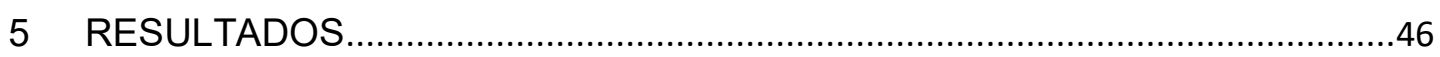

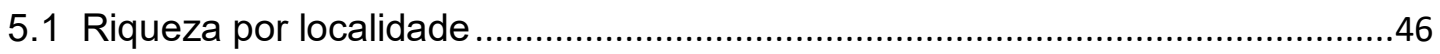

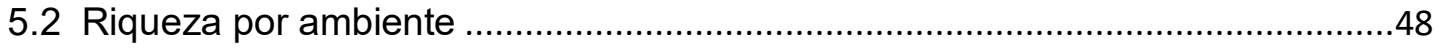

5.3 Índices de Diversidade: Perfis de diversidade .................................................51

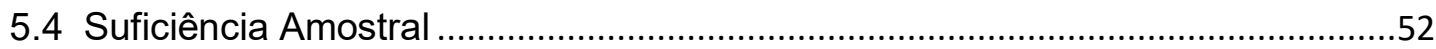

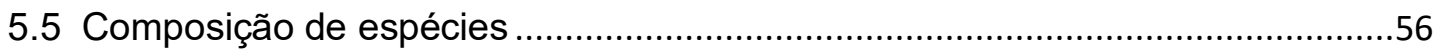

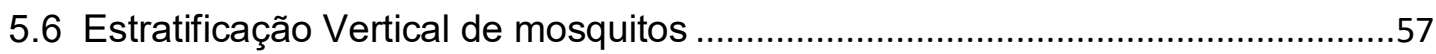

5.7 Sazonalidade e Abundância de mosquitos ...........................................................66

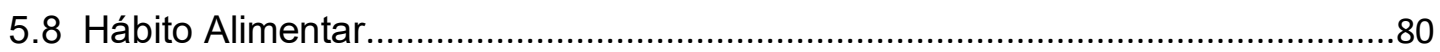

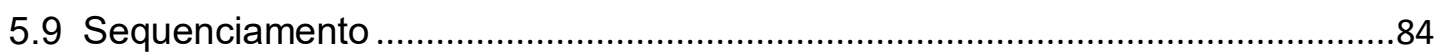

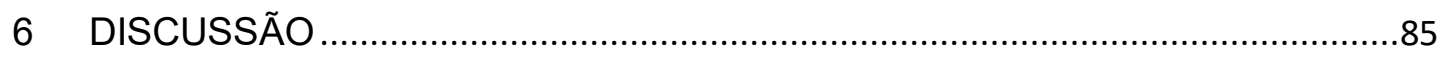

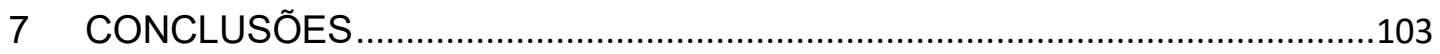

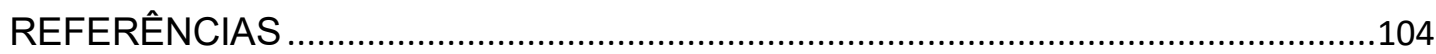




\section{INTRODUÇÃO}

\subsection{Família Culicidae: Diversidade e Bioecologia.}

A família Culicidae Meigen, 1818 compreende um táxon monofilético da ordem Diptera'. São popularmente conhecidos como mosquitos, pernilongos, carapanãs e muriçocas, entre outros nomes dependendo da região no Brasil pesquisada ${ }^{2}$. Possui conhecimentos pouco explorados em relação a seu papel na ecologia reprodutiva de plantas como polinizadores, no entanto, sua maior importância está no papel desses insetos na saúde pública com fator de incômodo e na transmissão de patógenos aos animais silvestres, homem e animais domésticos ${ }^{3,4}$.

O ciclo de vida desses insetos é do tipo holometábolo, compreendendo as fases de ovo, quatro estádios larvais, pupa e adultos alados, sendo as duas primeiras fases do desenvolvimento ocupando nichos aquáticos e o adulto é terrestre ${ }^{5,6}$. Alguns gêneros de mosquitos depositam seus ovos nas superfícies úmidas dos possíveis criadouros, enquanto outras depositam diretamente na lâmina d'água ${ }^{2}$.

Segundo o inventário taxonômico de mosquitos $^{7}$ os culicídeos são representados por mais de 3.550 espécies válidas ocupando amplamente todas as regiões biogeográficas do mundo, sendo a região Neotropical a que detém o maior nível de endemicidade de espécies ${ }^{8}$. A família está dividida em duas subfamílias Anophelinae com três gêneros e Culicinae com 110 gêneros divididos em 11 tribos $^{7}$.

No Brasil, a fauna de mosquitos é composta por mais de 490 espécies reconhecidas, distribuídas em seus diferentes biomas e gêneros como Haemagogus, Chagasia e representantes da tribo Sabethini, como, Limatus, Runchomyia, Sabethes, Trichoprosopon são exclusivos do país 9 . 
Os mosquitos muito presentes em São Paulo, foram estudados por Urbinatti et al. ${ }^{10}$ no Parque Ecológico do Tietê identificaram 22 espécies, sendo $90 \%$ dos indivíduos representantes da espécie Culex (Culex) quinquefasciatus. Taipe-Lagos e Natal ${ }^{11}$ no Parque Ecológico do Tietê identificaram 25 espécies. Na região da Serra da Cantareira, Montes ${ }^{12}$ identificou 21 espécies distribuídas em 11 gêneros. Em 2011, Silvério e Urbinatti ${ }^{13}$ identificaram 13 espécies de mosquitos em um piscinão de contenção de cheias na Zona Leste do município. Ribeiro et al. ${ }^{14} \mathrm{em}$ pesquisa na Área de Proteção Ambiental Capivari-Monos em ambiente silvestre e antrópico observaram diversidade de 91 táxons, sendo o ambiente antrópico mais rico e diverso. Outra pesquisa importante para o conhecimento da fauna de mosquitos do município de São Paulo foi publicada recentemente, por MedeirosSouza et al. ${ }^{15}$, onde observaram a fauna de mosquitos de 59 parques urbanos revelando 53 espécies.

\subsection{Estratificação Vertical e Acrodendrofilia de Mosquitos: ecologia e implicações epidemiológicas}

Diversos estudos sobre estratificação vertical de culicídeos foram realizados em várias partes do mundo, com intuito de verificar de que maneira os mosquitos se distribuem, quais são os fatores que influenciam sua riqueza, abundância, distribuição espacial e como realizam suas funções ecológicas em áreas silvestres, rurais e urbanas ${ }^{16-20}$.

Sabe-se que algumas espécies de mosquitos são mais abundantes na copa das árvores recebendo o nome de acrodendrófilos, enquanto outros ocorrem em níveis mais próximos ao solo, e ainda, para algumas espécies as elevações verticais são indiferentes ${ }^{21}$. A literatura cita alguns fatores endógenos e exógenos aos mosquitos que determinam tal comportamento de estratificação vertical. Bates ${ }^{16}$ listou sete fatores extrínsecos e intrínsecos que acreditou influenciar na distribuição 
vertical de mosquitos, tais como, os gradientes de temperatura, umidade, luminosidade, resistência específica à dessecação, locais para oviposição, enxameamento dos machos na atividade reprodutiva e o encontro de recursos alimentares, inferindo também sobre uma possível tendência de mosquitos em procurar alimento em determinados vertebrados. No Brasil, Forattini et al. ${ }^{22}$ chegaram a resultados semelhantes sobre espécies de mosquitos, estratificação vertical e seus hábitos alimentares.

Aragão ${ }^{17}$ estudou as variações microclimáticas de temperatura, umidade relativa e evapotranspiração da vegetação, relacionando com o comportamento ecológico dos anofelinos do subgênero Kerteszia na transmissão de plasmódios. Love e Smith ${ }^{23}$ estudaram a estratificação vertical em seis níveis de altura, e seus resultados levaram à estruturação da comunidade de mosquitos em quatro padrões de distribuição das espécies encontradas, apontando que, em alguns casos houve correlação entre a distribuição vertical dos mosquitos e seus hábitos alimentares.

Love e Smith ${ }^{23}$ encontraram mosquitos do gênero Anopheles se alimentando frequentemente do homem e outros mamíferos no nível do solo. No entanto, sua frequência em coletas foi maior em alturas acima de 2 metros, sugerindo que a disponibilidade de hospedeiros habituais de certas espécies de mosquitos pode influenciar seu comportamento entre os estratos nos diferentes ambientes de floresta. Mitchell e Rockett ${ }^{18}$ identificaram variações sazonais na população de mosquitos do gênero Aedes e Culex coletados em ambiente florestado, sendo espécies do gênero Aedes mais abundantes em junho e Culex em agosto.

Em um surto de transmissão ativa de casos de West Nile Vírus (WNV) em 2002 e 2003 ocorrido nos Estados Unidos, verificou-se que no mínimo seis espécies de mosquitos coletados, portavam o arbovírus e Culex pipiens habitando principalmente a copa das árvores, enquanto, Cx. salinarius ocupando os nichos mais próximos ao nível do solo tiveram os maiores índices de capturas e ainda 
neste estudo, Cx. pipiens apresentou as maiores taxas de isolamento para o vírus nos anos consecutivos ${ }^{24}$.

No Brasil, durante as pesquisas de Deane et al. ${ }^{25-27}$, notou-se que na região da Serra da Cantareira, Região Metropolitana de São Paulo, mais de 99\% dos indivíduos de Anopheles (Kerteszia) cruzii, principal vetor de plasmódios causadores de malária humana e símia no bioma Mata Atlântica, foram coletados na altura da copa das árvores. Nesta área $62 \%$ dos bugios apresentaram infecção por plasmódios. O mesmo ocorreu no município de Campo Alegre, Santa Catarina, onde aproximadamente $90 \%$ dos $A n$. cruzii foram coletados na altura da copa e $43 \%$ dos bugios apresentaram infecção por plasmódios, sem infecção humana ${ }^{27}$. Tal padrão também pôde ser observado em coletas realizadas no município de Guaíba, no Rio Grande do Sul e em Santa Leopoldina no Espirito Santo ${ }^{28,29}$. Por sua vez, no município de Joinville, Santa Catarina, onde ocorre a malária símia e humana, $42 \%$ dos An. cruzii foram coletados no nível do solo sugerindo que esta espécie se desloca entre os estratos verticais das árvores na mata ${ }^{27}$.

\subsection{Comportamento Alimentar de Mosquitos}

O estudo do comportamento alimentar de mosquitos é importante, pois sua relação com animais vertebrados endotérmicos e ectotérmicos na aquisição de sangue revelam suas adaptações no meio ambiente, servem para a avaliação de sua capacidade vetorial e para a compreensão do ciclo de transmissão de patógenos ${ }^{30,31}$.

As fêmeas de mosquitos se alimentam mais frequentemente de mamíferos e aves e na literatura especializada há poucos relatos de mosquitos se alimentando em repteis, anfíbios e peixes pulmonados ${ }^{32,33}$. Com relação ao volume de sangue ingerido por fêmeas durante um repasto sanguíneo, Clements ${ }^{5}$ mensurou gravimetricamente as quantidades para várias espécies, encontrando uma média 
de sangue ingerido de $2,66 \mu \mathrm{L}$ para Coquillettidia richiardii, Aedes cinereus $(3,71 \mu \mathrm{L})$, Aedes cantans $(6,07 \mu \mathrm{L})$ e Culiseta annulata $(6,04 \mu \mathrm{L})$. Ainda, o autor afirma que as espécies menores tendem a ingerir um volume maior de sangue por unidade de peso corporal, mostrando que Ae. cinereus ingeriu em média um volume de 1,33 vezes o tamanho corpóreo enquanto que Cs. annulata ingeriu 0,82 vezes seu tamanho ${ }^{5}$.

O que se tem observado em ambiente natural é que, culicídeos ingerem somente poucas frações de sua capacidade completa de ingestão de sangue em um repasto sanguíneo, porque o comportamento defensivo das espécies hospedeiras impede seu ingurgitamento total, sendo assim, uma única fêmea pode necessitar de mais de um repasto sanguíneo ${ }^{34-36}$.

Mucci et al..$^{37}$ em áreas com histórico de transmissão da febre amarela silvestre reconheceram quatro espécies mais abundantes que representaram 95\% das espécies ingurgitadas, com repastos sanguíneos em duas ou mais fontes, e para o principal vetor da febre amarela Haemagogus janthinomys/capricornii foram detectados repastos em aves, bovino e primata sugerindo que esta espécie transita entre os estratos verticais, podendo infectar também homem suscetível no solo.

No estudo conduzido por Carvalho et al. ${ }^{38}$ em sete parques urbanos da cidade de São Paulo (Anhanguera, Shangrilá, Santo Dias, Alfredo Volpi, Chico Mendes, Carmo e Ibirapuera), foram coletadas 510 fêmeas ingurgitadas, e, das amostras testadas foram detectadas por PCR suas fontes sanguíneas em $82,6 \%$ onde, as cinco espécies mais abundantes formaram três grupos e foram classificadas em mosquitos que se alimentaram em homem e cão, homem e aves e homem e roedores e 18,3\% apresentaram discordância gonotrófica com repastos mistos em duas ou mais fontes. As espécies ingurgitadas encontradas por Carvalho et $a l^{38}$ são consideradas oportunistas se alimentando em fontes variadas, porém, Culex (Culex) nigripalpus teve uma associação positiva pela ornitofilia, indicando 
ser epidemiologicamente importante seu monitoramento, pois essa espécie é capaz de transmitir encefalite de Saint Louis (entre outras arboviroses) em que aves participam como reservatórios e esse arbovírus já foi isolado em aves na Mata Atlântica ${ }^{39,40}$.

De acordo com Muriu et al. ${ }^{41}$ para haver a infecção do homem, um mosquito deve ter se alimentando pelo menos duas vezes, para então, posteriormente picar um humano suscetível. O grau de contato homem-vetor é de grande importância no controle de doenças, uma vez que, os culicídeos com comportamento antropofílico são considerados os mais importantes vetores em saúde pública, e na maioria das vezes estes são os mais abundantes no ambiente, principalmente os ambientes impactados pelas ações do Homem.

$\mathrm{Na}$ atração de mosquitos a seus hospedeiros, estão envolvidos inúmeros fatores tais como, os físicos a umidade relativa e temperatura e os químicos tais como os odores ${ }^{42}$. Mosquitos utilizam de seus órgãos sensoriais (principalmente antenas) para identificar atrativos chamados kairomônios, que são substâncias emitidas por hospedeiros (imperceptíveis aos mesmos) favoráveis aos mosquitos ${ }^{43,44}$. Wright ${ }^{45}$ considerou apenas dois fatores (calor e umidade) como sendo os principais atrativos para mosquitos na identificação do hospedeiro humano. Khan ${ }^{46}$ mencionou que além da temperatura corporal, outros fatores estavam envolvidos na atração de mosquitos para humanos como a cor da pele e odores do corpo. Price et al. ${ }^{47}$ estudando fêmeas da espécie Anopheles quadrimaculatus, inferiram que estas foram atraídas principalmente pelos odores químicos emitidos pela pele, enquanto Posey e Schreck ${ }^{48}$ mostraram que foram identificado atrativos para mosquitos no suor humano, observando que ocorrem variações na atração, onde, de doze mosquitos testados 4 não apresentaram atração, outros quatro foram fracamente atraídos e os mais atraídos pelo suor humano foram Aedes aegypti, Ae. albopictus e Anopheles albimanus. 
Silver ${ }^{44}$ relata que há dois tipos de suor, e há uma estratificação vertical no corpo humano em relação a esta substância, sendo écrina nas mãos e pés, apócrina nas axilas, regiões perigenital e perianal. $\mathrm{O}$ ácido lático produzido por glicólise nas glândulas sudoríparas écrinas em excesso, principalmente na secreção do suor, varia em composição de pessoa para pessoa ${ }^{44}$.

\subsection{Técnicas para identificação de Hábitos Alimentares em mosquitos}

Foram desenvolvidas diversas técnicas para diagnóstico dos recursos alimentares de culicídeos e para conhecimento dos ciclos naturais de transmissão de patógenos. Basicamente as técnicas e métodos analíticos utilizados para identificação das fontes de sangue para os mosquitos, surgiram de técnicas forenses e propostas acadêmicas ${ }^{5}$. Clements ${ }^{5}$ cita um livro pioneiro de "Nuttall datado de 1904", que descrevia a técnica de precipitina utilizada para identificação do sangue de diferentes táxons animais, mais tarde essa técnica foi adaptada para identificação de mosquitos ingurgitados.

As mais usuais ao longo da história desenvolvidas pela necessidade ecoepidemiológica são: a reação de precipitina, a cristalização da hemoglobina, as reações de aglutinação, o teste de hemaglutinação passiva, o método imunohistoquímico de imunofluorescência, a reação em cadeia da polimerase e o sequenciamento de DNA ${ }^{30,32,49-52}$.

Nas últimas décadas, as técnicas de biologia molecular têm se tornado cada vez mais utilizadas na identificação dos hospedeiros de mosquitos e outros artrópodes vetores por apresentar vantagens e especificidade confiável pela utilização de primer específico na identificação de sequências alvo do DNA de vertebrados ${ }^{44}$

Uma das inovações recentes está em usar a técnica de PCR juntamente com a confirmação por sequenciamento das amostras, oferecendo mais 
credibilidade aos resultados $^{52}$. Atualmente, diversos são os marcadores utilizados na identificação dos recursos sanguíneos em insetos hematófagos. A utilização de marcadores moleculares que podem ser constituintes dos genes mitocondriais, como por exemplo, o citocromo B que apresenta a vantagem de estar inserido no genoma mitocondrial em regiões conservadas, não sofrendo recombinação e, além disso, a disponibilidade de sequências completas no "Genbank" e em inúmeras publicações científicas permite uma comparação extensa da similaridade entre as espécies e facilita seu uso ${ }^{53}$.

\subsection{Concordância e discordância gonotrófica}

Segundo Clements ${ }^{5}$ a capacidade reprodutiva de fêmeas de culicídeos é afetada pela nutrição das formas de seu ciclo de vida nos estádios de larvas e adultos. Com as condições inadequadas presentes em criadouros com baixa qualidade (e.g. nutrientes), as larvas se subdesenvolvem e consequentemente afetam o tamanho corporal do adulto, podendo afetar também o número de ovaríolos e a fecundidade. Clements ${ }^{5}$ menciona que o total de ovos por oviposição é função do número de ciclos gonotrófico completos. Briegel ${ }^{54}$ encontrou relação positiva no tamanho corporal de fêmeas e fertilidade e volume de sangue ingerido em Ae. aegypti sugerindo que o tamanho das fêmeas provavelmente determina o número de ovaríolos em seus ovários. Estudos experimentais demonstraram que, quando determinada espécie de mosquito se alimenta em sua fonte habitual produz mais ovos do que quando se alimenta em espécies de hospedeiros não habituais, pois a composição do sangue varia de acordo com o hospedeiro, e essa variação afeta a produção de ovos em mosquitos ${ }^{5}$.

Se para fêmeas a ingestão de sangue traz benefícios de sobrevivência, perpetuação da espécie, além de outras funções, em machos, o sangue produz baixa expectativa de sobrevivência ${ }^{55}$. Em testes de laboratório, onde sangue de 
animais vertebrados foi fornecido para alimentação de machos de $C x$. quinquefasciatus, as proteínas do sangue parecem ser desfavoráveis e tóxicas, prejudicando, assim, suas funções e levando o indivíduo ao declínio ${ }^{55}$. Além disso, diferenças estruturais na anatomia das peças bucais de machos e fêmeas de mosquitos, principalmente na mandíbula de machos, os tornam inaptos em perfurar a pele de hospedeiros para realizar a hematofagia ${ }^{5}$.

Ambos os sexos, macho e fêmea de mosquitos, se alimentam de carboidratos de onde obtém energia para realizar suas funções básicas na natureza ${ }^{56}$. Estes recursos naturais incluem: néctar floral, frutos e tecidos vegetais em decomposição ${ }^{57}$, bem como soluções açucaradas expelidas por insetos afídeos e coccídeos aproveitadas como recurso em interação ecológica por Ae. taeniorhynchus (Haeger, 1955) ${ }^{58}$, e espécies de mosquitos do gênero Malaya, se alimentando de substâncias açucaradas regurgitadas por formigas do gênero Crematogaster ${ }^{59}$.

As fêmeas de mosquitos anautógenas, de modo geral, além de se alimentarem dos recursos energéticos citados, apresentando hábito hematofágico (com exceção até o momento do gênero Toxorhynchites) e alimentando-se do sangue de animais vertebrados, em que as proteínas presentes na composição do sangue contribuem com aminoácidos para o desenvolvimento de seus ovaríolos e produção de ovos ${ }^{3,5,56}$.

Embora a fecundidade por ciclo gonotrófico seja aumentada por alimentação de açúcares, em longo prazo, diminui o fitness reprodutivo em espécies antropofílicas como, por exemplo, Ae. aegypti, sendo necessária a variação na alimentação entre néctar e sangue ${ }^{60}$.

Um dos problemas da hematofagia no contexto da saúde pública, é que quando realizada por espécies de insetos vetores e seus hospedeiros infectados (amplificadores) em período de viremia (incubação intrínseca) inicia-se um ciclo de 
transmissão ${ }^{3}$. Esses insetos adquirem patógenos que realizam ciclo biológico no interior de seu organismo, produzindo fases de vida infectantes que atravessam barreiras internas até atingirem suas glândulas salivares, sendo que após a incubação extrínseca (ocorre no inseto) passam a transmitir o patógeno até o fim de suas vidas, a suas novas fontes de repasto sanguíneo, aumentando o número de hospedeiros infectados no ambiente ${ }^{61}$. Esse processo promove a amplificação do agente patogênico no ambiente, sua dispersão e manutenção através da estrutura da paisagem ${ }^{56,61}$.

Muitas fêmeas de mosquitos exibem um processo denominado concordância gonotrófica $^{62}$, que é a realização de oviposição precedida de apenas um repasto sanguíneo, sendo o número de ovos produzidos diretamente proporcional ao tamanho do repasto realizado ${ }^{63}$. Quando há discordância gonotrófica fêmeas precisam se alimentar novamente, realizando múltiplos repastos sanguíneos na mesma espécie ou em espécies diferentes de hospedeiros para uma única oviposição ${ }^{56}$. Nesse caso, fêmeas aumentam as chances de contato com hospedeiros infectados e assim iniciar novos ciclos de transmissão para hospedeiros suscetíveis ${ }^{2,3}$.

Estudos de laboratório demonstraram que o tempo médio de digestão do sangue ingerido foi de 60 horas para Ae. aegypti e An. quadrimaculatus e de 70 horas para Cx. quinquefasciatus ${ }^{56}$. Nesse período, as fêmeas procuram abrigo e ficam em repouso para realizar a digestão, sendo possível sua coleta pela técnica de aspiração ${ }^{3}$.

\subsection{A Área de Proteção Ambiental Capivari Monos e o Parque Estadual da Cantareira como paisagens patogênicas}

A cidade de São Paulo, situada na região de Mata Atlântica do sudeste brasileiro, possui mais de 12 milhões de habitantes, vivendo em uma área territorial 
de $\left(1.521,11 \mathrm{~km}^{2}\right)^{64}$. Esse município teve seu crescimento desordenado, principalmente na segunda metade do século $X X$, e enfrenta na atualidade uma crise ambiental urbana intensificada ${ }^{65}$. Pouco resta da cobertura vegetal nativa e a paisagem alterada da cidade cria um cenário de vegetação modificada que se molda em fragmentos de diversos tamanhos e variados graus de conectividade, provocados pela substituição da vegetação nativa pelas edificações ${ }^{66}$.

Além dos mais de cem parques urbanos representados por fragmentos de diferentes tamanhos, isolados em meio à urbanização da cidade de São Paulo, existem duas regiões com extensão significativa de vegetação contínua que merecem atenção quanto à biodiversidade que abrigam ${ }^{15}$. Ao norte, o Parque Estadual da Cantareira (PEC), com mais de sete mil hectares, e ao sul da cidade a Área de Proteção Ambiental Capivari-Monos (APA), que abrange 1/6 da área do município de São Paulo ${ }^{67}$. Essas duas áreas constituem refúgio para biodiversidade de animais e plantas da cidade de São Paulo ${ }^{68}$.

O subdistrito de Parelheiros, onde está localizada a APA Capivari-Monos, apresenta um histórico de focos de malária autóctone que abrange esta região e suas adjacências, correspondentes ao Parque Estadual da Serra do Mar e municípios vizinhos como Embu-Guaçu, São Bernardo do Campo, Itanhaém, Guarujá e Juquitiba ${ }^{69}$. Casos de malária autóctone têm sido registrados e associados à presença de mosquitos anofelinos, sendo um problema de saúde enfrentado pela população que adentra a mata de forma ocupacional ou que reside em suas bordas, além disso, o mosaico de ambientes criados pelas práticas agrícolas e de cultura de subsistência praticadas pelas famílias ocupantes da APA, podem promover impactos ao meio ambiente e risco ao transbordamento de agentes patogênicos, devido à exposição do homem e sua proximidade a mata ${ }^{14,61}$. Até o Censo do IBGE ocorrido em 2010, a população recenseada de Marsilac 
estava em torno de 8.258 pessoas com taxa de crescimento em decréscimo $(-0,18)$ em comparação aos Censos 2000/2010.

Pesquisa realizada nos bairros de Marsilac e Emburá, situados na Área de Proteção Ambiental (APA) Capivari-Monos, apresentou resultados interessantes. Ao longo do estudo foi visto que o principal vetor, An. (Ker.) cruzii, foi predominante em áreas com maior cobertura vegetal e foi encontrado infectado com $P$. vivax e $P$. malariae, no entanto, espécies de anofelinos que apareceram com maior frequência em áreas antrópicas como An. (Nys.) strodei, An. (Nys.) triannulatus, An. (Nys.) lutzii também foram encontradas portando plasmódios, o que sugere que as mesmas possam atuar no ciclo de transmissão nestes locais. Outro fato importante é que, embora não tenham sido identificados casos de malária desde agosto de 2010 nestas áreas, anofelinos coletados até o mês de abril de 2011, apresentaram resultados positivos para infecção por $P$. vivax, reforçando que indivíduos assintomáticos ou reservatórios não-humanos estejam atuando na manutenção de focos residuais ${ }^{14,70}$.

Do outro lado da cidade de São Paulo, situado na zona norte, o Parque Estadual da Cantareira (PEC), possui um histórico diferente em relação à malária, isto porque bugios (Alouatta guariba clamitans) que habitam esta região desenvolvem a forma silvestre da doença. Tal situação levou à realização de uma série de trabalhos por Deane e colaboradores entre as décadas de 1960 e $1970^{25,26}$ formando a base do conhecimento sobre a malária símia no Brasil ${ }^{71}$. Ressalta-se que o único caso de malária símia registrada em humanos no Brasil, ocorreu com um guarda florestal deste parque na década de 1960. O agente etiológico foi $P$. simium, similar ao P. vivax humano, e a espécie de vetor responsável foi An. (Ker.) cruzii $^{25}$.

Pesquisa sorológica realizada no PEC em 1997 mostrou a presença de anticorpos contra esporozoítos de $P$. vivax, suas variantes $(P$. vivax VK247 e 
P.vivax-like humano), P. brasilianum e $P$. malariae em funcionários cujas atividades estavam relacionadas à mata, evidenciando possível interação entre a forma símia e humana da malária ${ }^{72}$. Uma análise de amostras de sangue colhidas entre 1996 e 2011 de bugios oriundos da Serra da Cantareira e de Parelheiros, mostrou a presença de $P$. vivax e $P$. malariae, tornando-se mais uma evidência tanto da circulação de plasmódios quanto da participação de primatas não-humanos na cadeia de transmissão ${ }^{73,74}$. Além da malária, outras arboviroses podem ser descobertas dada a proximidade da população residente e o público visitante dessas áreas públicas presentes na cidade de São Paulo.

\subsection{Mosquitos vetores do vírus da Febre Amarela em São Paulo}

A febre amarela é uma doença viral febril aguda, inclusa no grupo de arboviroses, e endêmica nas regiões tropicais da América do Sul e da África ${ }^{75,76}$. vírus pertence ao gênero Flavivirus (Família Flaviviridae), circula de maneira indene, na região Amazônica, e de transição na região extra-Amazônica, principalmente entre primatas não humanos ${ }^{77}$ e é transmitido por mosquitos vetores biológicos ${ }^{78,79}$.

Embora os maiores hospedeiros e amplificadores do vírus da febre amarela sejam os primatas não humanos, uma pesquisa utilizando as técnicas de Hemaglutinação/ Inibição e Soroneutralização ${ }^{80}$ realizada em 24 espécies de mamíferos na Guiana Francesa, encontrou anticorpos contra vírus da febre amarela em sete espécies não primatas Choloepus didactylus (preguiça-de-dois-dedos), Bradypus tridactylus (preguiça-de-três-dedos), Tamandua tetradactyla (Tamanduámirim), Dasyprocta leporina (roedor da família Dasyproctidae), Coendou spp (porcoespinho), Eira barbara (Irara) e Tayassu tajacu (cateto, porco-do-mato), ampliando assim o rol de espécies que podem fazer a manutenção do vírus e sua dispersão em ambiente silvestre, todas elas encontradas nos biomas brasileiros. 
Os vetores artrópodes associados à transmissão são mosquitos principalmente dos gêneros Haemagogus, Sabethes, Psorophora e Aedes ${ }^{81}$ sendo Haemagogus janthinomys e Hg. leucocelaenus considerados como vetores principais do vírus da febre amarela no país ${ }^{82}$. Além dessas espécies, Hg.capricornii, Hg. albomaculatus, Hg. spegazzinii, Hg. tropicalis, Sabethes chloropterus, Sa. glaucodaemon, Sa. soperi, Sa. cyaneus, Sa. quasicyaneus, Sa. undosus/ fabricil ignotus, Ae. serratus, Ae. fulvus, Ae. scapularis, Ae. fluviatilis, Ae. terrens, Ae. albopictus, Psorophora albipes e Ps. ferox já foram encontradas naturalmente ou artificialmente infectadas pelo menos uma $v e z^{83,84}$ sendo sugeridas assim, como espécies vetores auxiliares na transmissão do vírus. Muitas dessas espécies com histórico de infecção por vírus da febre amarela foram encontradas nas áreas do Parque Estadual da Cantareira ${ }^{81}$.

Outra espécie de mosquito que pode atuar como vetor ponte do vírus da febre amarela em ambientes de transição (mata urbano) ainda em um ciclo silvestre, para ambientes urbanos, é o Ae. albopictus e quando este vírus transborda (spill over) para o ambiente urbano, a espécie Ae. aegypti transmite como vetor principal desse vírus em um ciclo urbano ${ }^{76}$.

Vasconcelos $^{82}$ menciona em seu trabalho, que a interação de cinco fatores principais foi fundamental para que o surto da febre amarela nos anos de $2008 \mathrm{e}$ 2009 nos estados de São Paulo e Rio Grande do Sul tivessem ocorrido, citando como fatores: a grande população humana suscetível; a elevada prevalência de vetores e hospedeiros primatas não humanos; condições climáticas favoráveis, sobretudo o excesso de chuvas no verão; a emergência de uma nova linhagem viral e a circulação de pessoas ou macacos infectados em fase de viremia.

Segundo o informe $n^{\circ} 12$ (atualização em 06/02/2018), publicado pelo Ministério da Saúde a situação epidemiológica da febre amarela no Brasil, registrou 3.481 epizootias em primatas não humanos com 499 mortes diagnosticadas (por 
laboratório) nos estados de Mato Grosso, Rio de Janeiro, Minas Gerais, sendo a maior contribuição ocorrendo no estado de São Paulo com 433 indivíduos mortos pela doença ${ }^{85}$. Dos 1.286 casos humanos notificados, 353 foram confirmados com 98 óbitos, no período de monitoramento da semana epidemiologia (SE) 05, até o momento nenhum caso urbano da doença foi notificado, apenas 1 caso autóctone foi observado ${ }^{85}$.

O perfil das pessoas nos casos positivos coincide com aquele geralmente observado nos surtos de FA silvestre, com a maioria dos pacientes do sexo masculino e idade economicamente ativa, uma vez que esses indivíduos se expõem com maior frequência a áreas e situações de risco, sobretudo em decorrência de atividades laborais ${ }^{85}$.

O último informe da febre amarela ( $\left.n^{\circ} 18\right)$ out/2018, mostra a situação atual da FA no Estado de São Paulo com 537 casos positivos confirmados. Destes, 498 autóctones e 35 importados, com letalidade para os autóctones de $172(34,5 \%)^{85}$. Na Capital, até o momento houve 13 casos positivos com 6 óbitos $(46,2 \%)$.

Segundo a Secretaria de Estado da Saúde nenhum caso ainda, foi considerado com urbano, e em sua maioria todos os casos ocorreram em regiões com história confirmada de epizootias ${ }^{85}$. 


\section{JUSTIFICATIVA}

Estudos sobre a ecologia de culicídeos em saúde pública são essenciais para a compreensão dos mecanismos dinâmicos de transmissão de patógenos potencialmente transmitidos de mosquitos para humanos e outros animais, e servem de base para a atuação da vigilância em saúde no controle de vetores ${ }^{15,86-}$ ${ }^{88}$. As atividades humanas, o crescimento demográfico e a expansão da malha urbana avançando sobre ambientes naturais, promovem a fragmentação dos habitats e aumentam as chances do contato do homem com patógenos circulantes transmitidos por mosquitos ${ }^{89,90}$.

Esses aspectos reais em diversas regiões do Brasil implicam em importantes impactos à saúde pública de municípios. Todos os anos, centenas de milhares de casos de morbidade são atribuídos às doenças transmitidas por mosquitos, impactando o sistema de saúde em suas esferas municipal, estadual e federal, gerando gastos elevados com ações de controle dos vetores (recursos humanos, equipamentos e insumos para tratamento de áreas infestadas por mosquitos), campanhas, internações e tratamento dos pacientes ${ }^{91}$. Só no ano de 2014, os repasses de verbas públicas para cada secretaria estadual e municipal do país somaram mais de 150 milhões de reais, para reforçar as ações de vigilância e controle no ano vigente (2015) das duas doenças dengue e chikungunya que elevam as estatísticas de saúde em todo o país ${ }^{91}$.

Pouco tem sido explorado sobre como as variações na diversidade e hábitos de culicídeos por se alimentar em diferentes estratos da vegetação, podem influenciar o aumento do risco de transmissão de patógenos ao homem, apesar de estudos apontarem que doenças como malária ${ }^{71,73,74}$, West Nile Virus ${ }^{24}$ e febre amarela $^{37}$ podem apresentar ciclos enzoóticos silenciosos nos estratos superiores da vegetação (copa), envolvendo mosquitos e aves ou primatas, sustentando a manutenção destes patógenos no ambiente. 
Alguns mosquitos que se alimentam do sangue de vertebrados arborícolas podem sustentar ciclos de transmissão de patógenos na altura das copas das árvores, outros que se alimentam em humanos ou outros mamíferos terrestres podem sustentar ciclos de transmissão no solo, e, ainda, há aquelas que podem servir de ponte entre ciclos enzoóticos que ocorrem em hospedeiros que abrigam a copa e os que abrigam o solo, podendo infectar o homem quando este adentra ou reside próximo a estes locais ${ }^{92,93}$. A escassez desses dados inviabiliza predições e inferências sobre os processos ecológicos atuantes ou os riscos associados à veiculação de patógenos por mosquitos.

As regiões da APA Capivari-Monos e do PEC apresentam paisagens que agregam elementos de feições mistas, com áreas de ocupação antiga e áreas recentemente invadidas. Ambas se situam em regiões periféricas, cuja população (residentes, funcionários ou visitantes) transita entre seus diferentes ambientes, estreitando a proximidade com animais silvestres que podem servir de reservatório e entrando em contato com mosquitos vetores que podem atuar como ponte, transportando patógenos de um ambiente a outro em ciclos silvestres e urbanos. 


\section{OBJETIVO GERAL}

Investigar as variações das assembleias de culicídeos nos diferentes estratos da vegetação e sua relação com hábitos alimentares em áreas com variados graus de interferência humana em duas unidades de conservação da cidade de São Paulo, a APA Capivari-Monos e Parque Estadual da Cantareira no período de 27 meses.

\subsection{OBJETIVOS ESPECÍFICOS}

a) Mensurar variações na riqueza, abundância e composição de culicídeos na altura do solo e da copa em ambientes com feições: periurbana, intermediária/rural e silvestre nas duas áreas de estudo;

b) Verificar a fonte alimentar de mosquitos ingurgitados coletados nos diferentes estratos da vegetação (copa e solo) de cada ambiente estudado;

c) Apontar espécies de mosquitos que possam servir de ponte para a circulação de patógenos entre os diferentes estratos da vegetação;

d) Analisar como variações no ambiente, tais como, componentes da paisagem e características abióticas (precipitação, temperaturas e umidade relativa), podem influenciar a diversidade e o hábito alimentar de mosquitos nos diferentes estratos da vegetação. 


\section{MATERIAL e MÉTODOS}

\section{1 Áreas de estudo}

O estudo foi desenvolvido a partir de dados coletados em duas Unidades de Conservação situadas no município de São Paulo: 1) no extremo sul da cidade, no distrito de Parelheiros, a Área de Proteção Ambiental (APA) Capivari-Monos, administrada pela Prefeitura do município, e 2) no extremo norte o Parque Estadual da Cantareira (PEC), administrado pelo Governo do Estado. Em cada uma das duas áreas, foram realizadas coletas mensais de insetos da família Culicidae com armadilhas luminosas tipo CDC em sete ambientes da paisagem com características periurbana, área de transição ou intermediária (rural) e silvestre.

\subsubsection{Zona Sul - Parelheiros: APA Capivari-Monos}

O núcleo urbano de Engenheiro Marsilac e a área rural em seus arredores dista aproximadamente $60 \mathrm{~km}$ do centro da capital e já ocupa os primeiros morros e vertentes oceânicas próximos a crista da Serra do Mar, com altitudes variando entre 740 a 800 metros acima do nível do mar $^{67}$. Considerando a classificação dinâmica de Tarifa e Armani ${ }^{94}$, o clima de Marsilac é do tipo Tropical Oceânico Super-úmido da fachada Oriental do Planalto Atlântico, mesoclima de morros, serras e escarpas do Alto Capivari-Monos, apresentando média anual das temperaturas de 19,6 a $19,3^{\circ} \mathrm{C}$.

O tipo de vegetação original da área é de Floresta Ombrófila Densa Montana, a qual está representada por remanescentes de Mata Atlântica em variados graus de conservação, sendo encontradas desde áreas em regeneração datadas da década de 1950, quando foi interrompida a exploração madeireira para fornecimento de carvão, até áreas recentemente degradadas devido à expansão urbana e rural. O bairro possui aproximadamente 8.280 habitantes e a densidade 
demográfica é de 39,7 habitantes por $\mathrm{km}^{2}$. A população é de baixa renda e a maior parte vive em núcleos rurais ${ }^{67}$.

A APA Capivari-Monos (Figura 1) tem a origem de seu nome ligada a dois importantes rios da região que alimentam as bacias Billings e Guarapiranga, e são considerados mananciais estratégicos, cuja proteção é essencial para o abastecimento de água da região metropolitana de São Paulo. O rio dos Monos recebeu este nome pela antiga presença do mono-carvoeiro ou muriqui (Brachyteles arachnoides), espécie de macaco que atualmente está ausente na área em questão. A APA Capivari-Monos abrange 1/6 da área do município de São Paulo, e compartilha $15 \%$ de sua área com o Parque Estadual da Serra do Mar, estando inserida na Reserva da Biosfera do Cinturão Verde de São Paulo ${ }^{67}$.
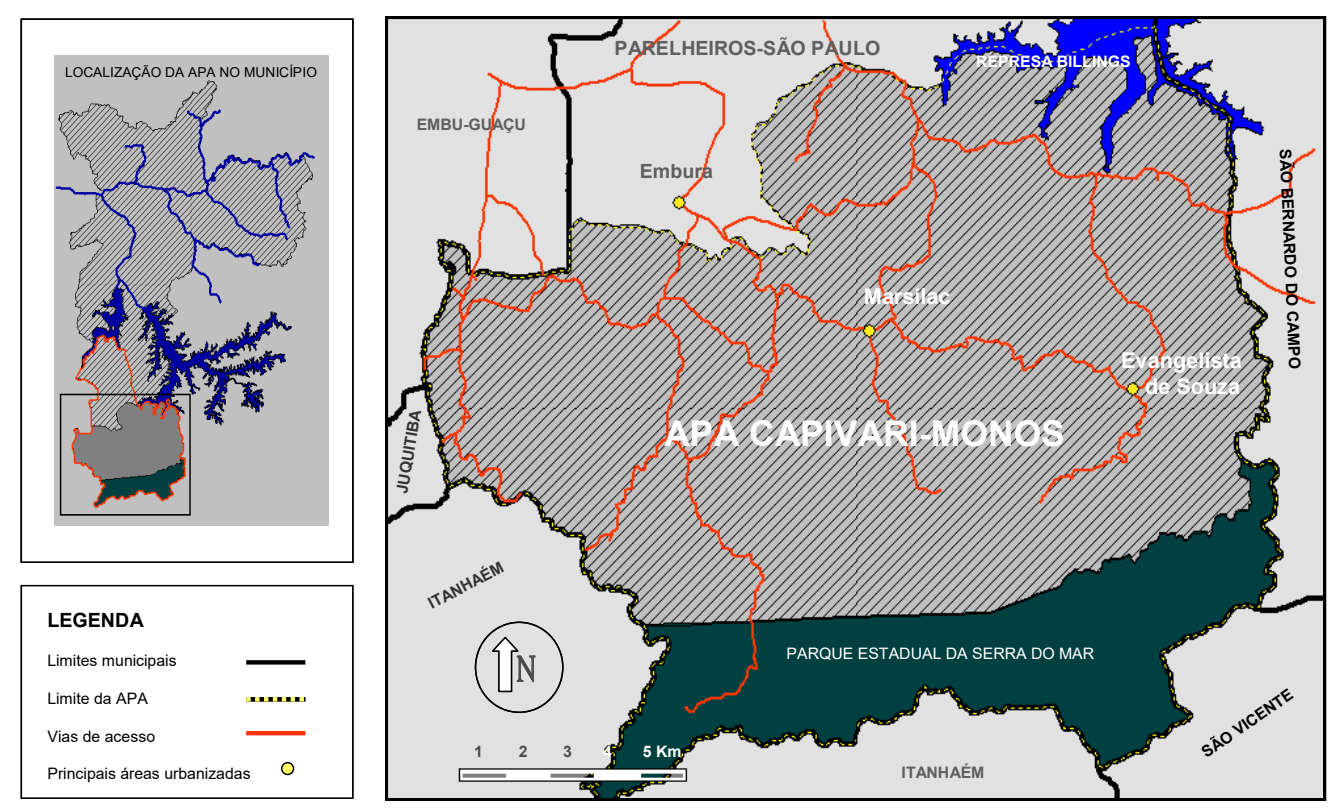

Figura 1 - Localização da área de estudo em relação ao município de São Paulo, subdistrito de Parelheiros, municípios vizinhos da Região Metropolitana de São Paulo, vias de acesso, principais áreas urbanizadas e áreas de preservação: APA Capivari-Monos e Parque Estadual da Serra do Mar (quadrante). 
As quatro áreas selecionadas para o estudo na APA Capivari-Monos são:

1) Ambiente Periurbano 1 (PER 1-APA): Bairro Emburá localizado próximo à entrada da APA (Figura 2), sob as coordenadas geográficas $23^{\circ} 53^{\prime} 8.90 " \mathrm{~S}$ 4644'29.39"O, constituído de área em expansão com domicílios em alvenaria e residentes fixos, propriedades particulares com estrutura de sítios com bordas na vegetação, proprietários realizam criação de animais e cultivo de subsistência, área com córregos e lagos artificiais;

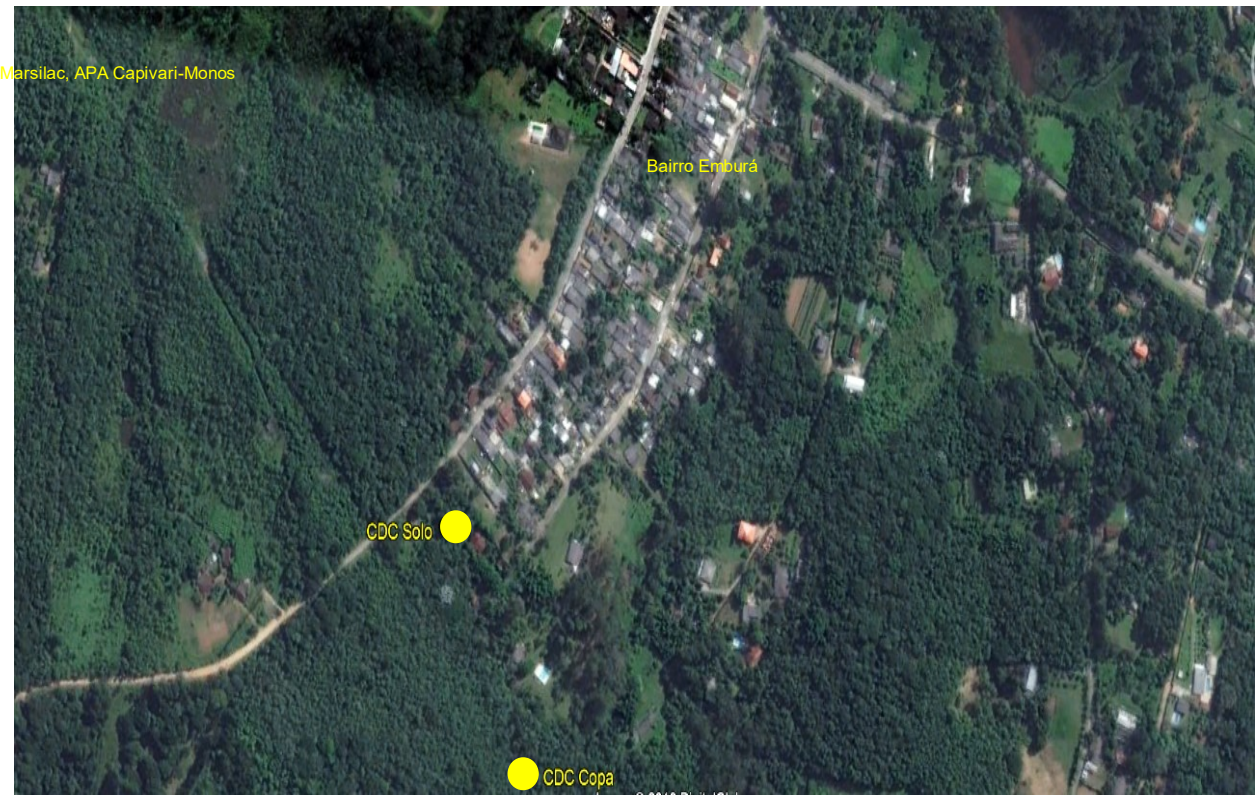

Figura 2 - Foto de Satélite Google Earth, mostrando o ambiente de coleta periurbano, situado no Bairro Emburá, Marsilac, ano de 2018.

2) Ambiente Periurbano 2 (PER 2-APA): vilarejo do Bairro Engenheiro Marsilac (Figura 3), próximo à linha de ferro Mairinque-Santos sob as coordenadas geográficas $23^{\circ} 54^{\prime} 23.71$ "S 46²4'29.15"O; 


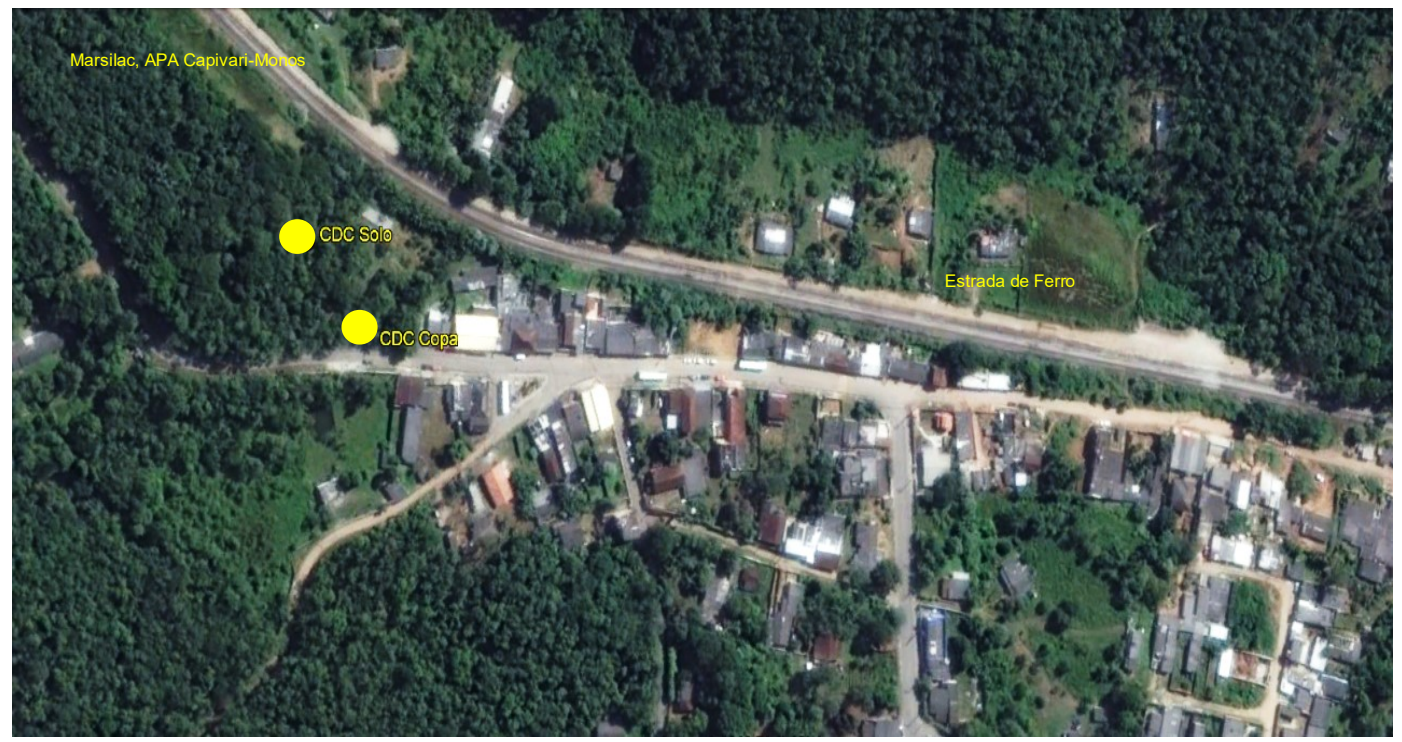

Figura 3 - Foto de satélite Google Earth, ambiente de coleta urbano, Vila Marsilac Marsilac, São Paulo.

3) Ambiente Intermediário (INT-APA): Sítio Águas de Siloé (Figura 4), localizado próximo ao núcleo urbano do bairro de Engenheiro Marsilac, constitui área de transição entre pasto e floresta, sob as coordenadas geográficas $23^{\circ} 54^{\prime} 37.60^{\prime S} 46^{\circ} 42^{\prime} 7.69^{\prime \prime} \mathrm{O}$

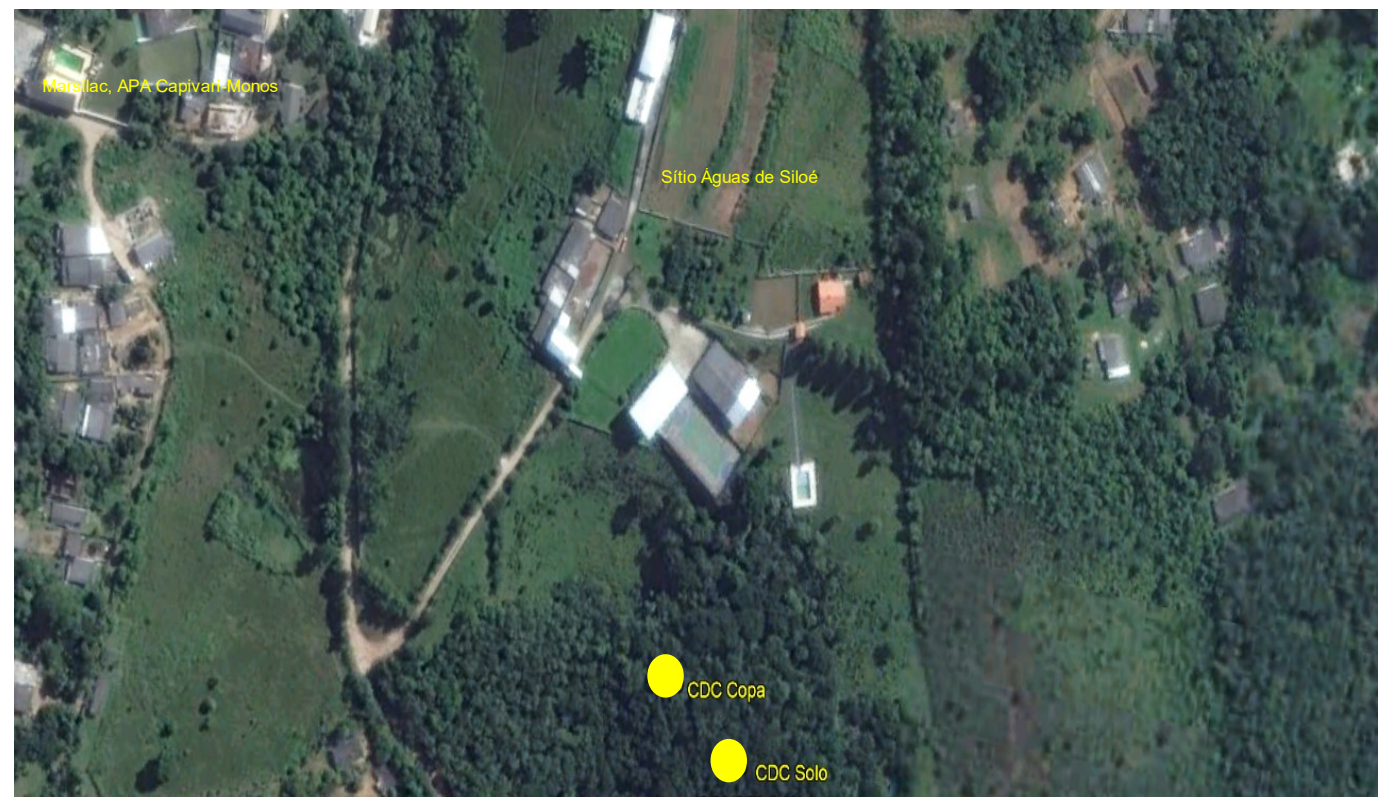

Figura 4 - Foto de satélite Google Earth, ambiente de coleta intermediário, Sitio Águas de Siloé, Marsilac, São Paulo. 
4) Ambiente Silvestre (SIL-APA): Mata em uma propriedade particular na Estrada para a Cachoeira do Marsilac (Figura 5), sob as coordenadas geográficas $23^{\circ} 56^{\prime} 22.68^{\prime \prime S} 46^{\circ} 41^{\prime} 39.54 " \mathrm{O}$.

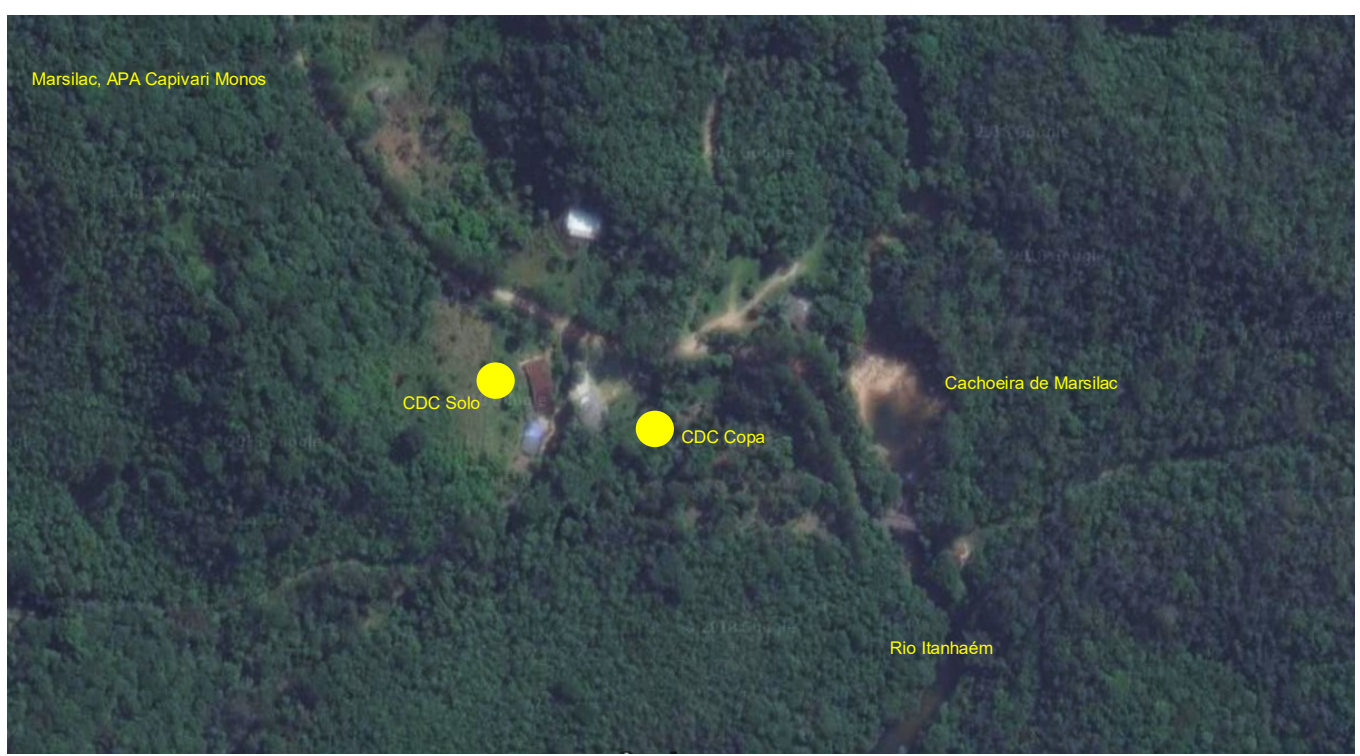

Figura 5 - Foto de satélite Google Earth, ambiente de coleta Silvestre, Cachoeira, Marsilac, São Paulo.

\subsubsection{Zona Norte - Serra da Cantareira: Parque Estadual da Cantareira}

O Parque Estadual da Cantareira (PEC) é um remanescente de mata tropical, situado dentro da região metropolitana de São Paulo, administrado pela Fundação Florestal da Secretaria do Meio Ambiente do Estado de São Paulo, recebendo em média 60 mil visitantes/ano ${ }^{68}$. Situa-se na região norte da cidade com porção de $4.278,50$ ha de vegetação, abrangendo também partes dos Municípios de Caieiras (149,17 ha), Mairiporã (798,00 ha) e Guarulhos (2.674,33 ha), totalizando área de 7.916,52 hectares (Figura 6).

O parque é dividido em quatro núcleos: Pedra Grande, Engordador, Águas Claras e Cabuçu, e uma área adjacente onde situa-se o Parque Estadual Alberto Löefgren, conhecido popularmente como Horto Florestal, que amortece as pressões 
negativas geradas pela expansão urbana e absorve parte da demanda por recreação ao ar livre ${ }^{68}$.

Com altitudes variando entre 755 e 1.215 metros acima do nível do mar, a região possui vegetação típica de Mata Atlântica, rica em bromélias e espécies exóticas introduzidas, como bambu e pinus ${ }^{68}$. Considerando a classificação dinâmica de Tarifa e Armani ${ }^{94}$, o clima do PEC é do tipo Tropical Úmido Serrano, mesoclima Cantareira-Jaraguá. Nesse tipo climático a temperatura média está entre 17,7 e $19,3^{\circ} \mathrm{C}$ e a pluviosidade é de 1.400 a $1.590 \mathrm{~mm}$.

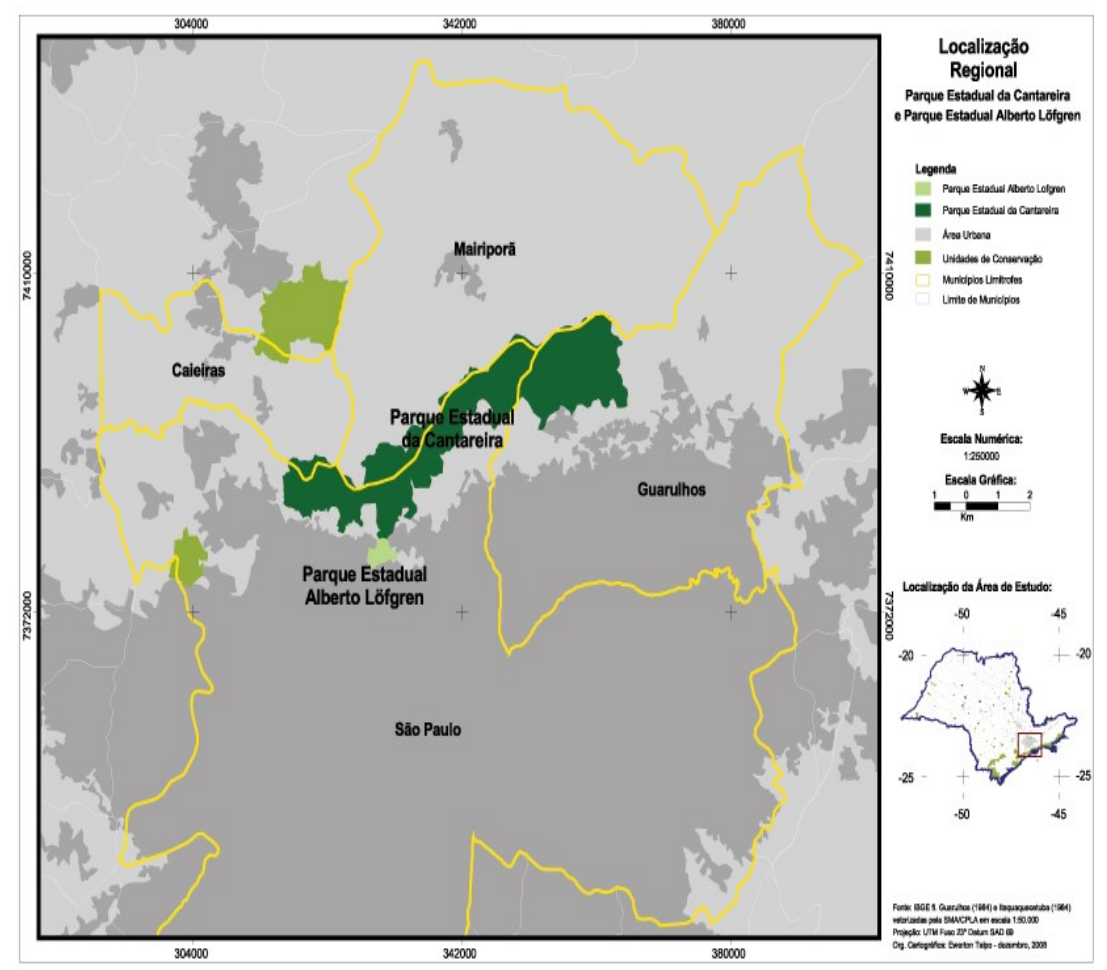

Figura 6 - Localização do Parque Estadual da Cantareira, divisa com os municípios de Caieiras, Mairiporã e Guarulhos da Região Metropolitana de São Paulo.

Os três ambientes selecionadas para o estudo no Parque Estadual da Cantareira foram:

1) Ambiente Periurbano (PER-PEC): Área limite entre o Núcleo Pedra Grande e moradias nas imediações da Rua Fructuoso Viana (Figura 7), situada no 
Bairro Vila Rosa - Trilha da Bica, coordenadas geográficas $23^{\circ} 27^{\prime} 13.62$ ”S e $46^{\circ} 38 ' 9.70^{\prime \prime} \mathrm{O}$.

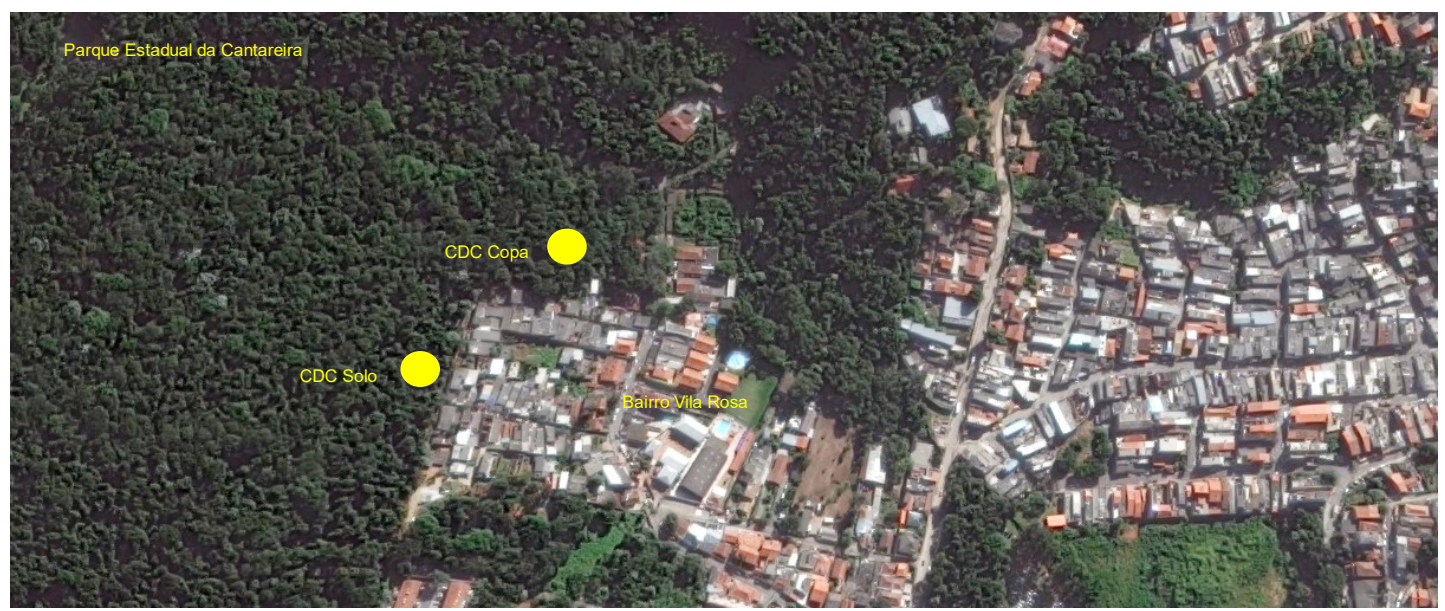

Figura 7 - Foto Google Earth, mostrando o ambiente periurbano situado às margens do Parque Estadual da Cantareira, os pontos em amarelo simbolizam as armadilhas CDC copa e solo e seus locais de instalação durante os anos de estudo, no período de fevereiro de 2015 a abril de 2017.

2) Ambiente Intermediário (INT-PEC): Sede Administrativa do Parque no interior do núcleo Pedra Grande (Figura 8) (23²6'51.90”S $46^{\circ} 38^{\prime} 5.46^{\prime \prime} \mathrm{)}$;

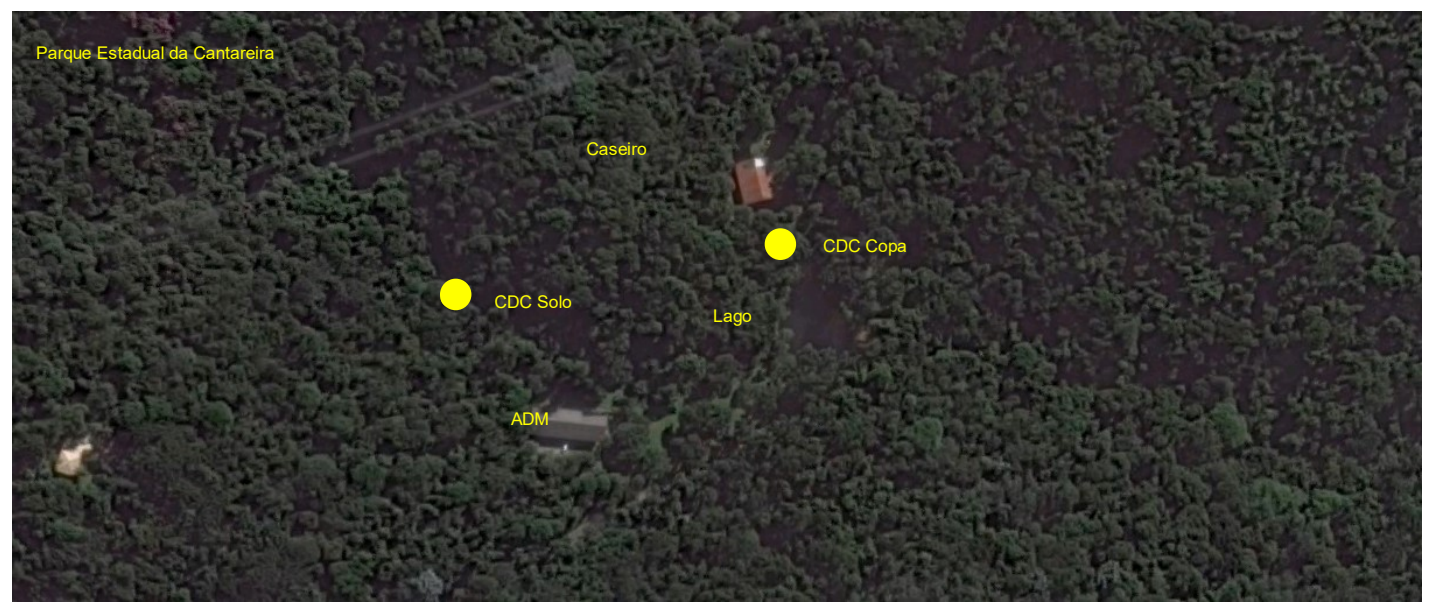

Figura 8 - Foto Google Earth, mostrando o ambiente intermediário situado dentro do Parque Estadual da Cantareira, onde está instalada a antiga administração do parque, pontos em amarelo simbolizam as armadilhas CDC copa e solo e seus locais de instalação durante os anos de estudo, no período de fevereiro de 2015 a abril de 2017. 
3) Ambiente Silvestre (SIL-PEC): Floresta em estágio avançado de regeneração na Trilha do Pinheirinho (Figura 9), situada próximo ao núcleo Águas Claras (2324'37.44"S 46³7'12.30”O).

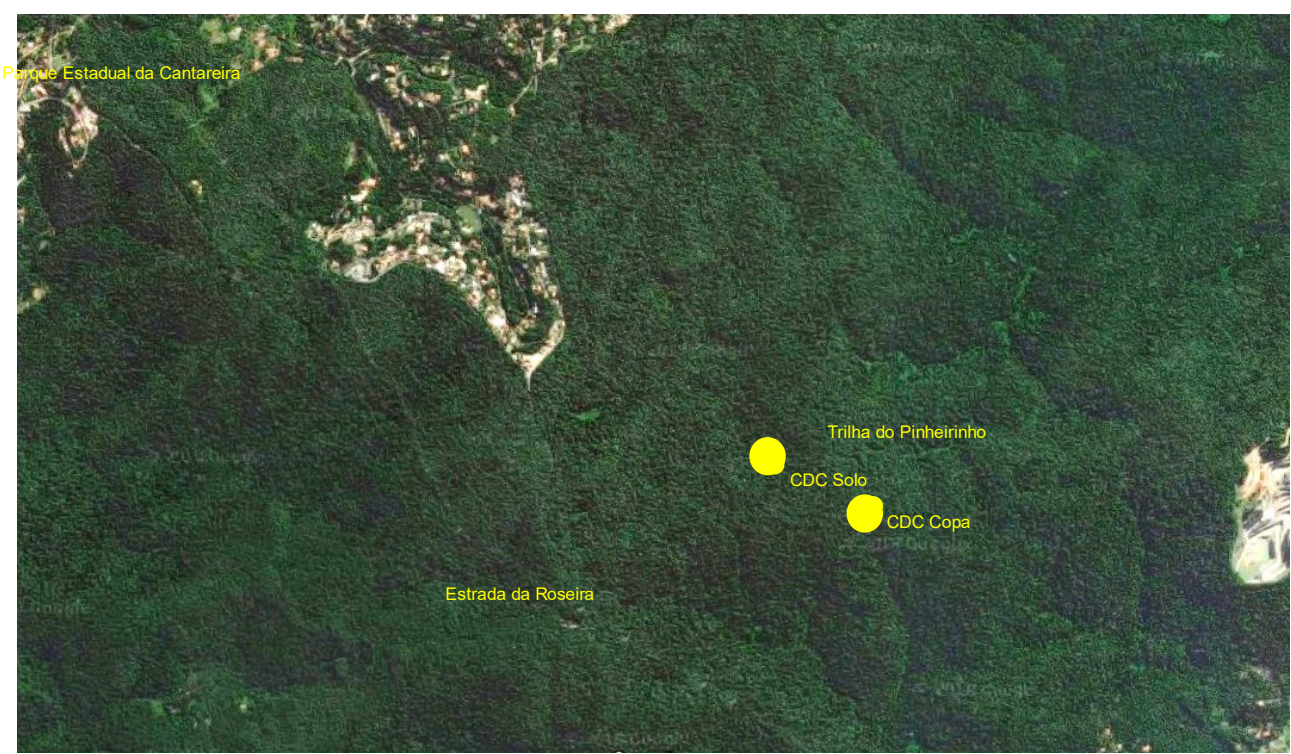

Figura 9 - Foto Google Earth, mostrando o ambiente silvestre, Trilha do Pinheirinho, situada no município de Mairiporã e pertencente ao Parque Estadual da Cantareira, pontos em amarelo simbolizam as armadilhas CDC copa e solo e seus locais de instalação durante os anos de estudo, no período de fevereiro de 2015 a abril de 2017.

\subsection{Coleta de culicídeos: Estratificação Vertical}

Mosquitos adultos foram coletados em sete ambientes, uma vez por mês, no período de fevereiro de 2015 a abril de 2017, totalizando 27 amostras. Duas armadilhas tipo CDC com $300 \mathrm{~g}$ de atrativo gelo seco $\left(\mathrm{CO}_{2}\right)$ foram instaladas simultaneamente uma a 1 metro do solo (CDC Solo) e outra na altura da copa das árvores variando 10 a 30 metros (CDC Copa) em cada ambiente. As armadilhas (etiquetadas copa e solo) foram distribuídas no ambiente de forma a distanciar uma das outras no mínimo $20 \mathrm{~m}$, de acordo com as características da paisagem, sempre procurando local sem muita interferência de ventos fortes, abrigo de chuva, e com cobertura de vegetação. 
As coletas com armadilhas CDC tiveram duração de 18 horas e sua instalação ocorreu no inicio da tarde sempre às 14 horas, com substituição da câmara coletora no inicio do crepúsculo vespertino e esta, retirada as $7 \mathrm{~h}$ da manhã, passando pelos crepúsculos vespertino e matutino de forma a coletar tanto mosquitos de hábitos diurnos quanto aqueles de hábitos crepusculares ou noturnos. Os horários dos crepúsculos vespertino e matutino variaram de acordo com os dados obtidos no Centro de Previsão de Tempo e Estudos Climáticos CPTEC/INPE a cada coleta. O esforço amostral em horas no estudo foi de $486 \mathrm{~h}$ de funcionamento por armadilha em cada estrato (copa e solo) para cada ambiente. Os mosquitos coletados no período diurno foram separados dos coletados no período vespertino/ noturno com a troca das câmaras coletoras das armadilhas CDC copa e solo de todas as armadilhas instaladas nos ambientes.

\subsection{Coleta de mosquitos ingurgitados: Hábito Alimentar}

Para a verificação do comportamento alimentar foram incluídas as técnicas de aspiração mecânica e armadilha de Shannon nas amostragens. Coletas com utilização de aspirador de $\mathrm{Nasci}^{95} \mathrm{com}$ bateria de $12 \mathrm{~V}$, foram realizadas em cada localidade por um período de 20 minutos com pausas de 5 em 5 minutos uma em cada ambiente, para substituição da rede de coleta. A técnica consiste em aspirar a vegetação de sub-bosque, ocos de árvores, troncos caídos com a finalidade de coletar mosquitos ingurgitados em repouso em seus abrigos. A coleta com armadilha de Shannon iniciou-se no crepúsculo vespertino permanecendo ativa por $2 \mathrm{~h}$ subsequentes.

\subsection{Obtenção dos dados climáticos}

Dados sobre temperatura mínima, média e máxima, precipitação e umidade relativa das regiões estudadas foram obtidos junto ao Centro de Gerenciamento de 
Emergências Climáticas (CGE), da Prefeitura do Município de São Paulo (PMSP) por meio de estações meteorológicas automáticas das localidades Jaçanã/Tremembé (estação PMSP/jT-01) distante $7,4 \mathrm{~km}$ e Barragem de Parelheiros (estação PMSP/PA-01) distante 44 km da APA Capivari Monos.

\subsection{Identificação e Catalogação}

A identificação morfológica e catalogação dos espécimes foram realizadas no Laboratório de Entomologia e Saúde Pública da Faculdade de Saúde Pública, da Universidade de São Paulo - (LESP/USP), seguindo as chaves dicotômicas disponíveis: Lane ${ }^{96}$, Consoli e Lourenço-de-Oliveira ${ }^{2}$ e Forattini ${ }^{3}$. As abreviações da bionomia zoológica (gêneros e subgêneros) seguiram as recomendações de Reinert ${ }^{97}$. Os mosquitos foram levados do campo ao laboratório, vivos em gaiolas de criação com informações da coleta (rotuladas) e foram mortos com vapores de clorofórmio antes de sua identificação. Todo o material de cada coleta foi triado e os mosquitos separados dos demais artrópodes, depositados em caixas entomológicas rotuladas por localidade, ambiente de coleta, técnica de coleta, estrato, altura, data e espécie. Os dados foram cadastrados em planilha eletrônica no Microsoft Excel ${ }^{\circledR} 2010$.

Os espécimes visualmente detectados com conteúdo sanguíneo (Figura 10) em seu abdômen (tempo <24h), após sua identificação, foram separados e acondicionados em tubos de centrífuga de 1,5 mL com álcool absoluto para inativar o processo de digestão e conservar as amostras para posterior processamento de extração de DNA e técnica de Reação em cadeia da polimerase - PCR convencional. 

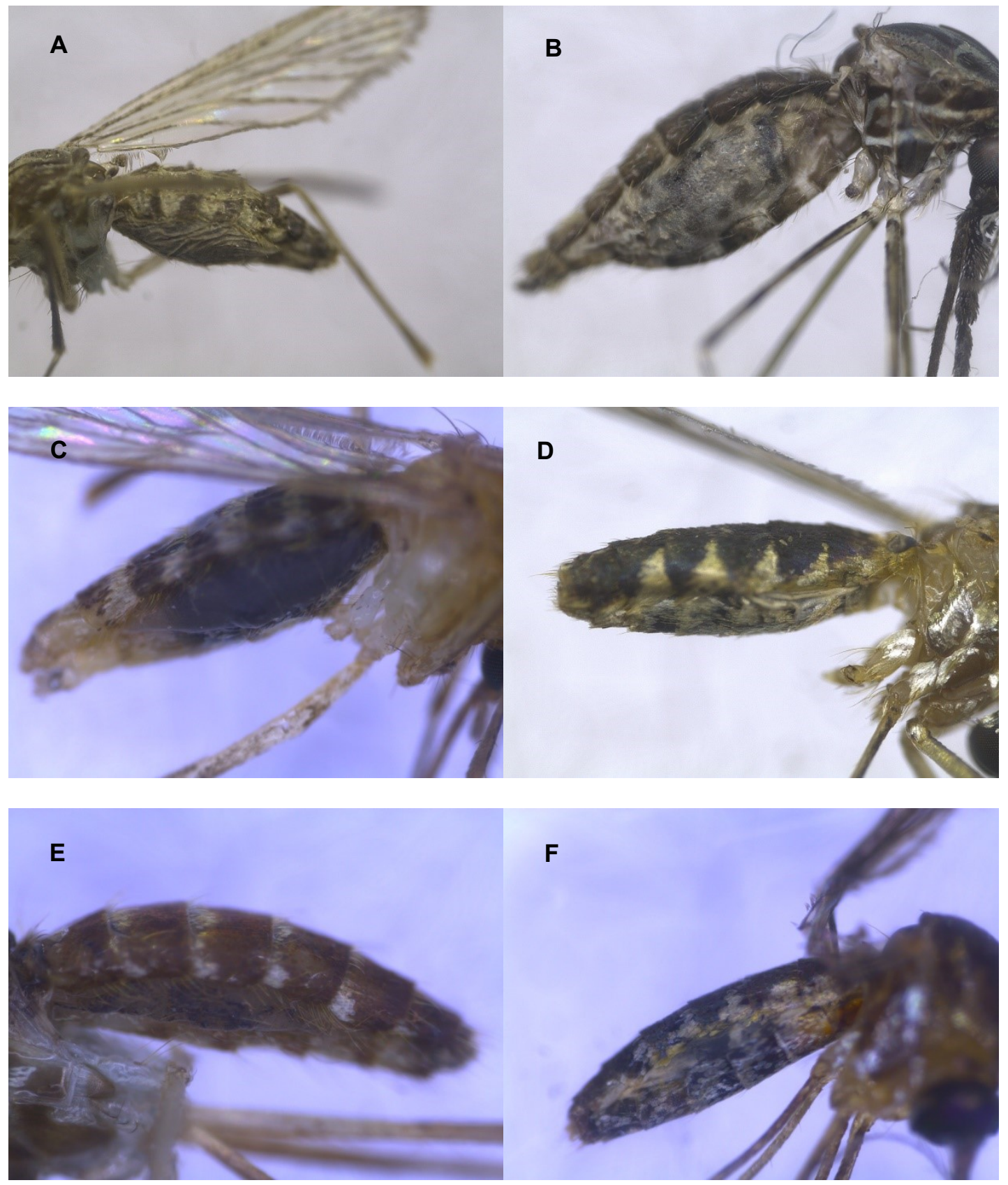

Figura 10 - Fotos de abdomens de mosquitos ingurgitados, coletados no período de fevereiro de 2015 a abril de 2017, no Parque Estadual da Cantareira e Área de Proteção Ambiental Capivari-Monos, em $A=C u l e x$ (Microculex) lanei, $\mathrm{B}=$ Anopheles (Kerteszia) cruzii, $\mathrm{C}=$ Culex (Culex) nigripalpus, $\mathrm{D}=$ Limatus durhamii, E=Culex (Culex) dolosus/eduardoi e $\mathrm{F}=$ Wyeomyia (Phoniomyia) edwardsi. 


\subsection{Identificação do Comportamento Alimentar}

\subsubsection{Extração de DNA}

As amostras foram individualizadas em tubos de centrífuga de 1,5 mL e numeradas sequencialmente para extração do material genético da fonte de repasto sanguíneo. A extração do DNA genômico do hospedeiro e não do mosquito, foi feita (utilizando-se o mosquito inteiro), com o Kit DNeasy Blood and Tissue Handbook (Qiagen), seguindo o protocolo do fabricante para eritrócitos nucleados e anucleados. Todas as extrações foram realizadas em capela de fluxo de ar.

Amostras de sangue de cada representante da Classe dos Mamíferos e Aves foram utilizadas para servir de controles positivos nas reações de PCR primer específico. Os trabalhos de determinação do repasto sanguíneo foram realizados no Laboratório de Sistemática Molecular II, da Faculdade de Saúde Pública da Universidade de São Paulo.

\subsubsection{Reação em Cadeia da Polimerase (PCR)}

A identificação do comportamento alimentar foi realizada utilizando-se a técnica de Reação em Cadeia da Polimerase (PCR) convencional. Foram utilizados dois sets de primers disponíveis na literatura, que amplificam o gene mitocondrial citocromo B. Cada oligonucleotídeo foi submetido a gradiente de temperaturas no termociclador para verificar o melhor funcionamento (temperatura ótima de cada primer), esse procedimento foi feito para padronizar o tempo das reações de amplificação no termociclador utilizado.

A técnica foi realizada em duas etapas: a primeira para amplificar fragmentos das Classes Aves (508 pb) e Mammalia (772 pb). 
A segunda etapa consistiu em amplificações para detectar repastos em mamíferos específicos de acordo coma fauna local observada na região com os seguintes primers: cão (153pb), gato (180 pb), roedor (196pb), bovino (271 pb), equino (235 pb), humano (228pb) e primatas não humano - PNH (480pb) como verifica-se na Tabela 1 padronizada ${ }^{98-101}$. Nas amplificações positivas para Classe Aves não foi utilizado nenhum primer específico para diferenciar as ordens.

Controles positivos foram utilizados para validação da reação e servir de parâmetro nas comparações com as alturas das bandas das amostras provenientes dos mosquitos. Controle negativo também foi utilizado em todas as reações, para certificar que não houve contaminação durante a manipulação das reações. Todas as reações foram realizadas em capela de fluxo de ar para evitar contaminações e perdas de amostras e material.

Tabela 1 - Ordem específica dos grupos de primers e espécies usadas em identificação de hábito alimentar. Temperaturas de anelamento padronizadas por gradiente.

\begin{tabular}{|c|c|c|c|}
\hline $\begin{array}{l}\text { Animal } \\
\text { Testado }\end{array}$ & Sequência do primer & $\begin{array}{c}\text { Temp. de } \\
\text { anelamento } \\
\text { pad. }\left({ }^{\circ} \mathrm{C}\right)\end{array}$ & $\begin{array}{l}\text { Amplificação } \\
(\mathbf{p b})\end{array}$ \\
\hline Aves & $\begin{array}{l}\text { F: GACTGTGACAAAATCCCNTTCCA } \\
\text { R: GGTCTTCATCTYHGGYTTACAAGAC }\end{array}$ & 60 & 508 \\
\hline Mamíferos & $\begin{array}{l}\text { F: CGAAGCTTGATATGAAAAACCATCGTTG } \\
\text { R: TGTAGTTRTCWGGGTCHCCTA }\end{array}$ & 50 & 772 \\
\hline Bovino & $\begin{array}{l}\text { F: GCCATATACTCTCCTTGGTGACA } \\
\text { R: GTAGGCTTGGGAATAGTACGA }\end{array}$ & 61 & 271 \\
\hline Gato & $\begin{array}{l}\text { F: TTCTCAGGATATACCCTTGACA } \\
\text { R: GAAAGAGCCCATTGAGGAAATC }\end{array}$ & 60 & 180 \\
\hline Cão & $\begin{array}{l}\text { F: GAACTAGGTCAGCCCGGTACTT } \\
\text { R: CGGAGCACCAATTATTAACGGC }\end{array}$ & 67 & 153 \\
\hline Equino & $\begin{array}{l}\text { F: CCCTAAGCCTCCTAATCCGT } \\
\text { R: AGGAATGATGGGGGAAGTAA }\end{array}$ & 56 & 235 \\
\hline Humano & $\begin{array}{l}\text { F: TTCGGCGCATGAGCTGGAGTCC } \\
\text { R: TATGCGGGGAAACGCCATATCG }\end{array}$ & 65 & 228 \\
\hline PNH & $\begin{array}{l}\text { F: CCTCTTTCCTGCTGCTAATG } \\
\text { R: TTTGATACTGGGATATGGCG }\end{array}$ & 58 & 480 \\
\hline Roedor & $\begin{array}{l}\text { F: CGGCCACCCAGAAGTGTACATC } \\
\text { R: GGCTCGGGTGTCTACATCTAGG }\end{array}$ & 60 & 196 \\
\hline
\end{tabular}

As reações foram feitas em placas para PCR (Invitrogen ${ }^{\circledR}$ ) 96 poços. Foi adicionado em cada tubo da placa de PCR $4 \mu \mathrm{L}$ de MIX de PCR (Solis BioDyne ${ }^{\circledR}$ ), 1 
$\mu \mathrm{L}$ de primer reverse, $1 \mu \mathrm{L}$ de primer forward, $2 \mu \mathrm{L}$ de DNA da amostra e $12 \mu \mathrm{L}$ de água de injeção para completar um volume final de $20 \mu \mathrm{L}$ por amostra.

As reações foram realizadas em termociclador (Mastercycler Gradient, Eppendorf $^{\circledR}$ Nexus), e os parâmetros para ciclagem variaram de acordo com as publicações de cada primer.

\subsubsection{Eletroforese em gel de agarose}

Os produtos da PCR foram observados por eletroforese em gel de agarose a 1,5\%, preparado com o tampão Tris-borato-EDTA (TBE 1X). Pipetou-se $2 \mu l$ de amplicon em cada poço do gel de agarose. Utilizou-se $0,6 \mu l$ de tampão carregador de amostra (glicerina e azul de bromofenol) e corada com $1 \mu$ le GelRed $^{\mathrm{TM}}$ (10.000X) Biotium, seguindo orientações do fabricante. Utilizou-se o marcador de peso molecular 100pb DNA Ladder Plus Amresco ${ }^{\circledR}$ e intensidade de corrente de 6v/cm. O gel foi coberto com tampão de corrida TBE 10X na cuba de eletroforese horizontal e após a corrida, foi observado através do transiluminador Syngene ${ }^{\circledR} \mathrm{em}$ fonte de luz ultravioleta de $302 \mathrm{~nm}$.

As amostras que apresentaram os fragmentos nas respectivas alturas de pares de banda mencionados na Tabela 1 e seus respectivos controles positivos foram consideradas positivas para a presença de sangue dos primers analisados.

\subsubsection{Sequenciamento}

Após as reações de amplificação por PCR algumas amostras positivas foram quantificadas usando a ferramenta Low Mass Ladder Invitrogem ${ }^{\circledR}$ em quantidade de $4 \mu \mathrm{L}$ de Low Mass Ladder; $1 \mu \mathrm{L}$ de carregador de amostra; $1 \mu \mathrm{L}$ de GeIRed $^{\circledR}$ e $2 \mu \mathrm{L}$ de amostra, para sequenciamento de moléculas de DNA por eletroforese capilar, com a finalidade de verificar a especificidade dos primers 
utilizados. As estapas de preparação das amostras antes do sequenciamento foram realizadas pelos técnicos do serviço de sequenciamento do IMT/USP.

As reações de sequenciamento foram feitas nos dois sentidos forward e reverse com o kit comercial ABI Prism dGTP Big Dye ${ }^{\circledR}$ Terminator v3.1 (P E Applied Biosystem, Warrington, UK), foi utilizado neste estudo $1 \mu \mathrm{L}(10 \mu \mathrm{m})$ do primer (oligonucleotídio), $\pm 40 \mathrm{ng}$ de DNA de fragmentos do gene mitocondrial citocromo $\mathrm{B}$ de cada vertebrado analisado. As reações foram realizadas em termociclador Mastercycler Gradient, Eppendorf ${ }^{\circledR}$ Nexus com os ciclos de temperatura programados para: $96^{\circ} \mathrm{C}$ por 2 min seguidos por 35 ciclos de 45 seg a $96^{\circ} \mathrm{C}, 30 \mathrm{seg}$ a $50^{\circ} \mathrm{C}, 4$ min a $60^{\circ} \mathrm{C}$. Após a amplificação, as amostras foram mantidas a $4^{\circ} \mathrm{C}$ até a precipitação.

A etapa de precipitação das amostras para sequenciamento foi realizada pela equipe técnica do serviço da Rede Premium da Faculdade de Medicina da Universidade de São Paulo, submetidas em sequenciador automático ABI PRISM 3100 Genetic Analyzer. O resultado dos sequenciamentos realizados foi verificado no software ChromasPro versão 2.6 .4 e a similaridade das sequências foram verificadas pela ferramenta BLAST - Basic Local Alignment Search Tool. 


\subsection{Análise dos dados}

\subsubsection{Riqueza}

Para verificar a riqueza nos ambientes pesquisados foram combinados 0 uso de duas métricas que avaliam a riqueza propriamente dita e a uniformidade que representa a distribuição das abundâncias ${ }^{102}$.

O termo riqueza de espécies foi introduzido por Mclntosh ${ }^{103}$ e é considerada a mais antiga e intuitiva medida de diversidade biológica, segundo Magurran ${ }^{104}$. Colwell ${ }^{105}$ enfatiza que a riqueza de espécies é o número de espécies de um particular táxon, ou forma de vida que caracteriza uma particular comunidade biológica, habitat, ou tipo de ecossistema, que varia de acordo com a escala utilizada.

Para Magurran ${ }^{104}$, riqueza de espécies pode ser definida como o número de espécies de determinado táxon em uma assembleia, pois a simples contagem de espécies não satisfaz o conceito de diversidade biológica. Quando uma comunidade apresenta suas espécies com distribuição de suas abundâncias iguais, seria classificada como totalmente uniforme, porém, na prática em seu ambiente natural é muito difícil encontrar essa distribuição ${ }^{102}$, principalmente no bioma Mata Atlântica que é considerado um dos mais diversos Hotspots mundiais ${ }^{106}$.

O conceito de espécie adotado neste trabalho foi o conceito exposto em 1969 por Theodosius Dobzhansky e Ernst Mayr denominado conceito biológico de espécie, que define as espécies como "grupos de populações naturais intercruzantes que são reprodutivamente isolados de outros grupos". As morfoespécies foram consideradas como categorias taxonômicas equivalentes a espécies e utilizadas nos cálculos para medir a diversidade, uma vez que, sua inclusão nas comparações não modifica significativamente as estimativas de 
riqueza, inflando a quantidade de espécies entre os ambientes estudados a tal ponto que inviabilizasse esse trabalho.

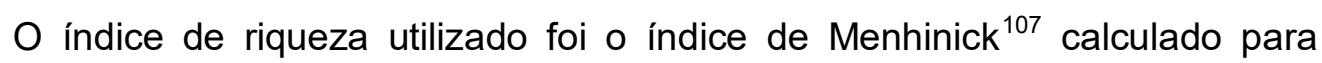
verificar a variação entre os estratos verticais copa e solo de cada ambiente expresso pela fórmula:

$$
\mathrm{D}_{M n}=\frac{\mathrm{S}}{\sqrt{N}}
$$

\section{Onde:}

$\mathbf{S}=$ número de espécies;

$\mathbf{N}=$ número total de indivíduos na amostra.

Essa medida é fortemente influenciada pelo esforço amostral.

\subsubsection{Diversidade $\alpha$ de Espécies}

\subsubsection{1 Índices de Diversidade}

Um índice de diversidade pode ser considerado como uma única estatística que incorpora informações da comunidade que podem ser avaliada por dois parâmetros: riqueza e uniformidade ${ }^{102}$, esses dois parâmetros são chamados também de medidas de heterogeneidade ${ }^{108}$.

Os índices não paramétricos de Shannon $H^{\prime}$ e Simpson (1-D) foram mostrados por meio de perfis de diversidade para expressar as características na escala de assembleias de mosquitos nos ambientes estudados. O termo assembleia restringe-se a denominação dada para os subconjuntos dos táxons relacionados filogeneticamente, por exemplo, espécies de mosquitos da Mata Atlântica.

O índice de Shannon é derivado da teoria da informação, possui unidades que variam conforme a base logarítmica utilizada e, ele, dá mais peso a riqueza de espécies $^{102}$. O índice de Simpson calcula a probabilidade de dois indivíduos 
retirados ao acaso de uma comunidade, pertencerem a mesma espécies, no caso da expressão 1-D as espécies retiradas ao acaso da comunidade são diferentes ${ }^{104}$. A uniformidade entre os ambientes foi medida pelo índice de Pielou (J') pela fórmula:

$J^{\prime}=H^{\prime} / \ln S$

Onde:

J'= uniformidade de Pielou;

$H^{\prime}=H_{\max }$ diversidade máxima possível;

$\mathrm{Ln}=$ logaritmo natural;

$S=$ riqueza

\subsubsection{Perfis de Diversidade}

Melo ${ }^{102}$ enfatiza que embora os valores de riqueza, índice de Shannon $\left(H^{\prime}\right)$ e de Simpson pareçam totalmente diferentes, eles diferem basicamente no peso que dão a espécies raras em uma amostra, onde, para a riqueza tem-se o peso máximo, pois espécies raras tem o mesmo peso que espécies comuns, para o índice de Shannon têm-se o peso intermediário e para o índice de Simpson tem-se um peso mínimo.

A principal proposta dos perfis de diversidade, como a série de Hill e a série de Rényi é comparar a diversidade de várias amostras generalizando o componente riqueza ( $\alpha=0$, número de espécies), a diversidade (índice exponencial de Shannon $\alpha=1$; recíproca do índice de Simpson $\alpha=2$ ) e a dominância (recíproca da abundância proporcional da espécie mais comum, índice de Beger-Parker $\alpha=$ inf), ou seja, descreve a relação entre os índices ${ }^{109}$.

Para dizer se uma assembleia é mais diversa que a outra é necessário verificar o índice, ou seja, depende do índice utilizado, por exemplo, os índices de Shannon $\left(H^{\prime}\right)$ e Simpson (1/D) ${ }^{108,110}$. Na medida em que, aumenta-se o parâmetro $\alpha$ 
caminhando para a direita do gráfico, tem-se uma maior ênfase a equabilidade das abundâncias e a espécies dominantes.

Neste trabalho foi utilizado a série de Rényi, dada por:

$$
\mathrm{H}_{\alpha}=\left(\ln \left(\mathrm{pi}^{\alpha}{ }_{1}+\mathrm{pi}^{\alpha}{ }_{2}+\mathrm{pi}^{\alpha}{ }_{3 \ldots} \ldots+\mathrm{pi}^{\alpha}{ }_{\mathrm{s}}\right)\right) /(1-\alpha)
$$

Onde:

$H_{\alpha}=$ valor do índice de diversidade para o parâmetro $\alpha(\alpha \geq 0, \alpha \neq 1)$;

$p_{1}+p_{2}+p_{3 \ldots} \ldots+p_{s}=$ são proporções de indivíduos das espécies $1,2,3 \ldots \mathrm{S}$.

Para calcular os perfis de diversidade dos estratos copa e solo comparando os ambientes da APA e PEC, foi utilizado o software Paleontological Statistic-PAST versão $3.18^{112}$

\subsubsection{Suficiência Amostral}

A suficiência amostral foi verificada por meio da construção de curvas de acúmulo de espécies calculadas para cada ambiente baseada nas coletas mensais (amostras) das assembleias de mosquitos com intervalo de confiança 95\% e estimativa de riqueza total pelo estimador Jackkinife de $1^{\text {a }}$ ordem com 1000 aleatorizações sem reposição. Para esta análise foi utilizado o software Estimate ${ }^{111}$ para o cálculo das curvas de acúmulo de espécies.

\subsubsection{Composição de espécies}

A diversidade $\beta$ (beta) são as diferenças de composição de espécies entre áreas de diversidade $\alpha$, ou a modificação na composição das espécies em um gradiente ambiental $^{107}$. Foi utilizado o índice de Bray-Curtis para dados de abundância e apresentados em um Dendrograma, afim de, comparar a similaridade 
na composição de espécies entre os sete ambientes das áreas de estudo. Foi utilizado o software Paleontological Statistic - PAST versão $3.18^{112}$.

\subsection{Estratificação Vertical: Frequência copa e solo}

A frequência foi verificada dividindo-se a ocorrência da espécie no estrato pela somatória dos dois estratos. Apenas as espécies mais abundantes foram utilizadas para o cálculo.

Para comparar se houve ou não diferença entre a ocorrência da espécie nos estratos copa e solo foi utilizado o software PAST e R, pelo teste de Mann-Whitney. A ausência de diferença na significância estatística (valor de $p \leq 0,05$ ) na diferença de frequência entre a copa e solo, pode evidenciar mobilidade da espécie entre os estratos e indicar espécies que podem servir de ponte na transmissão de patógenos.

\subsection{Sazonalidade}

Os dados climáticos (precipitação, temperaturas mínima, média e máxima e umidade relativa) de cada localidade foram fornecidos pelo Centro de Gerenciamento de Emergências Climáticas da Prefeitura Municipal de São Paulo (CGE-PMSP) para os anos de 2015, 2016 e 2017.

Utilizaram-se os dados acumulados de 30 dias que antecederam as coletas para a precipitação, e as médias aritméticas mensais (30 dias) de temperatura e umidade relativa. Foram utilizados os dados totais de riqueza e abundância das espécies obtidos nos estratos copa e solo de cada ambiente e estrato vertical e a mesma análise foi realizada para as espécies mais abundantes.

O teste de correlação de Spearman $\left(r_{s}\right)$ foi calculado utilizando o software estatístico Paleontological Statistics - PAST v3.20. Esse teste indica correlação entre postos e não entre os valores efetivamente medidos, o seu cálculo baseia-se 
nas diferenças entre os postos de $\mathrm{x}$ e $\mathrm{y}$. Os valores indicativos variam de -1 que indica a correlação perfeita negativa, zero indica ausência de correlação e 1 indica a correlação perfeita positiva.

\subsection{Comportamento Alimentar de mosquitos}

Para verificar o comportamento alimentar das espécies coletadas ingurgitadas foi realizado um teste de permutação, com 10.000 permutações sem reposição em ambiente computacional do software $\mathrm{R}^{113}$. Foram selecionadas as espécies com frequência igual ou maior a três observações de repastos em qualquer um dos 9 primers (fontes) verificados. O teste de Qui-quadrado foi realizado com 10,000 permutações utilizando a função "permat" com algoritmos "swap" do pacote Vegan, do software R, esta função mantém fixos ambos totais marginais, aleatorizando apenas os valores das células da matriz de dados de contagem. Essa análise calcula os valores esperados e retorna os valores de significância ( $p$-value), do cálculo entre os valores observados e esperados.

Se um número maior do que o esperado para determinada espécie de mosquito foi observada se alimentando na mesma fonte, pode indicar que a espécie de mosquito, apresenta certa atração pela fonte alimentar e assim determinar seu comportamento. 


\section{RESULTADOS}

\subsection{Riqueza por localidade}

No período de 27 meses de estudo foram coletados em armadilhas CDC nos estratos copa e solo um total de 10.070 espécimes de culicídeos adultos, sendo 89 machos e 9.981 fêmeas. Nas duas áreas de estudo foram identificadas 95 espécies/categorias taxonômicas, distribuídas em 16 gêneros: Aedeomyia, Aedes, Anopheles, Chagasia, Coquillettidia, Culex, Haemagogus, Limatus, Mansonia, Psorophora, Runchomyia, Sabethes, Shannoniana, Trichoprosopon, Uranotaenia e Wyeomyia. A distribuição dos gêneros pode ser observada na Tabela 2.

Tabela 2 - Distribuição dos gêneros coletados em armadilhas CDC copa e solo, no período de fevereiro de 2015 a abril de 2017, na APA Capivari Monos e no PE Cantareira.

\begin{tabular}{lcclcc}
\hline Gêneros APA & Indivíduos & $\mathbf{\%}$ & Gêneros PEC & Indivíduos & $\%$ \\
\hline Culex & 4528 & 60,60 & Culex & 1013 & 38,99 \\
Anopheles & 904 & 12,10 & Wyeomyia & 991 & 38,14 \\
Wyeomyia & 823 & 11,01 & Limatus & 234 & 9,01 \\
Limatus & 397 & 5,31 & Runchomyia & 114 & 4,39 \\
Aedes & 342 & 4,58 & Aedes & 113 & 4,35 \\
Coquillettidia & 149 & 1,99 & Trichoprosopon & 51 & 1,96 \\
Runchomyia & 118 & 1,58 & Sabethes & 23 & 0,89 \\
Mansonia & 113 & 1,51 & Anopheles & 17 & 0,65 \\
Trichoprosopon & 35 & 0,47 & Psorophora & 15 & 0,58 \\
Sabethes & 18 & 0,24 & Coquillettidia & 8 & 0,31 \\
Uranotaenia & 16 & 0,21 & Mansonia & 8 & 0,31 \\
Psorophora & 13 & 0,17 & Haemagogus & 7 & 0,27 \\
Aedeomyia & 10 & 0,13 & Shannoniana & 3 & 0,12 \\
Shannoniana & 3 & 0,04 & Uranotaenia & 1 & 0,04 \\
Chagasia & 3 & 0,04 & & & $\mathbf{1 0 0}$ \\
Total & $\mathbf{7 4 7 2}$ & $\mathbf{1 0 0}$ & Total & $\mathbf{2 5 9 8}$ & \\
\hline
\end{tabular}

Um total de $24,7 \%$ dos espécimes coletados na APA e 12,5\% para PEC não puderam ser identificados até o nível de espécie por estarem danificados ou por limitações nas chaves de identificação, além disso, algumas espécies necessitam de indivíduos machos (genitália) ou de formas imaturas (larvas de $4^{\circ}$ estádio) para separá-las, o que neste estudo fica inviabilizado, pelo método de coleta empregado. 
As coletas foram simultâneas em cada localidade e a equipe foi composta de dois coletores por ambiente, exceto para os ambientes silvestres onde a equipe foi formada por até quatro pessoas. As armadilhas permaneceram em funcionamento por $16 \mathrm{~h}$ em cada ambiente/estrato por coleta. O esforço amostral total foi de 432 horas de funcionamento de cada armadilha, em cada estrato por ambiente.

A riqueza total da APA Capivari-Monos somando-se todas as espécies/categorias taxonômicas (todos ambiente e estratos) foi de 75 espécies/categorias taxonômicas distribuídas em 15 gêneros e sua abundância total de 7.472 indivíduos, (7.422 † e 50 §), sendo o gênero Haemagogus ausente nesta localidade durante o estudo.

Para o Parque Estadual da Cantareira a riqueza nas condições já elencadas anteriormente para a APA, foi de 58 espécies/categorias taxonômicas distribuídas em 14 gêneros e abundância total de 2.598 indivíduos (2.559 † e 39 ふै) sendo os gêneros Aedeomyia e Chagasia ausentes nesta localidade ao longo do período estudado. A Figura 11 mostra a diferença na riqueza total entre as localidades de estudo.

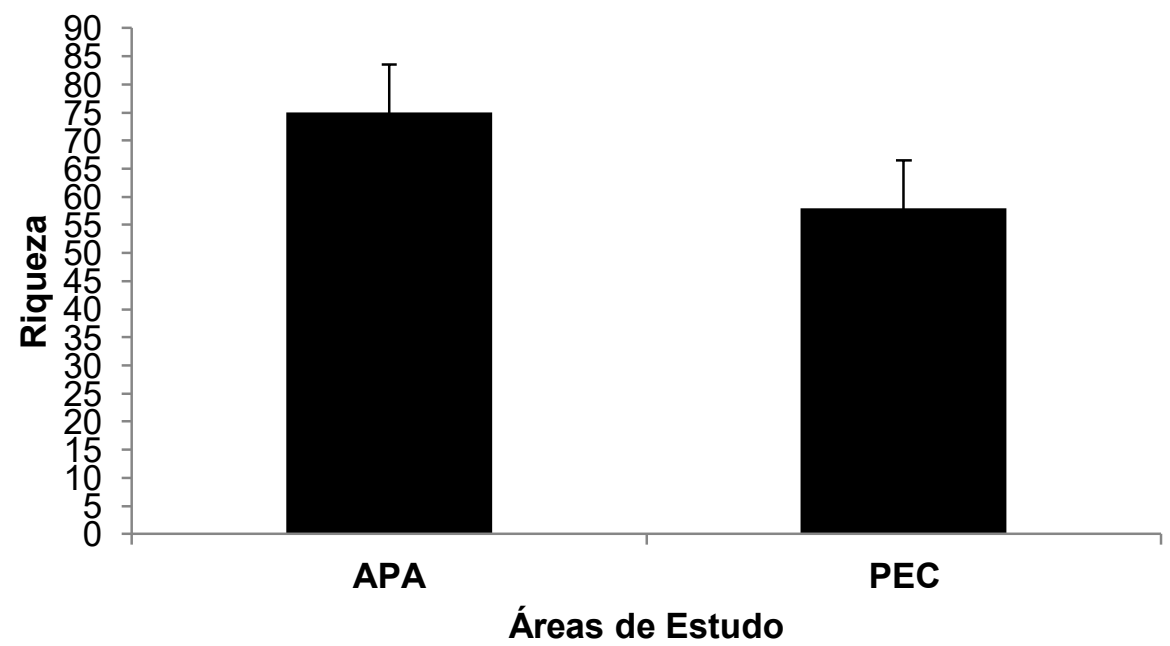

Figura 11 - Riqueza total de mosquitos (IC95\%) coletados com armadilhas CDC copa e solo, na APA Capivari Monos e PE Cantareira, durante o período de fevereiro de 2015 a abril de 2017. 
No geral, a riqueza total observada na escala localidade na APA, foi de 58 espécies/categorias taxonômicas coletadas no estrato copa e 60 no estrato solo. No PEC, não houve diferença sendo coletadas 43 espécies/ categorias taxonômicas em ambos os estratos. Quando verificada a abundância das espécies, na APA maior número de indivíduos $(5.023=67 \%)$ foi coletado no estrato copa do que no estrato solo $(2.449=33 \%)$ enquanto que na localidade PEC, os espécimes foram coletados em maior proporção no estrato solo $(1.436=55 \%)$ do que no estrato copa $(1.162=45 \%)$ Figura 12 .

\section{APA Capivari Monos}

$$
\text { - Copa } \backsim \text { Solo }
$$

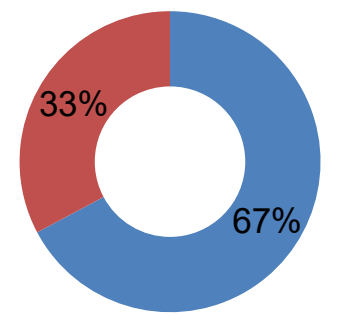

PE Cantareira

- Copa $\backsim$ Solo

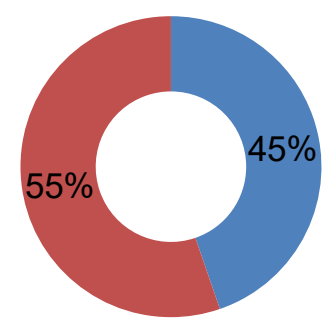

Figura 12. Abundância total de mosquitos nos estratos verticais copa e solo, coletados em armadilhas CDC na APA Capivari Monos e Parque Estadual da Cantareira, durante o período de fevereiro de 2015 a abril de 2017.

Quando observada a distribuição das abundâncias das espécies que ocorreram na APA, o mês de maio de 2015 representou a maior abundância de espécimes sendo a maior proporção ocorrendo na copa. No PEC, a distribuição das abundâncias das espécies ocorreu nos meses mais quentes e chuvosos, sendo o estrato solo apresentando a maior proporção de indivíduos coletados.

\subsection{Riqueza por ambiente}

A riqueza por ambiente foi verificada pela contagem de espécies. $O$ ambiente mais rico em número de espécies na localidade APA foi o ambiente 
periurbano 1 com 52 espécies/categorias taxonômicas. O segundo ambiente mais rico em espécies foi o ambiente silvestre com 47 espécies/categorias taxonômicas e o ambiente periurbano 2 e intermediário tiveram a mesma riqueza 42 espécies/categorias taxonômicas (Figura 13).

Espécies

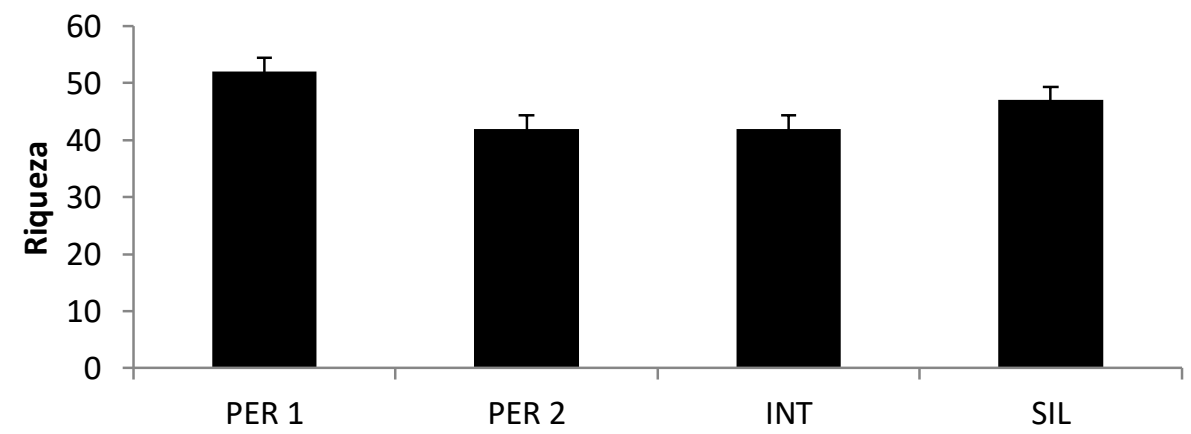

Figura 13 - Riqueza total de mosquitos (IC95\%) coletados com armadilhas CDC nos estratos copa e solo, instaladas nos ambientes da APA Capivari Monos, nos ambientes periurbano 1 , periurbano 2 , intermediário e silvestre, durante 0 período de fevereiro de 2015 a abril de 2017.

Na localidade PEC o ambiente com maior riqueza foi o intermediário com 36 espécies/categorias taxonômicas, seguido do silvestre 30 e periurbano com 29 (Figura 14).

Espécies

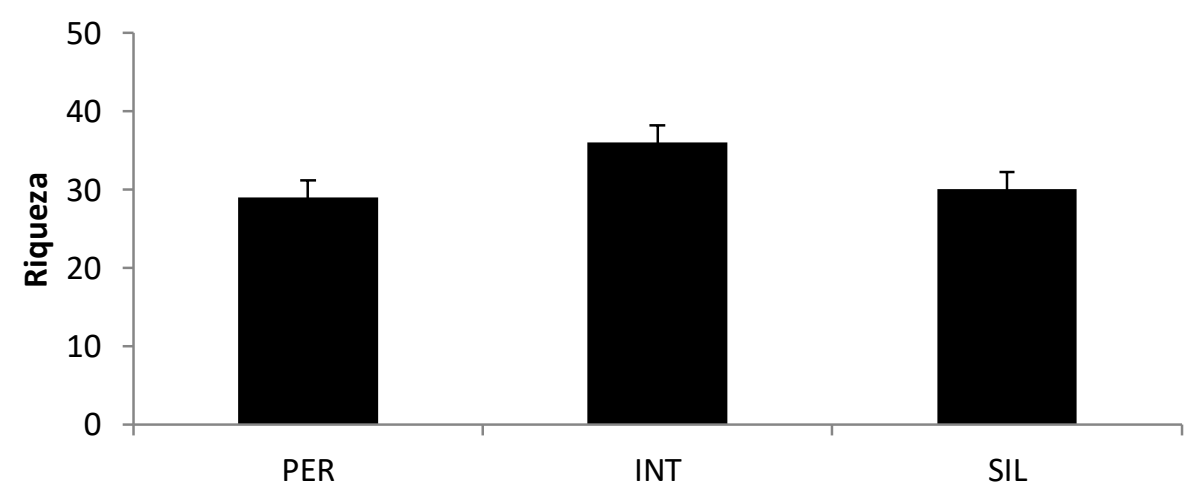

Figura 14 - Riqueza total de mosquitos (IC95\%) coletados com armadilhas CDC nos estratos copa e solo, instaladas nos ambientes da PE Cantareira, nos ambientes periurbano, intermediário e silvestre, durante o período de fevereiro de 2015 a abril de 2017. 
Em ambientes mais heterogêneos, é esperada maior diversidade de espécies, pois esses ambientes proporcionam maior gama de micro habitats e microclimas, consequentemente as espécies encontram recursos e nichos adequados a sua ocorrência, manutenção e permanência.

A uniformidade entre os ambientes, mostrada na Figura 15 foi obtida pela medida de uniformidade de Shannon, também conhecida com Equabilidade de Pielou - J' que leva em consideração o grau de uniformidade dado pela abundância das espécies.

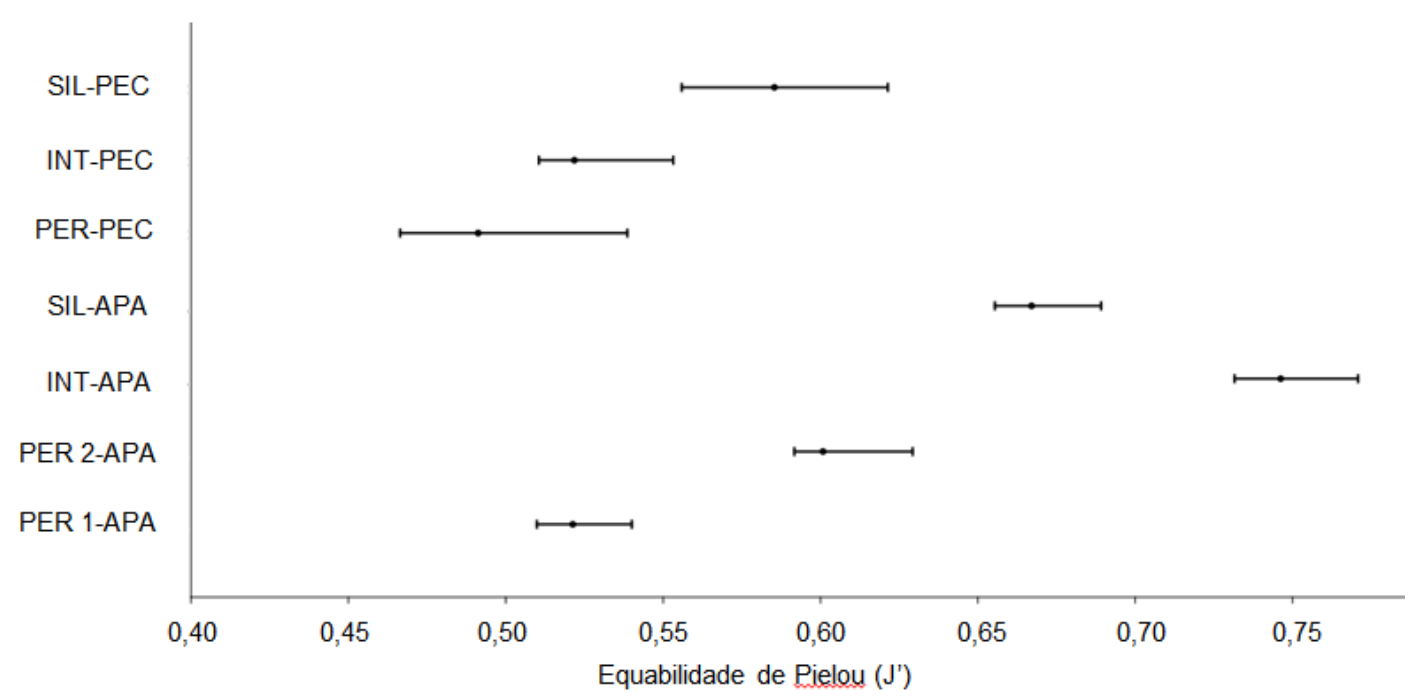

Figura 15 - Comparação da uniformidade nas abundâncias das assembleias de mosquitos coletados nos sete ambientes das localidades de estudo APA Capivari Monos e Parque Estadual da Cantareira, no período de fevereiro de 2015 a abril de 2017.

Como observado na figura 15 , os dados mensurados revelam que na APA Capivari Monos, o ambiente mais equitativo foi o intermediário, seguido do ambiente silvestre e o ambiente com maior dominância foi o periurbano 1 . No PE Cantareira, o ambiente mais equitativo foi o silvestre e o ambiente com maior dominância o periurbano. 


\section{3 Índices de Diversidade: Perfis de diversidade}

Os perfis de diversidade dados pela série de Renýi foram empregados para verificar a ordenação dos ambientes estudados, comparando as diferenças entre os índices de diversidade com os dados obtidos para cada ambiente ${ }^{114}$. A série de Renýi generaliza o número total de espécies (riqueza total, $\alpha=0$ ), a diversidade medida pelos índices de Shannon ( $\alpha=1)$ e Simpson $(\alpha=2)$ e a dominância medida pelo índice de Berger-Parker ( $\alpha=$ inf.).

As Figuras 16 e 17 ilustram os perfis de diversidade encontrados nas assembleias de mosquitos coletados nos ambientes da APA Capivari Monos e PE Cantareira, respectivamente.

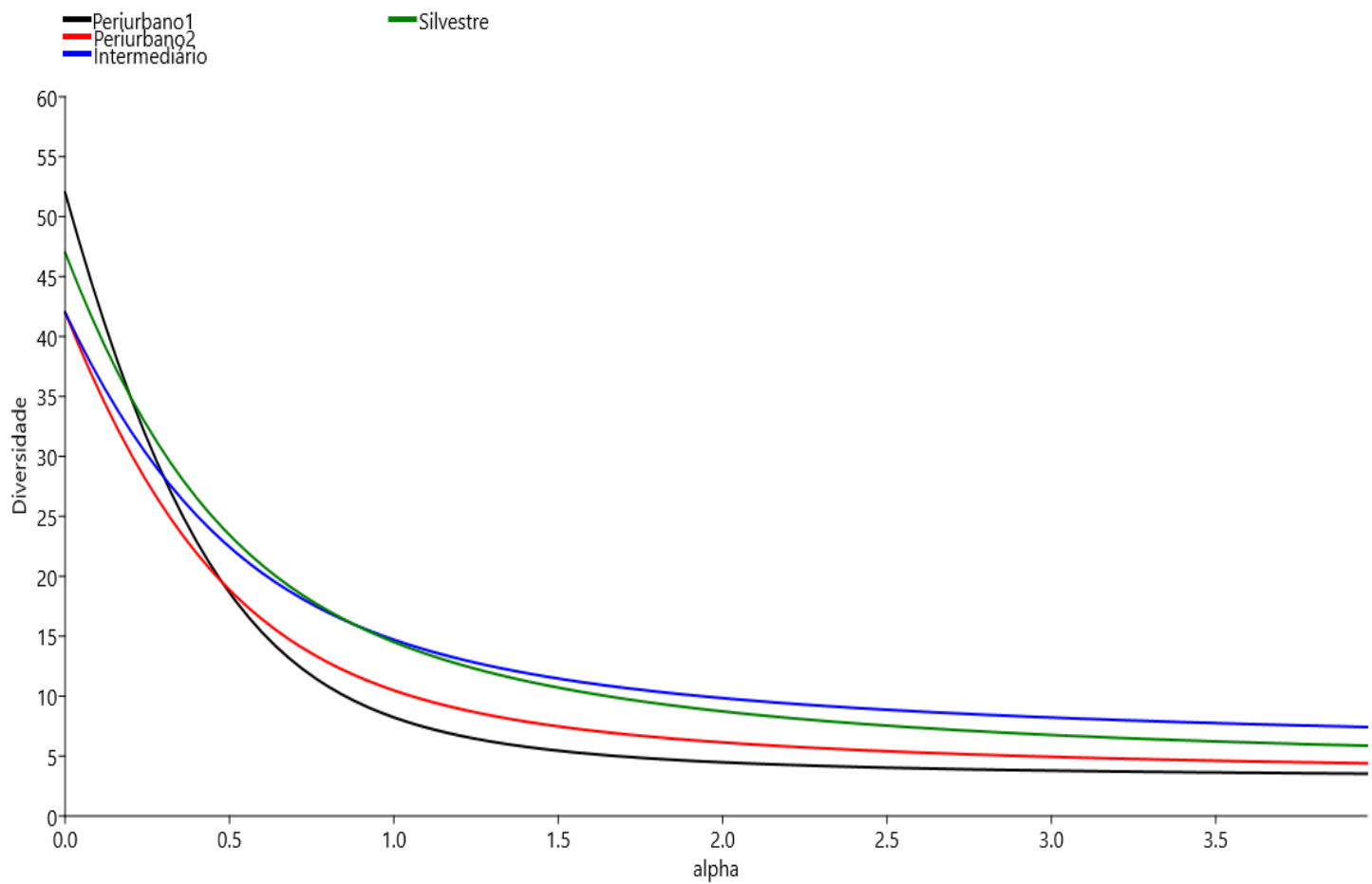

Figura 16 - Comparação entre os Perfis de diversidade para os dados de abundância total de mosquitos coletados nos ambientes da APA Capivari-Monos com uso da série de Renýi. Para o parâmetro $\alpha=0$, o valor de diversidade é igual ao número de espécies nas amostras. Para $\alpha=1$, o valor de diversidade é equivalente ao índice de Shannon (base neperiana), para $\alpha=2$ o valor é equivalente ao índice de Simpson e para a tendendo ao infinito o valor referese ao índice de dominância de Berger-Parker (1/d). 
Observa-se que em ambas as figuras 16 e 17 há a intersecção das curvas dos perfis de diversidade dos ambientes estudados.

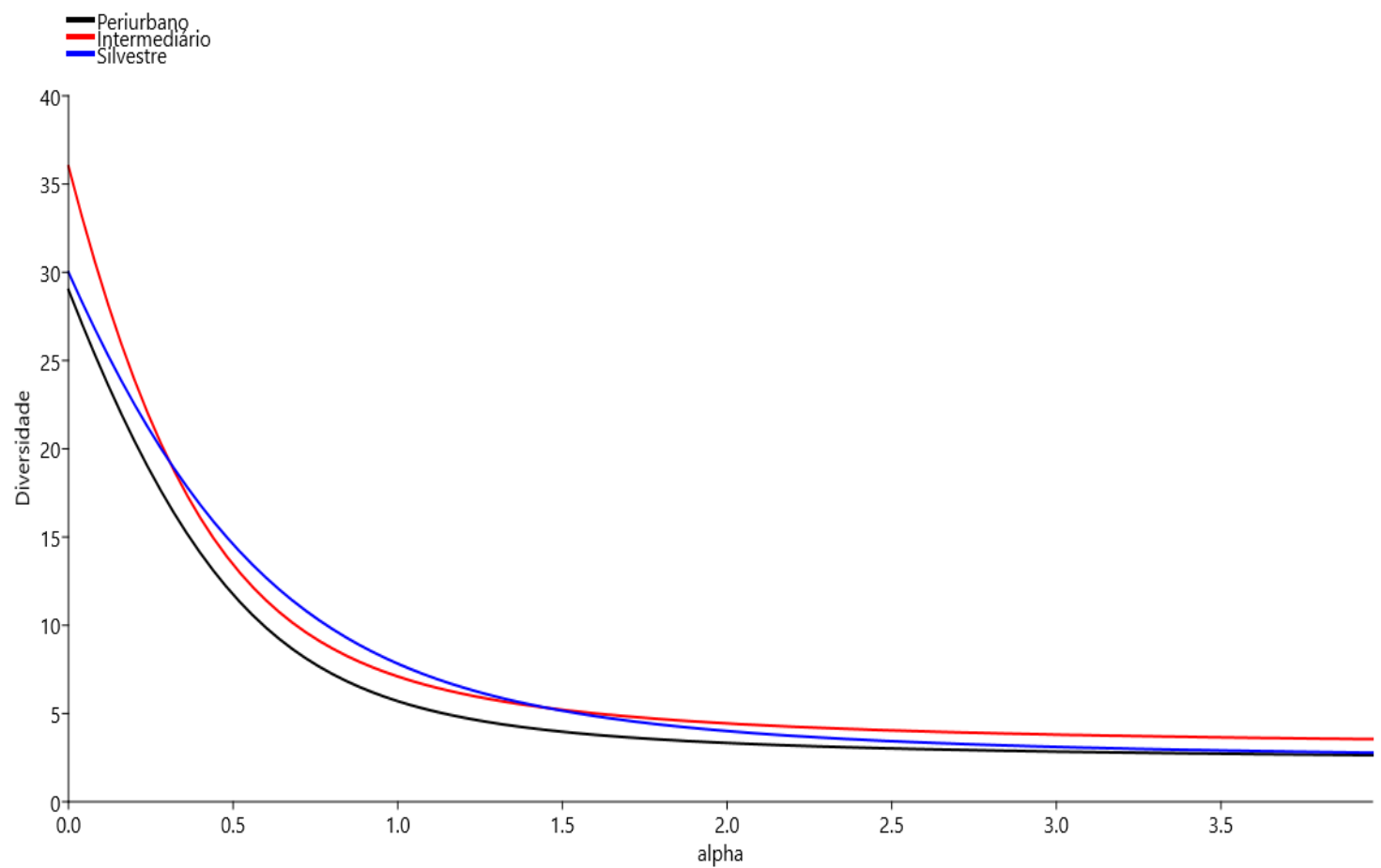

Figura 17 - Comparação entre os Perfis de diversidade para os dados de abundância total de mosquitos para os ambientes da PEC com uso da série de Renýi. Para o parâmetro $\alpha=0$, o valor de diversidade é igual ao número de espécies nas amostras. Para $\alpha=1$, o valor de diversidade é equivalente ao índice de Shannon (base neperiana), para $\alpha=2$ o valor é equivalente ao índice de Simpson e para a tendendo ao infinito o valor refere-se ao índice de dominância de Berger-Parker (1/d).

\subsection{Suficiência Amostral}

A suficiência amostral foi verificada pela construção de curvas de acúmulo de espécies para as duas localidades (Figura 18) e para cada ambiente (Figura 19 e 20), com base em amostras e intervalo de confiança de 95\% (IC95\%), utilizando o software EstmateS ${ }^{\circledR}$, com 1000 randomizações sem reposição. As curvas foram comparadas com estimativa de riqueza total pelo estimador Jackkinife de $1^{\text {a }}$ ordem, que mede a riqueza total utilizando o número de espécies que ocorrem em apenas uma amostra uniques. 


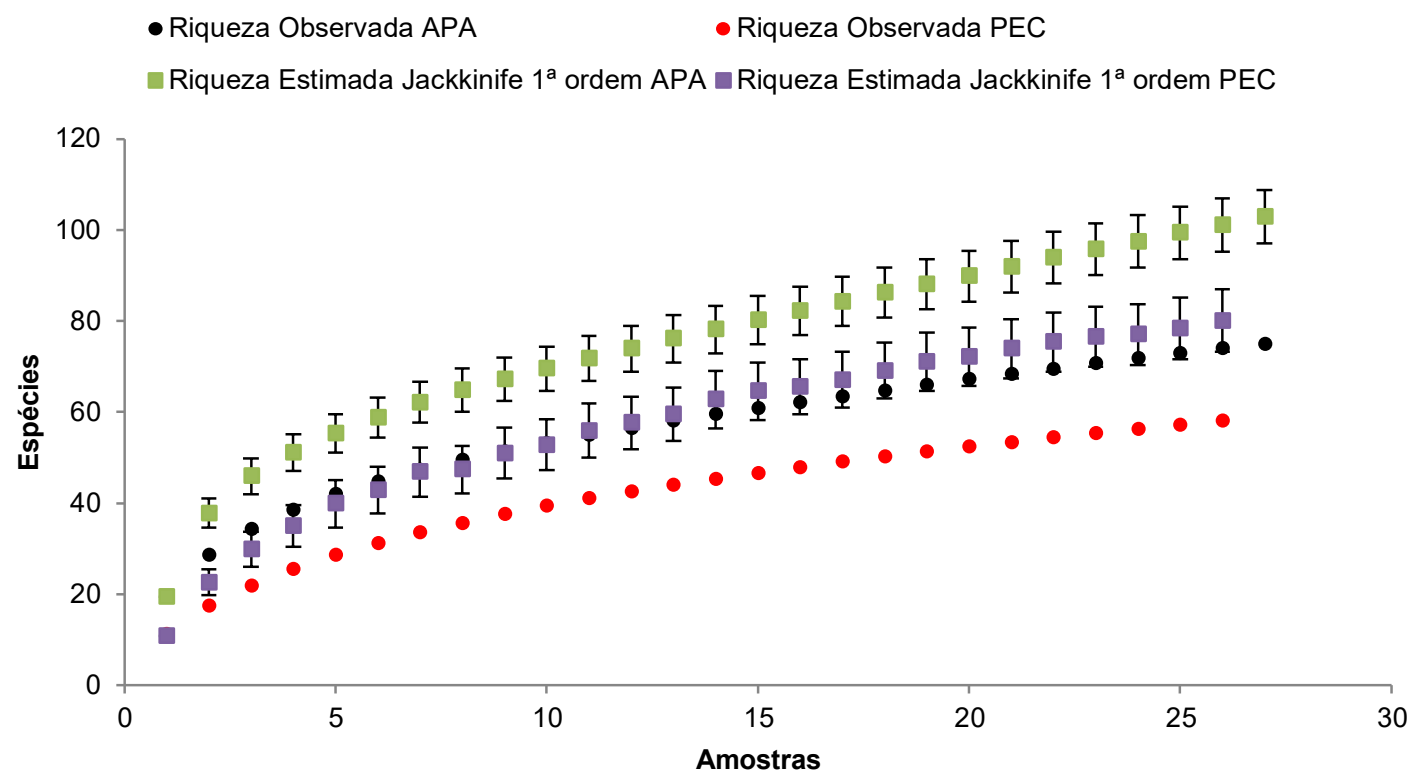

Figura 18 - Comparação da riqueza estimada por curva de acúmulo de espécies calculada pelos dados de abundância de cada coleta e IC95\%, no período de fevereiro de 2015 a abril de 2017, na APA Capivari Monos e no PE Cantareira.

As Figuras 19 e 20 mostram as curvas de acúmulo de espécies pelo estimador Jackkinife de $1^{\text {a }}$ ordem obtidas para cada um dos ambientes estudados. As curvas de acúmulo de espécies revelaram que o esforço amostral não foi suficiente para revelar todas as espécies existentes em cada ambiente, sendo que o aumento do esforço amostral em cada ambiente estudado revelaria mais espécies, aumentando assim a riqueza local. 
Periurbano 1

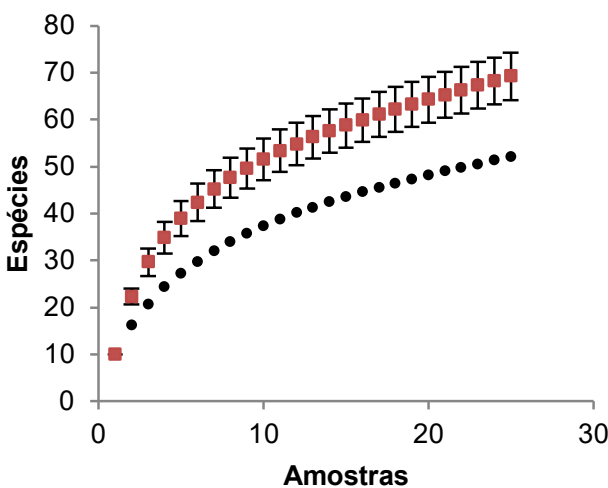

- Riqueza Observada - Riqueza Estimada

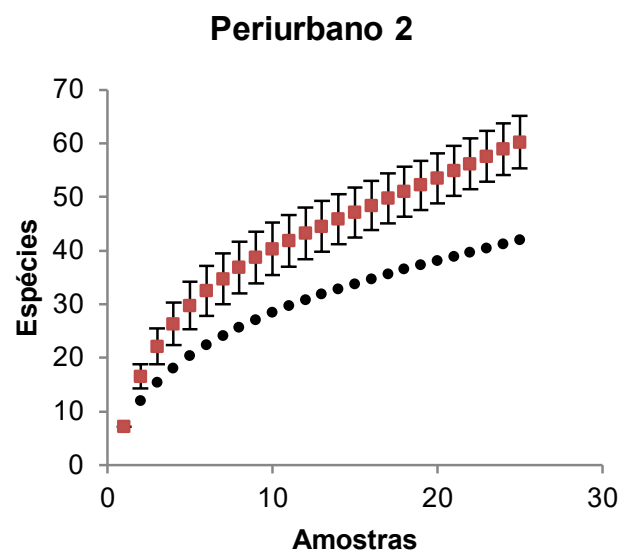

- Riqueza Observada $\quad$ Riqueza Estimada
Intermediário

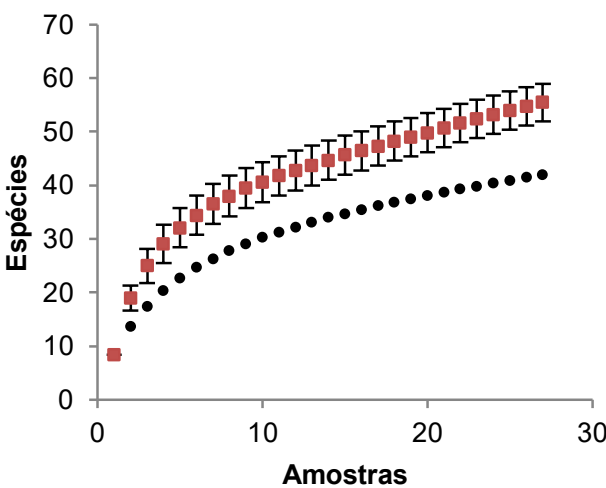

- Riqueza Observada - Riqueza Estimada
Silvestre

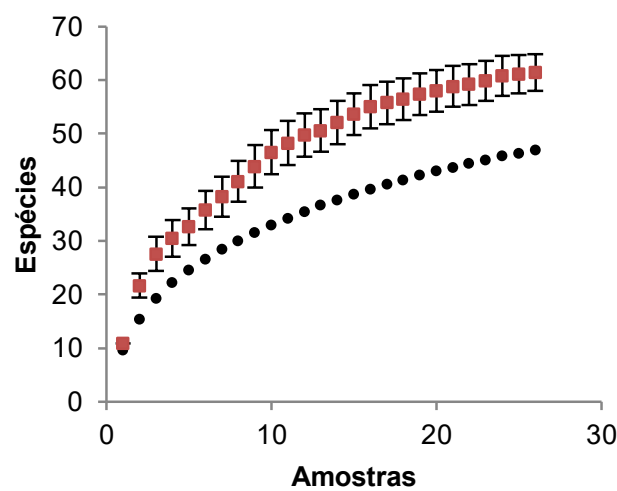

- Riqueza Observada - Riqueza Estimada

Figura 19 - Comparação das riquezas estimadas nos ambientes pelas curvas de acúmulo de espécies, pelo estimador Jackkinife de $1^{\text {a }}$ ordem (IC95\%) baseadas nas amostras obtidas no período de fevereiro de 2015 a abril de 2017, nos ambientes da APA Capivari-Monos. 
Periurbano

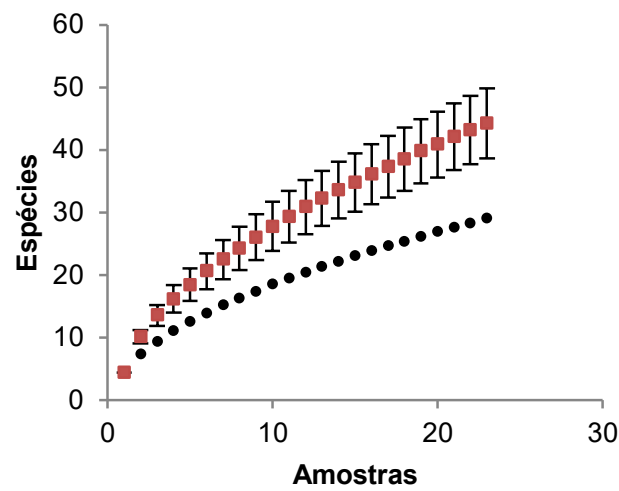

- Riqueza Observada - Riqueza Estimada
Intermediário

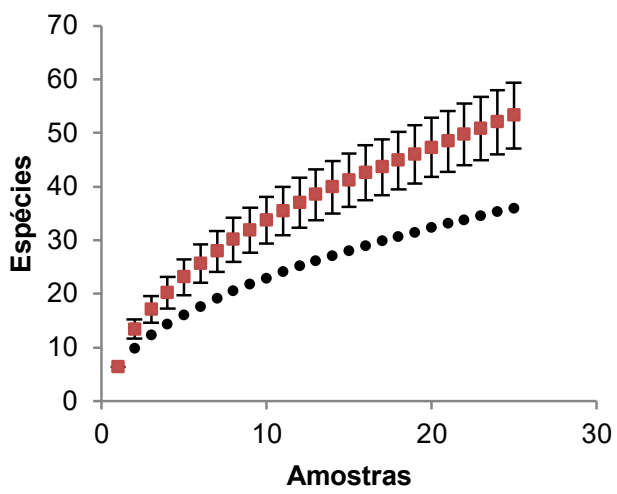

- Riqueza Observada - Riqueza Estimada

\section{Silvestre}

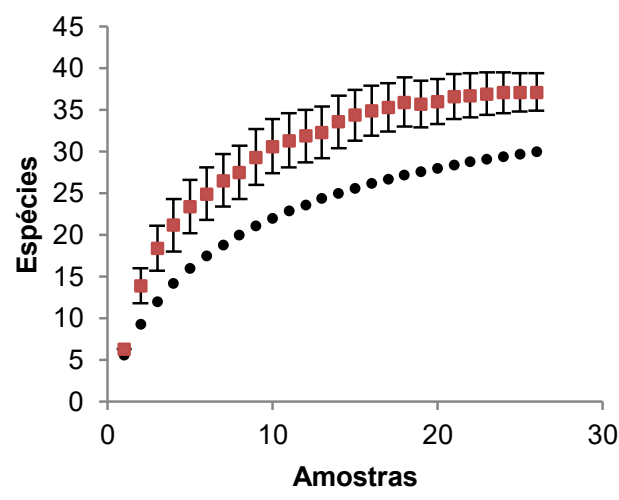

- Riqueza Observada - Riqueza Estimada

Figura 20 - Comparação das riquezas estimadas nos ambientes pelas curvas de acúmulo de espécies, pelo estimador Jackkinife de $1^{\text {a }}$ ordem baseadas nas amostras obtidas no período de fevereiro de 2015 a abril de 2017, na localidade PE Cantareira. 


\subsection{Composição de espécies}

A composição das assembleias de mosquitos nos estratos foi comparada pela análise hierárquica de cluster UPGMA (Unweighted pair-group average) que é a média de pares de grupos não ponderados, onde os grupos são agregados com base nas distâncias médias entre todos os membros dos grupos. Para esta análise foi utilizado o índice de similaridade/ dissimilaridade de Bray-Curtis para dados de abundância. A Tabela 3 mostra a matriz de resultados de proximidade e distância na composição de espécies entre os ambiente de coleta. A menor similaridade foi verificada entre o ambiente periurbano da PEC e o periurbano 1 da $\operatorname{APA}(0,138)$ e a maior similaridade foi verificada entre os ambientes periurbano 2 e o intermediário da APA $(0,742)$. De modo geral, houve mais similaridade na composição de espécies de mosquitos entre os ambientes de uma mesma localidade de estudo, do que entre os ambientes equivalentes entre as duas localidades (APA - PEC).

Tabela 3 - Matriz de distância entre os ambientes das áreas de estudo APA e PEC. Índice de similaridade de Bray-Curtis para dados de abundância dos estratos copa e solo.

\begin{tabular}{|c|c|c|c|c|c|c|}
\hline & PER-PEC & INT-PEC & SIL-PEC & PER1-APA & PER2-APA & INT-APA \\
\hline INT-PEC & 0,424 & & & & & \\
\hline SIL-PEC & 0,521 & 0,516 & & & & \\
\hline PER1-APA & 0,138 & 0,229 & 0,179 & & & \\
\hline PER2-APA & 0,290 & 0,309 & 0,247 & 0,595 & & \\
\hline INT-APA & 0,363 & 0,355 & 0,337 & 0,476 & 0,742 & \\
\hline SIL-APA & 0,291 & 0,365 & 0,282 & 0,388 & 0,599 & 0,659 \\
\hline
\end{tabular}


O dendrograma da Figura 21 mostra que na APA os ambientes que compartilharam mais espécies foram o periurbano 2 (PER 2) e o ambiente intermediário (INT), enquanto que no PE Cantareira os ambientes foram o silvestre (SIL) e o periurbano (PER).

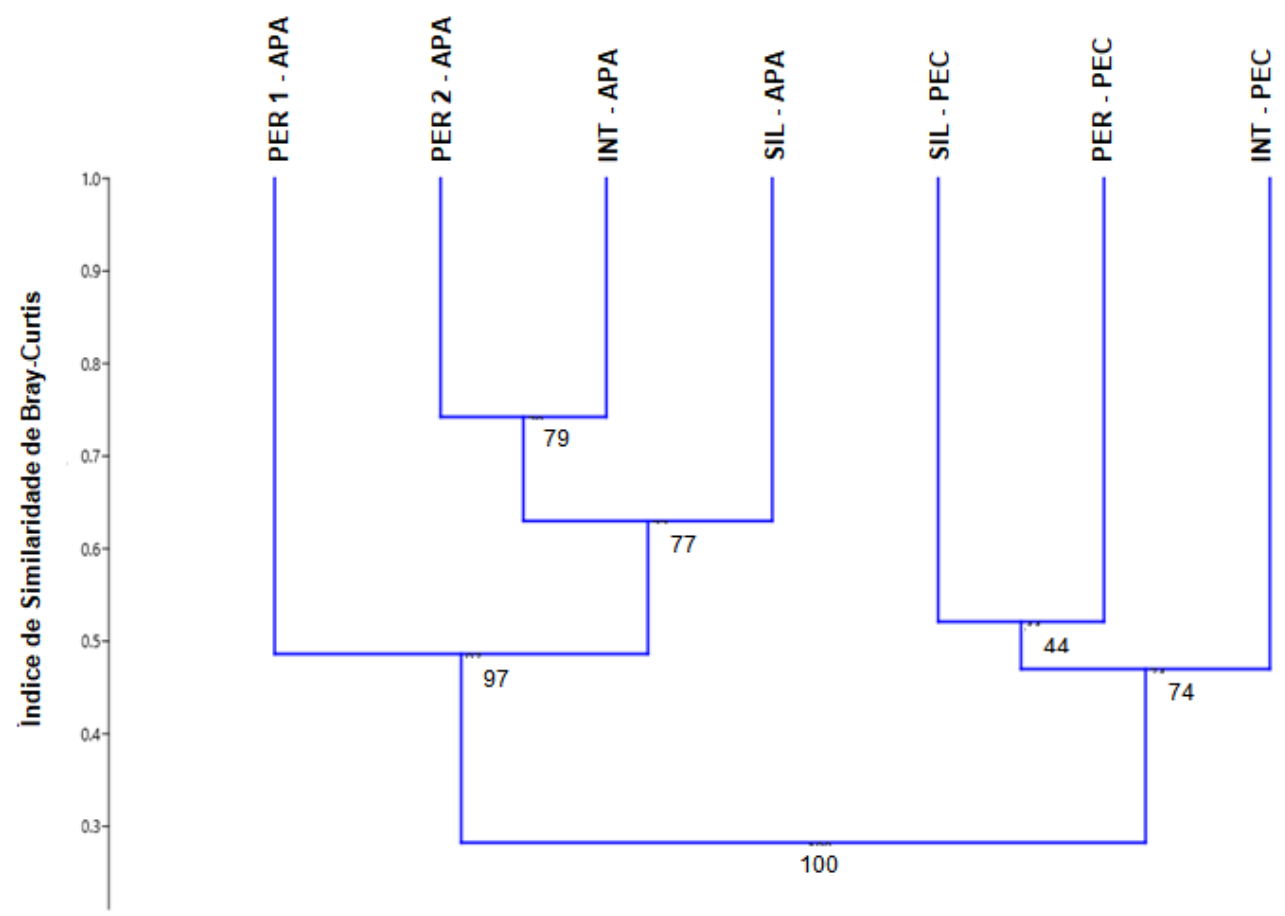

Figura 21 - Dendrograma UPGMA mostrando o agrupamento (1000 bootstraps) dos sete ambientes de estudo na APA Capivari-Monos e no Parque Estadual da Cantareira de acordo com a similaridade na composição de espécies de culicídeos. Coeficiente de correlação cofenético $=0,9398$. PER, ambiente periurbano; INT, ambiente intermediário e SIL, ambiente silvestre.

\subsection{Estratificação Vertical de mosquitos}

A variação da riqueza acumulada por estrato copa e solo de cada ambiente ao longo de cada coleta, pode ser observada na Tabela 4 e Figura 22. 
Tabela 4 - Dados da diversidade alfa para os ambientes e estratos copa e solo obtidos por coleta, no período de fevereiro de 2015 a abril de 2017, APA Capivari Monos.

\begin{tabular}{lcccccccc}
\hline \multicolumn{1}{c}{ Índices } & $\begin{array}{c}\text { PER 1 } \\
\text { Copa }\end{array}$ & $\begin{array}{c}\text { PER 1 } \\
\text { Solo }\end{array}$ & $\begin{array}{c}\text { PER 2 } \\
\text { Copa }\end{array}$ & $\begin{array}{c}\text { PER 2 } \\
\text { Solo }\end{array}$ & $\begin{array}{c}\text { INT } \\
\text { Copa }\end{array}$ & $\begin{array}{c}\text { INT } \\
\text { Solo }\end{array}$ & $\begin{array}{c}\text { SIL } \\
\text { Copa }\end{array}$ & $\begin{array}{c}\text { SIL } \\
\text { Solo }\end{array}$ \\
\hline $\begin{array}{l}\text { Riqueza } \\
\text { Observada }\end{array}$ & 45 & 31 & 32 & 31 & 37 & 35 & 37 & 37 \\
Abundância & 2131 & 440 & 932 & 661 & 840 & 670 & 1120 & 728 \\
Menhinick & 1,19 & 1,30 & 1,13 & 1,19 & 1,33 & 1,30 & 1,18 & 1,30 \\
Simpson 1-D & 0,71 & 0,64 & 0,62 & 0,55 & 0,66 & 0,64 & 0,57 & 0,64 \\
Shannon $\boldsymbol{H}^{\prime}$ & 1,52 & 1,21 & 1,15 & 1,13 & 1,41 & 1,27 & 1,22 & 1,35 \\
Berger-Parker & 0,43 & 0,48 & 0,49 & 0,57 & 0,46 & 0,48 & 0,57 & 0,47 \\
\hline
\end{tabular}

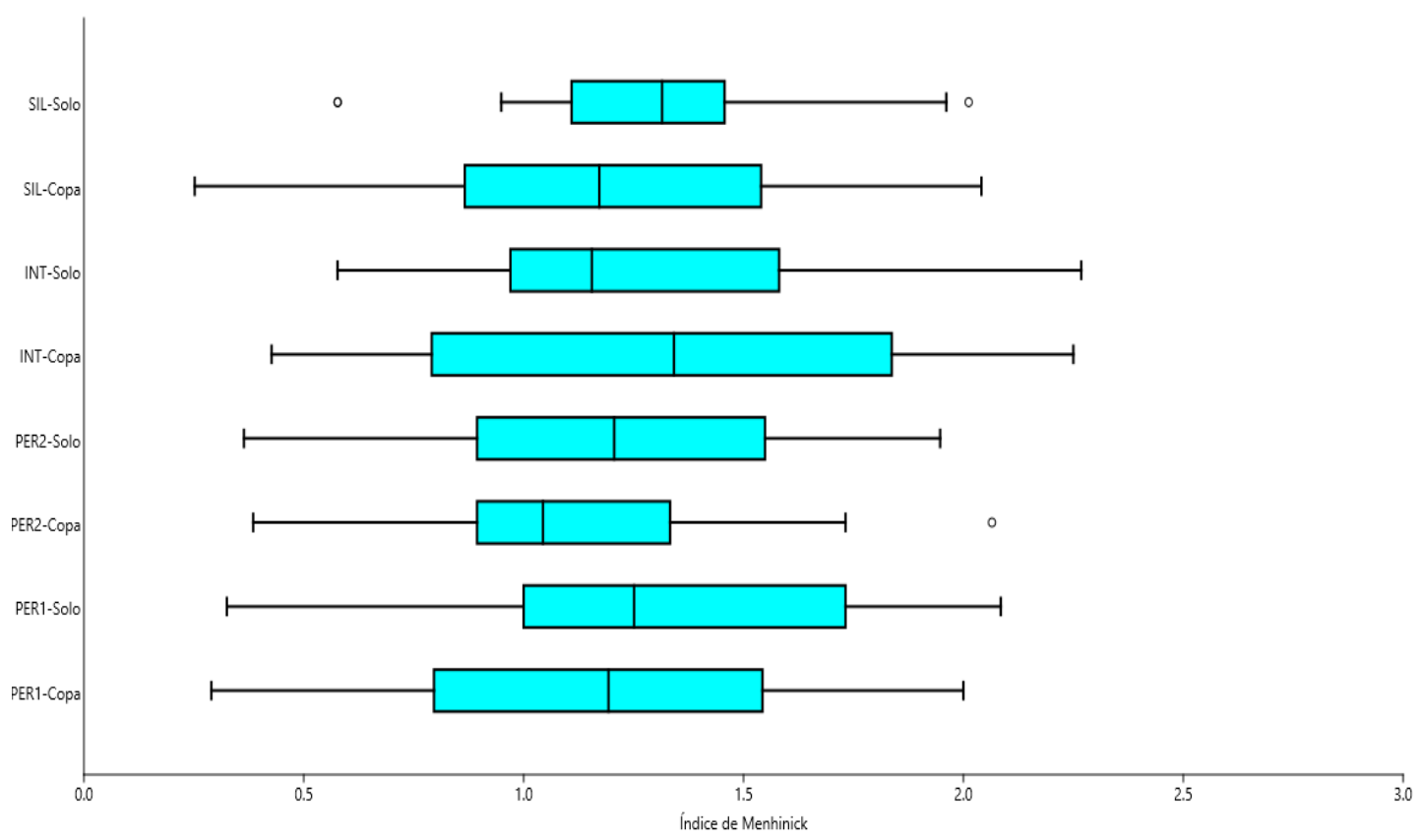

Figura 22 - Variação da riqueza acumulada de espécies, estimada pelo índice de Menhinick no período de Fevereiro de 2015 a Abril de 2017, entre os estratos copa e solo nos ambientes da APA Capivari Monos. 
Observa-se que na APA, para cada ambiente na escala estrato vertical a riqueza medida pelo índice de Menhinick mostrou pouca variação, sendo no estrato solo nos ambientes periurbano 1 , periurbano 2 e silvestre com maior riqueza no estrato solo e no ambiente intermediário maior riqueza no estrato copa. Maior abundância foi observada no estrato copa do ambiente periurbano 1 (2.131 espécimes), com a espécie Cx. nigripalpus e Cx. (Cux.) sp somando $65 \%$ desse total de espécimes coletados neste estrato. O ambiente silvestre foi o segundo ambiente com maior abundância, com as espécies An. cruzii com 481 espécimes e Cx. nigripalpus com 239 espécimes, ambas ocorrendo com maior frequência no estrato copa e somando $52 \%$ do total de espécimes coletadas neste estrato.

Os dados sobre a diversidade alfa para os ambientes e estratos copa e solo do PE Cantareira podem ser visualizados na Tabela 5 e Figura 23.

Tabela 5 - Dados da diversidade alfa para os ambientes e estratos copa e solo obtidos por mês no período de fevereiro de 2015 a abril de 2017 para o PE Cantareira.

\begin{tabular}{lcccccc}
\hline \multicolumn{1}{c}{ Índices } & PER Copa & PER Solo & INT Copa & INT Solo & SIL Copa & SIL Solo \\
\hline Riqueza Observada & 22 & 18 & 24 & 28 & 24 & 25 \\
$\begin{array}{l}\text { Abundância } \\
\text { Menhinick }\end{array}$ & 126 & 331 & 788 & 528 & 248 & 577 \\
Simpson 1-D & 1,18 & 1,07 & 1,01 & 0,98 & 1,20 & 1,05 \\
Shannon $\boldsymbol{H}^{\prime \prime}$ & 0,42 & 0,48 & 0,47 & 0,44 & 0,47 & 0,43 \\
& 0,72 & 0,86 & 0,91 & 0,83 & 0,89 & 0,83 \\
Berger-Parker & 0,65 & 0,63 & 0,64 & 0,68 & 0,62 & 0,69 \\
\hline
\end{tabular}




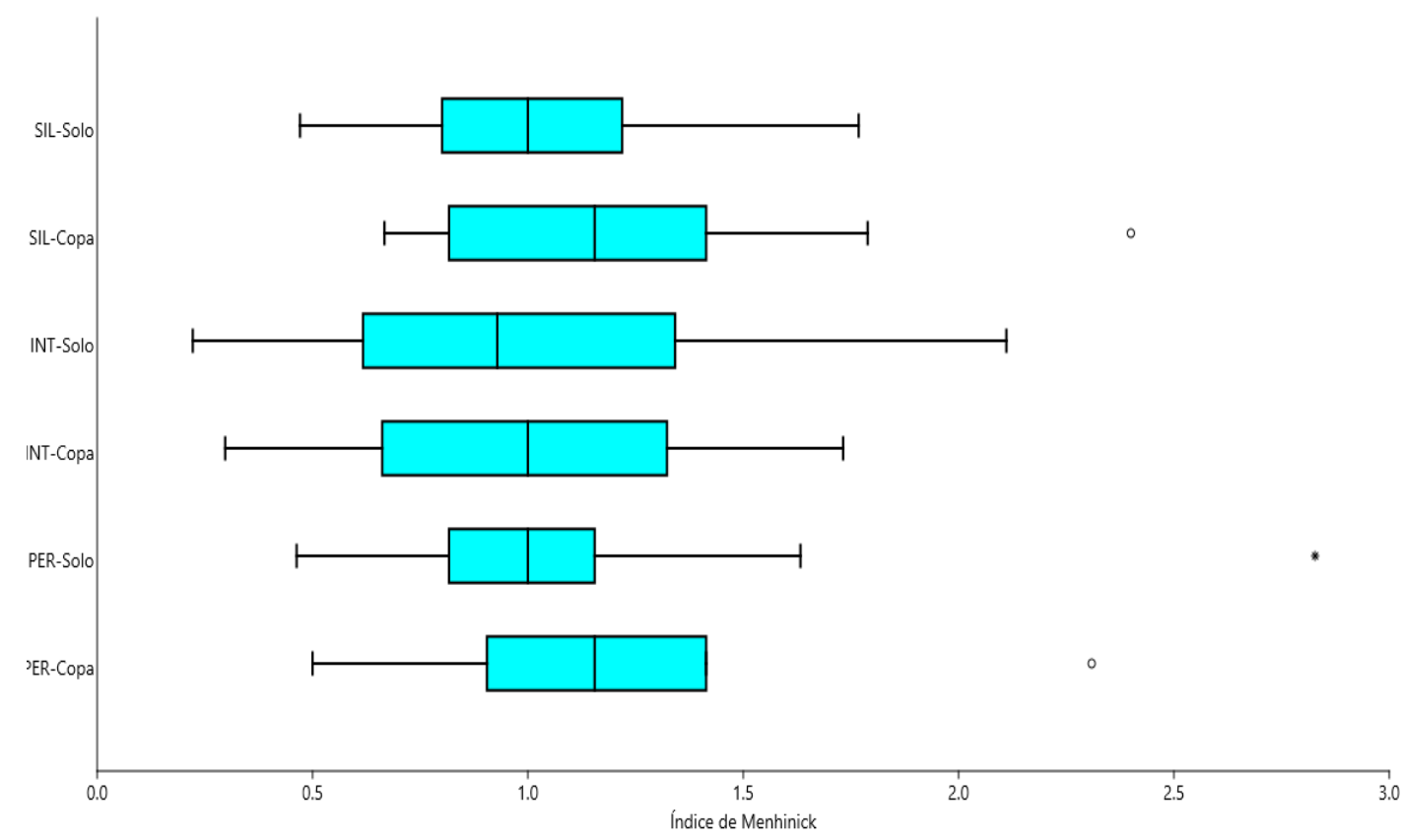

Figura 23 - Variação da riqueza acumulada de espécies, estimada pelo índice de Menhinick no período de Fevereiro de 2015 a Abril de 2017, entre os estratos copa e solo nos ambientes da PE Cantareira.

Os parâmetros de diversidade alfa na escala estrato vertical, calculados a cada coleta em cada ambiente do PE Cantareira, apresentaram pouca variação, com tendência a uma maior riqueza no estrato copa do que no estrato solo. A menor abundância de espécies foi observada no ambiente periurbano no estrato copa e a maior abundância foi observada no ambiente intermediário no mesmo estrato. $\mathrm{O}$ índice de riqueza de Menhinick ${ }^{115}$ revelou maior riqueza no estrato copa do ambiente silvestre e o menor valor deste índice foi observado no estrato solo do ambiente intermediário da localidade PEC.

O índice de dominância de Simpson (1-D) variou muito pouco entre os ambientes e estratos (Tabela 5). O índice de Shannon $H^{\prime}$ foi maior no estrato copa do ambiente intermediário e o menor valor deste índice foi observado no estrato copa do ambiente periurbano. O índice de Berger-Parker mostrou valores equivalentes entre os estratos nos ambientes pesquisados. 
O teste de Mann-Whitney para o ambiente periurbano 1 da APA, na comparação entre a riqueza ocorrida na copa e no solo apresentou diferença significativa $(U=192 ; z=-2,9926 ; p=0,003)$ entre as médias da copa 6,9 $($ IC95\% $5,7-8,0)$ e solo 4,8 (IC95\% 3,6 - 5,9). Não houve diferença entre os dados de riqueza na copa e no solo para os ambientes periurbano 2, intermediário e silvestre.

No PEC, a comparação entre as riquezas dos estratos não apresentou diferença estatística significativa para os ambientes periurbano e intermediário. No ambiente silvestre do PEC, o teste de Mann-Whitney mostrou significância estatística $(U=231,5 ; z=-1,9585 ; p=0,05)$ para os dados de riqueza entre a copa com média de 3,0385 (IC95\% 1,8 - 4,3) e o solo com média de 3,9 (IC95\% 3,1 $4,7)$.

As espécies mais abundantes na APA foram Cx. nigripalpus (1817/ 24,3\%) e An. cruzii (901/12,1\%), ambos ocorrendo principalmente no estrato copa de todos os ambientes. Cx. (Cux.) sp esteve entre as categorias taxonômicas com maior número de indivíduos, mas não foi analisada para as diferenças entre os estratos, pois poderia representar qualquer uma das espécies já identificadas para o subgênero Culex. A observação de Cx. quinquefasciatus na APA, mostrando maior frequência no estrato solo e maior ocorrência no ambiente silvestre, merece atenção dado o local de sua ocorrência ser considerado ambiente com maior preservação e pouca interferência antrópica (Tabela 6).

No PE Cantareira as espécies mais abundantes foram Wyeomyia (Prosopolepis) confusa (973/37,5\%), Culex (Melanoconion) vaxus (18\%) e Limatus durhamii (9\%). Wy. confusa e Li. durhamii ocorrendo principalmente no solo e Cx. vaxus ocorrendo na copa. Outra espécie importante Cx. nigripalpus apresentou 186 espécimes $(7,2 \%)$, coletados em todos os pontos e estratos (Tabela 7$)$. 
Para analisar se houve diferença estatística significante entre as espécies mais abundantes em cada localidade e sua frequência nos estratos foi utilizado o teste não paramétrico de Mann-Whitney, realizado no software PAST v3.20.

Na APA, An. cruzii apresentou maior abundância em armadilha na copa (650 indivíduos) do que no solo (251 indivíduos). Sua frequência em 27 coletas realizadas foi de 19 no estrato copa e 12 no estrato ao nível do solo. A média de indivíduos por coleta foi de 34,2 espécimes no estrato copa e 13,2 no estrato solo. Na comparação entre os dados obtidos nos estratos verticais, o teste de MannWhitney foi estatisticamente significante $(U=82,5 ; z=-2,8646 ; p=0,004)$, mostrando que nesta localidade esta espécie apresenta diferença entre os estratos, tendendo a frequentar mais a copa do que o solo. Para $C x$. nigripalpus foram coletados 1630 indivíduos no estrato copa (média $=65,2$ ) e no solo 187 indivíduos (média $=7,5)$ por coleta. Esta espécie teve frequências de 21 ocorrências na copa e 22 ocorrências no solo em 27 amostras. O teste de Mann-Whitney não apresentou diferença estatística significante $(U=278,5 ; z=0,65455 ; p=0,51276)$.

No PEC, para a espécie Wyeomyia (Prl.) confusa foram coletados 149 indivíduos na copa (média $=6,5$ ) e 824 indivíduos no solo e média de 35,8 . Esta espécie apresentou frequência de $23 / 27$ coletas no estrato solo e 15/27 coletas no estrato copa. O teste estatístico indicou que houve uma diferença estatística significativa entre os estratos copa e solo $(U=110,5 ; z=-3,3835 ; p=0,001)$.

A espécie do subgênero Melanoconion, Cx. (Mel.) vaxus, coletada apenas no ambiente intermediário da PEC, apresentou abundância de 467 espécimes, sendo 463 no estrato copa $($ média $=22,1$ ) e apenas 4 ao nível do solo (média $=$ 0,2 ). Sua frequência foi de $22 / 27$ coletas na copa e apenas $3 / 27$ coletas no solo. $O$ teste estatístico indicou que houve uma diferença estatisticamente significativa entre os estratos copa e solo $(U=7 ; z=-5,6273 ; p=<0,0001)$ sendo mais frequente no estrato copa. Li. durhamii apresentou ocorrência de 10/27 e 14/27 nos 
estratos copa e solo, respectivamente. No total foram coletados 234 espécimes, sendo 44 em CDC copa (média = 2,9) e 190 em CDC solo (média =12,7). O teste estatístico apresentou significância estatística na comparação entre os estratos copa e solo $(U=46,5 ; z=-2,7379 ; p=0,01)$, sendo sua frequência maior no solo.

Outra espécie já representada como uma das mais abundantes que merece ser observada é Cx. nigripalpus, que no PEC foram coletados 186 indivíduos, dos quais 116 tiveram frequência no estrato copa (média $=5,5$ ) e 70 no estrato solo (média $=3,3$ ). Sua ocorrência em CDC copa foi de 19/27 coletas e em CDC solo foi de 12 em 27 coletas. O teste de Mann-Whitney não apresentou significância estatística na comparação entre os estratos copa e solo. 
Tabela 6 - Diversidade e estratificação vertical de mosquitos na área de estudo APA Capivari-Monos, coletas no período de fevereiro de 2015 a abril de 2017 .

\begin{tabular}{|c|c|c|c|c|c|c|c|c|c|c|}
\hline \multirow{3}{*}{ Espécies/Categorias Taxonômicas } & \multicolumn{8}{|c|}{ APA Capivari Monos } & \multirow{3}{*}{ Total } & \multirow{3}{*}{$\%$} \\
\hline & \multicolumn{2}{|c|}{ Periurbano 1} & \multicolumn{2}{|c|}{ Periurbano 2} & \multicolumn{2}{|c|}{ Intermediário } & \multicolumn{2}{|c|}{ Silvestre } & & \\
\hline & Copa & Solo & Copa & Solo & Copa & Solo & Copa & Solo & & \\
\hline Culex (Culex) nigripalpus & 743 & 30 & 409 & 89 & 262 & 45 & 216 & 23 & 1817 & 24,32 \\
\hline Culex (Culex) sp & 714 & 178 & 112 & 141 & 132 & 63 & 81 & 86 & 1507 & 20,17 \\
\hline Anopheles (Kerteszia) cruzii & 30 & - & 141 & 44 & 110 & 95 & 369 & 112 & 901 & 12,06 \\
\hline Wyeomyia (Prosopolepis) confusa & 42 & 32 & 22 & 51 & 53 & 96 & 55 & 85 & 436 & 5,84 \\
\hline Culex (Culex) chidesteri & 135 & 32 & 99 & 27 & 51 & 32 & 40 & 8 & 424 & 5,67 \\
\hline Limatus durhamii & 27 & 14 & 26 & 99 & 14 & 91 & 38 & 88 & 397 & 5,31 \\
\hline Culex (Melanoconion) ribeirensis & 163 & 25 & 10 & & 1 & 4 & 1 & 2 & 206 & 2,76 \\
\hline Culex (Culex) quinquefasciatus & 8 & 8 & 12 & 17 & 1 & - & 39 & 99 & 184 & 2,46 \\
\hline Culex (Culex) dolosus/eduardoi & 24 & 34 & 13 & 5 & 16 & 32 & 5 & 12 & 141 & 1,89 \\
\hline Wyeomyia (Phoniomyia) theobaldi & 36 & 2 & 9 & 7 & 25 & 11 & 34 & 16 & 140 & 1,87 \\
\hline Runchomyia (Runchomyia) reversa & 30 & 1 & 6 & 8 & 13 & 21 & 10 & 29 & 118 & 1,58 \\
\hline Aedes (Ochlerotatus) serratus & 6 & 7 & 2 & 12 & 9 & 19 & 41 & 21 & 117 & 1,57 \\
\hline Aedes (Georgecraigius) fluviatilis & 3 & 1 & - & 6 & 30 & 52 & 2 & - & 94 & 1,26 \\
\hline Coquillettidia (Rhynchotaenia) albifera & 6 & 30 & - & 23 & 14 & 6 & 6 & 8 & 93 & 1,24 \\
\hline Wyeomyia (Phoniomyia) davisi & 11 & 2 & 8 & 4 & 5 & 7 & 34 & 15 & 86 & 1,15 \\
\hline Outros* & 142 & 40 & 50 & 77 & 102 & 90 & 121 & 93 & 715 & 9,57 \\
\hline Total Geral & 2131 & 440 & 932 & 611 & 840 & 670 & 1120 & 728 & 7472 & 100 \\
\hline
\end{tabular}

Culex (Melanoconion) sp (81); Mansonia (Mansonia) indubitans (81); Aedes (Ochlerotatus) scapularis (55); Coquillettidia (Rhynchotaenia) venezuelensis (47); Wyeomyia (Phoniomyia) edwardsi (42); Culex (Culex) grupo Coronator (28); Mansonia (Mansonia) titilans (27); Aedes (Ochlerotatus) serratus/nubilus (25); Wyeomyia (Phoniomyia) sp (24); Wyeomyia (Phoniomyia) quasilongirostris (22); Wyeomyia (Phoniomyia) pallidoventer (21); Trichoprosopon pallidiventer (21); Aedes (Protomacleaya) terrens (20); Wyeomyia (Phoniomyia) pilicauda (19); Aedes (Ochlerotatus) crinifer (17); Wyeomyia (Phoniomyia) incaudata (16), Trichoprosopon pallidiventer/cashri/simle (14), Culex (Phenacomyia) cormiger (13), Aedes (Stegomyia) albopictus (13); Sabethes (Sabethes) purpureus (13); Psorophora (Janthinosoma) ferox (12); Culex sp (11); Aedeomyia (Aedeomyia) squamipennis (10); Coquillettidia (Rhynchotaenia) albicosta (6); Uranotaenia (Uranotaenia) geometrica (6); Uranotaenia (Uranotaenia) davisi (5); Wyeomyia

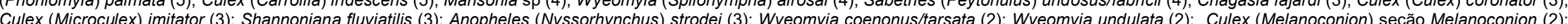
Uranotaenia (Uranotaenia) nataliae (2): Coquillettidia (Rhynchotaenia) chrysonotum/albifera (2): Culex (Melanoconion) bastagarius (2): Wyeomyia roucouyana/chalcocephala (2): Culex (Culex) Iygrus (2); Mansonia (Mansonia) wilsoni (2): Mansonia (Mansonia) pseudotitillans (2): Uranotaenia (Uranotaenia) sp (1): Sabethes sp (1): Wyeomyia (Triamyia) aporonoma (1): Mansonia (Mansonia) flaveol (1): Cus (Melanoconion) bahiensis (1): Uranotaenia (Uranotaenia) apicalis (1): Wyeomyia (Spilonympha) próx mystes (1); Psorophora (Janthinosoma) lutzii (1); Aedes (Stegomyia) aegypti (1); Coquillettidia (Rhynchotaenia) chrysonotum (1); Culex (Melanoconion) aliciae (1); Culex (Melanoconion) delpontei (1); Uranotaenia (Uranotaenia) pulcherrima (1). 
Tabela 7 - Diversidade e estratificação vertical de mosquitos na área de estudo Parque Estadual da Cantareira, coletas no período de fevereiro de 2015 a abril de 2017.

\begin{tabular}{|c|c|c|c|c|c|c|c|c|}
\hline \multirow{3}{*}{ Espécies/Categorias Taxonômicas } & \multicolumn{6}{|c|}{ PE Cantareira } & \multirow{3}{*}{ Total } & \multirow{3}{*}{$\%$} \\
\hline & \multicolumn{2}{|c|}{ Periurbano } & \multicolumn{2}{|c|}{ Intermediário } & \multicolumn{2}{|c|}{ Silvestre } & & \\
\hline & Copa & Solo & Copa & Solo & Copa & Solo & & \\
\hline Wyeomyia (Prosopolepis) confusa & 54 & 162 & 63 & 311 & 32 & 351 & 973 & 37,45 \\
\hline Culex (Melanoconion) vaxus & 1 & - & 463 & 4 & - & - & 468 & 18,01 \\
\hline Limatus durhamii & 12 & 107 & 31 & 49 & 1 & 34 & 234 & 9,01 \\
\hline Culex (Culex) nigripalpus & 17 & 14 & 75 & 52 & 24 & 4 & 186 & 7,16 \\
\hline Runchomyia (Runchomyia) reversa & 3 & - & 1 & 1 & 60 & 49 & 114 & 4,39 \\
\hline Aedes (Ochlerotatus) scapularis & 5 & 8 & 11 & 5 & 25 & 30 & 84 & 3,23 \\
\hline Culex (Melanoconion) $s p$ & - & 1 & 39 & 8 & 2 & 6 & 56 & 2,16 \\
\hline Culex (Culex) chidesteri & 1 & 1 & 16 & 6 & 9 & 2 & 35 & 1,35 \\
\hline Trichoprosopon pallidiventer/castroi/símile & - & - & - & 1 & 3 & 29 & 33 & 1,27 \\
\hline Outros* $^{*}$ & 29 & 22 & 53 & 54 & 59 & 42 & 259 & 9,97 \\
\hline Total Geral & 126 & 331 & 788 & 528 & 248 & 577 & 2598 & 100 \\
\hline
\end{tabular}

${ }^{*}$ Culex (Culex) dolosus/eduardoi (25); Trichoprosopon pallidiventer (18); Anopheles (Kerteszia) cruzii (17); Culex (Melanoconion) ribeirensis (16); Culex (Melanoconion) seção

Melanoconion (16); Sabethes (Sabethes) purpureus (15); Psorophora (Janthinosoma) ferox (14); Aedes (Georgecraigius) fluviatilis (13); Culex (Melanoconion) bahiensis (11); Aedes (Protomacleaya) terrens (9); Aedes (Stegomyia) albopictus (7); Mansonia (Mansonia) titillans (7); Haemagogus (Conopostegus) leucocelaenus (7); Culex (Melanoconion) grupo (Protomacleaya) terrens (9); Aedes (Stegomyia) albopictus (7); Mansonia (Mansonia) titilans (7); Haemagogus (Conopostegus) leucocelaenus (7); Culex (Melanoconion) grupo
Intrincatus (7), Culex (Melanoconion) pereyrai (6); Culex (Microculex) imitator (6); Wyeomyia (Phoniomyia) davisi (5); Culex (Carrollia) iridescens (5); Culex (Microculex) sp (5); Sabethes

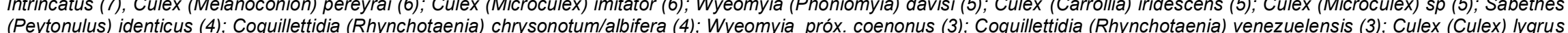
(Peytonulus) identicus (4); Coquillettidia (Rhynchotaenia) chrysonotum/albifera (4); Wyeomyia próx. coenonus (3); Coquillettidia (Rhynchotaenia) venezuelensis (3); Culex (Culex) lygrus
(3); Shannoniana fluviatilis (3); Culex (Culex) dolosus/eduardoi/restuans (3); Wyeomyia (Phoniomyia) theobaldi (2); Wyeomyia (Spilonympha) próx. mystes (2); Sabethes (Peytonulus) (3); Shannoniana fluviatilis (3); Culex (Culex) dolosus/eduardoi/restuans (3); Wyeomyia (Phoniomyia) theobaldi (2); Wyeomyia (Spilonympha) próx. mystes (2); Sabethes (Peytonulus)
undosus/fabricii/ignotus (2); Wyeomyia sp (2); Culex (Microculex) grupo Pleuristriatus (2); Wyeomyia felicia/pampithes (1); Culex (Carrollia) sp (1); Wyeomyia (Phoniomyia) sp (1); Culex
sp (1); Wyeomyia airosai/howardi/luteoventralis (1); Sabethes sp (1); Sabethes (Sabethes) gymnothorax (1); Culex (Melanoconion) aureonotatus (1); Culex (Melanoconion) grupo Atratus $s p(1)$; Wyeomyia airosai/howardi/luteoventralis (1); Sabethes sp (1); Sabethes (Sabethes) gymnothorax (1); Culex (Melanoconion) aureonotatus (1); Culex (Melanoconion) grupo Atratus
(1); Culex (Culex) declarator (1); Culex (Melanoconion) ocossa (1); Culex (Melanoconion) bastagarius (1); Wyeomyia coenonus/tarsata (1); Uranotaenia (Uranotaenia) davisi (1); Coquillettidia próx. chrysonotum (1); Mansonia (Mansonia) wilsoni (1); Psorophora (Janthinosoma) albipes (1). 


\subsection{Sazonalidade e Abundância de mosquitos}

Os dados das variáveis ambientais pluviosidade, temperaturas (mínima, média e máxima) e umidade relativa foram correlacionados com os dados de riqueza e abundância total entre os estratos copa e solo em todos os ambientes, bem como correlacionados para as espécies mais abundantes de cada localidade.

Na APA Capivari Monos, os dados ambientais de pluviosidade e umidade relativa, na estação quente e chuvosa mostraram que, para a precipitação acumulada dos 30 dias que antecederam as coletas, o regime de chuvas ocorre o ano todo com valores médios maiores que 190 milímetros e a umidade relativa média acima de $60 \%$.

Os períodos com precipitação mais elevada, de acordo com os dados obtidos para a APA, ocorreram de fevereiro e março de 2015; de outubro de 2015 a março de 2016; e de novembro de 2016 a abril de 2017. De maneira geral, pode se dizer que o período quente e chuvoso inicia-se em outubro e se estende até março do ano seguinte, com picos maiores que $400 \mathrm{~mm}$ no mês de março, podendo se estender até abril, mês que se mostra variável no volume de precipitação marcando a transição para o período frio e seco.

A estação fria e seca na APA compreendeu o período de abril a setembro, com os menores valores de precipitação acumulada no mês de agosto $(38,5 \mathrm{~mm}) \mathrm{e}$ setembro $(36,4 \mathrm{~mm})$ e umidade relativa de $52,9 \%$, ambos em 2015 . O mês de maio de 2016 representou o mês mais seco observado na APA, com precipitação de 8,1 milímetros e com umidade relativa de 53\% e agosto de 2016 apresentou 10,4 mm de precipitação e umidade relativa de $55 \%$.

As médias mensais da variável temperatura, no ano de 2015 variaram de $11,0^{\circ} \mathrm{C}$ no mês de agosto e $18,1^{\circ} \mathrm{C}$ no mês de março para temperatura mínima. As médias mensais observadas para a temperatura máxima variaram de $20,2^{\circ} \mathrm{C}$ a 
$28,3^{\circ} \mathrm{C}$, sendo o mês de julho a menor e o mês de fevereiro o de maior temperatura máxima.

Em 2016, as médias mensais para temperatura mínima variaram de $9,3^{\circ} \mathrm{C}$ em julho e $19,3^{\circ} \mathrm{C}$ em março. As médias mensais para temperatura máxima foram $19,3^{\circ} \mathrm{C}$ no mês de julho e $28,5^{\circ} \mathrm{C}$ no mês de março (Tabela 8 ).

Tabela 8 - Variáveis abióticas: pluviosidade, temperatura mínima, máxima e média, amplitude térmica e umidade relativa, dados fornecidos pelo Centro de Controle de Emergências-CGE/PMSP, estação meteorológica Barragem, Parelheiros, APA Capivari Monos, zona sul de São Paulo.

\begin{tabular}{|c|c|c|c|c|c|c|c|}
\hline Mês & Ano & $\begin{array}{l}\text { Pluviosidade } \\
\text { (mm) }\end{array}$ & $\begin{array}{l}\text { Temperatura } \\
\text { Mínima }\left({ }^{\circ} \mathrm{C}\right)\end{array}$ & $\begin{array}{l}\text { Temperatura } \\
\text { Máxima }\left({ }^{\circ} \mathrm{C}\right)\end{array}$ & $\begin{array}{l}\text { Temperatura } \\
\text { Média }\left({ }^{\circ} \mathrm{C}\right)\end{array}$ & $\begin{array}{c}\text { Amplitude } \\
\text { Térmica } \\
\left({ }^{\circ} \mathrm{C}\right)\end{array}$ & $\begin{array}{c}\text { Umidade } \\
\text { Relativa } \\
(\%)\end{array}$ \\
\hline FEV & 2015 & 232,1 & 17,8 & 28,3 & 23,1 & 10,5 & 65,2 \\
\hline MAR & 2015 & 429,2 & 18,1 & 27,4 & 22,8 & 9,3 & 70,1 \\
\hline ABR & 2015 & 276,6 & 16,9 & 25,4 & 21,2 & 8,5 & 73,8 \\
\hline MAI & 2015 & 121,6 & 14,2 & 22,5 & 18,4 & 8,3 & 80,9 \\
\hline JUN & 2015 & 81,1 & 13,5 & 21,6 & 17,6 & 8,1 & 75,3 \\
\hline JUL & 2015 & 109,4 & 12,1 & 20,2 & 16,2 & 8,1 & 76,9 \\
\hline AGO & 2015 & 38,5 & 11,0 & 22,1 & 16,6 & 11,1 & 65,8 \\
\hline SET & 2015 & 36,4 & 13,3 & 24,9 & 19,1 & 11,6 & 52,9 \\
\hline OUT & 2015 & 320,2 & 15,2 & 25,1 & 20,2 & 9,9 & 61,3 \\
\hline NOV & 2015 & 281,3 & 16,4 & 24,5 & 20,5 & 8,1 & 73,3 \\
\hline DEZ & 2015 & 247,4 & 17,4 & 25,2 & 21,3 & 7,8 & 74,4 \\
\hline \multicolumn{2}{|c|}{ Média } & 197,6 & 15,1 & 24,3 & 19,7 & 9,2 & 70,0 \\
\hline JAN & 2016 & 395,7 & 18,9 & 27,9 & 23,4 & 9,0 & 64,5 \\
\hline FEV & 2016 & 381,3 & 18,1 & 27,6 & 22,9 & 9,5 & 62,1 \\
\hline MAR & 2016 & 475,7 & 19,3 & 28,5 & 23,9 & 9,2 & 61,4 \\
\hline$A B R$ & 2016 & 175,6 & 18,2 & 27,7 & 23,0 & 9,5 & 66,0 \\
\hline MAI & 2016 & 8,1 & 16,5 & 27,6 & 22,1 & 11,1 & 53,1 \\
\hline JUN & 2016 & 357,0 & 13,7 & 20,7 & 17,2 & 7,0 & 80,0 \\
\hline JUL & 2016 & 170,0 & 9,3 & 19,3 & 14,3 & 10,0 & 67,9 \\
\hline AGO & 2016 & 10,4 & 11,0 & 21,6 & 16,3 & 10,6 & 55,0 \\
\hline SET & 2016 & 127,7 & 12,5 & 21,5 & 17,0 & 9,0 & 64,0 \\
\hline OUT & 2016 & 83,3 & 13,1 & 21,2 & 17,2 & 8,1 & 75,2 \\
\hline NOV & 2016 & 133,6 & 16,1 & 25,2 & 20,6 & 9,1 & 66,1 \\
\hline DEZ & 2016 & 278,4 & 15,1 & 24,0 & 19,6 & 8,9 & 72,3 \\
\hline \multicolumn{2}{|c|}{ Média } & 216,4 & 15,1 & 24,4 & 19,8 & 9,3 & 65,6 \\
\hline JAN & 2017 & 272,7 & 18,3 & 28,5 & 23,4 & 10,2 & 57,8 \\
\hline FEV & 2017 & 442,4 & 18,8 & 27,2 & 23,0 & 8,4 & 69,2 \\
\hline MAR & 2017 & 411,7 & 18,3 & 29,7 & 24,0 & 11,4 & 56,0 \\
\hline$A B R$ & 2017 & 324,2 & 16,8 & 25,3 & 21,0 & 8,5 & 72,8 \\
\hline \multicolumn{2}{|c|}{ Média } & 362,8 & 18,0 & 27,7 & 22,9 & 9,6 & 64,0 \\
\hline
\end{tabular}


$\mathrm{Na}$ APA, as abundâncias de mosquitos coletados foram bem distribuídas nos meses de coleta, com média em torno de 276 mosquitos por coleta, no entanto, a coleta do mês de maio de 2015 mostrou a maior abundância registrada no estudo, com 1859 espécimes de mosquitos coletados, principalmente no estrato copa que representou $94 \%$ dos espécimes coletados neste mês. Com relação a variável precipitação, de maneira geral, observa-se na Figura 24, não ser muito alterada com os picos de precipitação, apresentando distribuição das abundâncias regular, sem picos coincidindo com os períodos de maior precipitação.

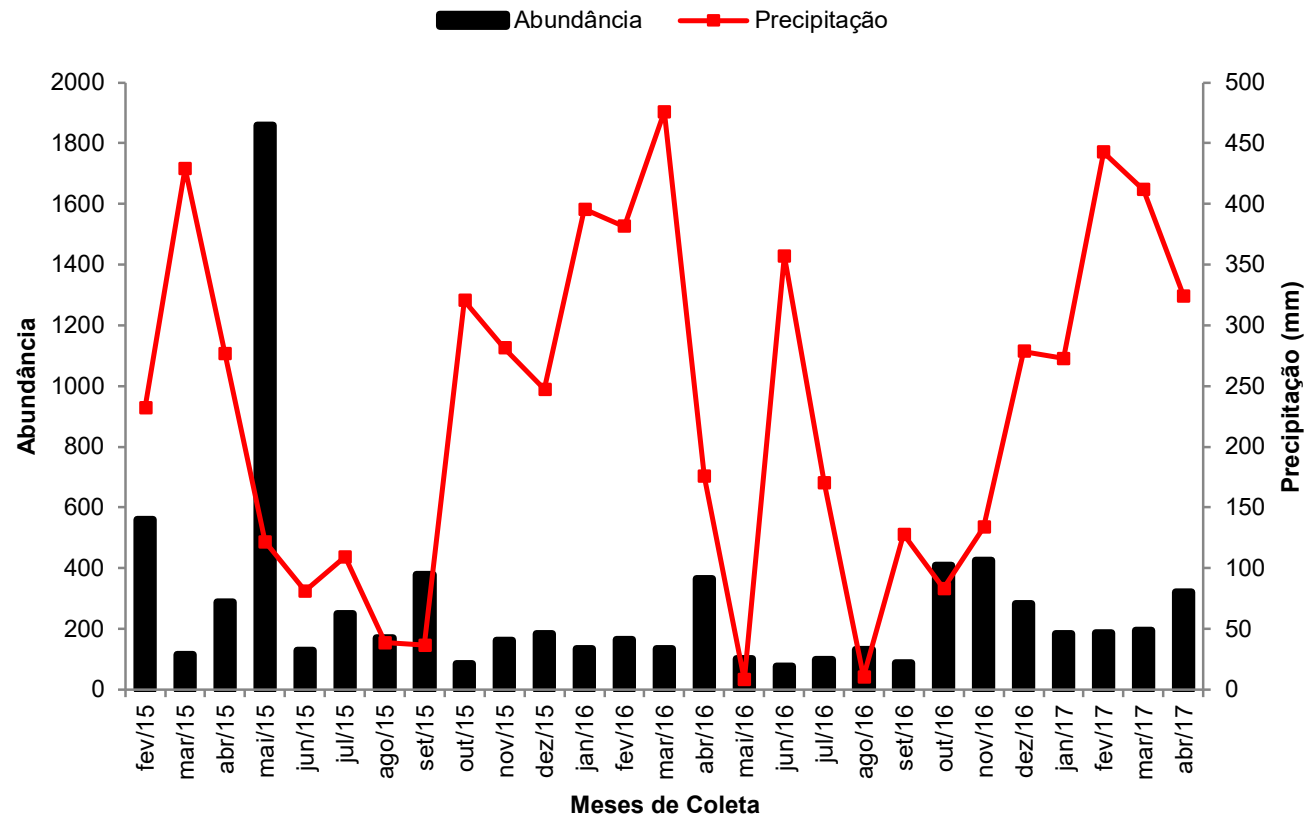

Figura 24 - Distribuição das abundâncias dos mosquitos coletados e sua relação com a precipitação acumulada de 30 dias anteriores a cada coleta, período de fevereiro de 2015 a abril de 2017, na localidade APA Capivari Monos.

Para o ambiente periurbano 1 na APA, não houve correlação com significância estatística entre os estratos e as variáveis ambientais. Para o ambiente periurbano 2, não houve correlação significativa no estrato copa, no entanto, no estrato solo houve correlação positiva com a variável temperatura máxima $\left(r_{s}=0,38818 ; p=0,05\right)$ e média $\left(r_{s}=0,39178 ; p=0,04\right)$. Para o ambiente 
intermediário, não houve correlação significativa com nenhuma das variáveis ambientais. No ambiente silvestre houve correlação positiva significativa entre a riqueza obtida no solo com as variáveis ambientais de temperatura mínima $\left(r_{s}=\right.$ $0,52855 ; p=0,01)$, máxima $\left(r_{s}=0,55298 ; p=0,003\right)$ e média $\left(r_{s}=0,54865 ; p=\right.$ 0,004).

Entre as espécies mais abundantes na APA, para $C x$. nigripalpus não houve correlação significativa entre os dados de abundância dos estratos e as variáveis ambientais. An. cruzii não apresentou significância estatística na correlação entre a abundância no estrato copa e as variáveis ambientais, no entanto, para os dados de abundância no estrato solo, houve correlação positiva e significância estatística com a variável temperatura mínima $\left(r_{s}=0,57052 ; p=0,05\right)$, máxima ( $r s=0,62757$; $p=0,03)$ e média $(r s=0,6251 ; p=0,03)$.

No PE Cantareira, as variáveis ambientais de precipitação, temperaturas (mínima, máxima e média) e umidade relativa, mostraram que a estação quente e chuvosa inicia-se em outubro e se estende até março, semelhante ao mesmo período observado para a localidade APA, porém, com valores das variáveis medidas menores, indicando ser uma região com clima diferente, mais seco.

Os dados de precipitação acumulada dos 30 dias anteriores a cada coleta variaram de modo que, no período quente e chuvoso de 2015, o mês de março apresentou o maior volume de precipitação com 257,8 milímetros e no ano de 2016 o mesmo mês apresentou 276,9 milímetros No ano de 2017, o mês de maior volume de precipitação foi janeiro com 377,6 milímetros. No período frio e seco no ano de 2015, os menores volumes de precipitação ocorreram no mês de junho com 23,7 milímetros e agosto com 16,5 mm, sendo este mês o mais frio e seco. No ano de 2016, o mês de abril apresentou o menor volume de precipitação acumulada do estudo 6,7 milímetro (Tabela 9). 
Tabela 9 - Variáveis abióticas: pluviosidade, temperatura mínima, máxima e média, amplitude térmica e umidade relativa, dados fornecidos pelo Centro de Controle de Emergências-CGE/PMSP, estação meteorológica Jaçanã/Tremembé, PE Cantareira, zona norte de São Paulo.

\begin{tabular}{|c|c|c|c|c|c|c|c|}
\hline Mês & Ano & $\begin{array}{l}\text { Pluviosidade } \\
\text { (mm) }\end{array}$ & $\begin{array}{l}\text { Temperatura } \\
\text { Mínima }\left({ }^{\circ} \mathrm{C}\right)\end{array}$ & $\begin{array}{l}\text { Temperatura } \\
\text { Máxima }\left({ }^{\circ} \mathrm{C}\right)\end{array}$ & $\begin{array}{l}\text { Temperatura } \\
\text { Média }\left({ }^{\circ} \mathrm{C}\right)\end{array}$ & $\begin{array}{l}\text { Amplitude } \\
\text { Térmica }\left({ }^{\circ} \mathrm{C}\right)\end{array}$ & $\begin{array}{c}\text { Umidade } \\
\text { Relativa } \\
(\%)\end{array}$ \\
\hline FEV & 2015 & 194,9 & 12,9 & 32,8 & 22,9 & 19,9 & 60,7 \\
\hline MAR & 2015 & 257,8 & 15,0 & 29,2 & 22,1 & 14,2 & 66,5 \\
\hline$A B R$ & 2015 & 105,4 & 17,5 & 28,6 & 23,1 & 11,1 & 61,8 \\
\hline MAI & 2015 & 32,1 & 14,8 & 24,6 & 19,7 & 9,8 & 64,6 \\
\hline JUN & 2015 & 23,7 & 13,9 & 25,2 & 19,6 & 11,3 & 63,5 \\
\hline JUL & 2015 & 40,2 & 12,7 & 24,0 & 18,4 & 11,3 & 63,2 \\
\hline AGO & 2015 & 16,5 & 8,0 & 27,6 & 17,8 & 19,6 & 32,7 \\
\hline SET & 2015 & 144,2 & 14,6 & 24,3 & 19,5 & 9,7 & 51,6 \\
\hline OUT & 2015 & 61,1 & 15,7 & 29,6 & 22,7 & 13,9 & 42,3 \\
\hline NOV & 2015 & 197,8 & 19,0 & 27,8 & 23,4 & 8,8 & 57,2 \\
\hline DEZ & 2015 & 167,7 & 19,6 & 28,5 & 24,1 & 8,9 & 58,3 \\
\hline \multicolumn{2}{|c|}{ Média } & 112,9 & 14,9 & 27,5 & 21,2 & 12,6 & 56,6 \\
\hline JAN & 2016 & 211,8 & 19,6 & 28,1 & 23,9 & 8,5 & 59,1 \\
\hline FEV & 2016 & 240,5 & 20,5 & 31,7 & 26,1 & 11,2 & 46,7 \\
\hline MAR & 2016 & 276,9 & 20,0 & 28,8 & 24,4 & 8,8 & 59,0 \\
\hline ABR & 2016 & 6,7 & 20,0 & 31,8 & 25,9 & 11,8 & 40,3 \\
\hline MAI & 2016 & 40,1 & 16,7 & 26,7 & 21,7 & 10,0 & 46,3 \\
\hline JUN & 2016 & 200,2 & 12,4 & 22,3 & 17,4 & 9,9 & 55,6 \\
\hline JUL & 2016 & 10,6 & 12,7 & 24,6 & 18,7 & 11,9 & 43,7 \\
\hline AGO & 2016 & 53,1 & 13,3 & 24,5 & 18,9 & 11,2 & 49,3 \\
\hline SET & 2016 & 22,6 & 15,5 & 26,0 & 20,8 & 10,5 & 48,5 \\
\hline OUT & 2016 & 114,7 & 16,5 & 27,1 & 21,8 & 10,6 & 49,4 \\
\hline NOV & 2016 & 217,7 & 16,7 & 27,0 & 21,9 & 10,3 & 54,2 \\
\hline DEZ & 2016 & 149,3 & 17,7 & 28,3 & 23,0 & 10,6 & 52,7 \\
\hline \multicolumn{2}{|c|}{ Média } & 128,7 & 16,8 & 27,2 & 22,0 & 10,4 & 50,4 \\
\hline JAN & 2017 & 377,6 & 20,3 & 32,3 & 26,3 & 12,0 & 44,4 \\
\hline FEV & 2017 & 139,2 & 20,1 & 31,0 & 25,6 & 10,9 & 47,9 \\
\hline MAR & 2017 & 132,3 & 20,0 & 30,0 & 25,0 & 10,0 & 53,5 \\
\hline$A B R$ & 2017 & 87,6 & 17,6 & 26,6 & 22,1 & 9,0 & 56,2 \\
\hline \multicolumn{2}{|c|}{ Média } & 184,2 & 19,5 & 30,0 & 24,7 & 10,5 & 50,5 \\
\hline
\end{tabular}

No PEC, a média de mosquitos por coleta foi de 96 indivíduos, com o estrato solo contribuindo com $55 \%$ dos espécimes coletados no estudo. Com relação à distribuição das abundâncias dos mosquitos, ao longo do estudo, observou-se, de modo geral que, os picos de abundância ocorreram coincidindo com os meses de elevado volume de precipitação acumulada (quentes e chuvosos) Figura 25. 


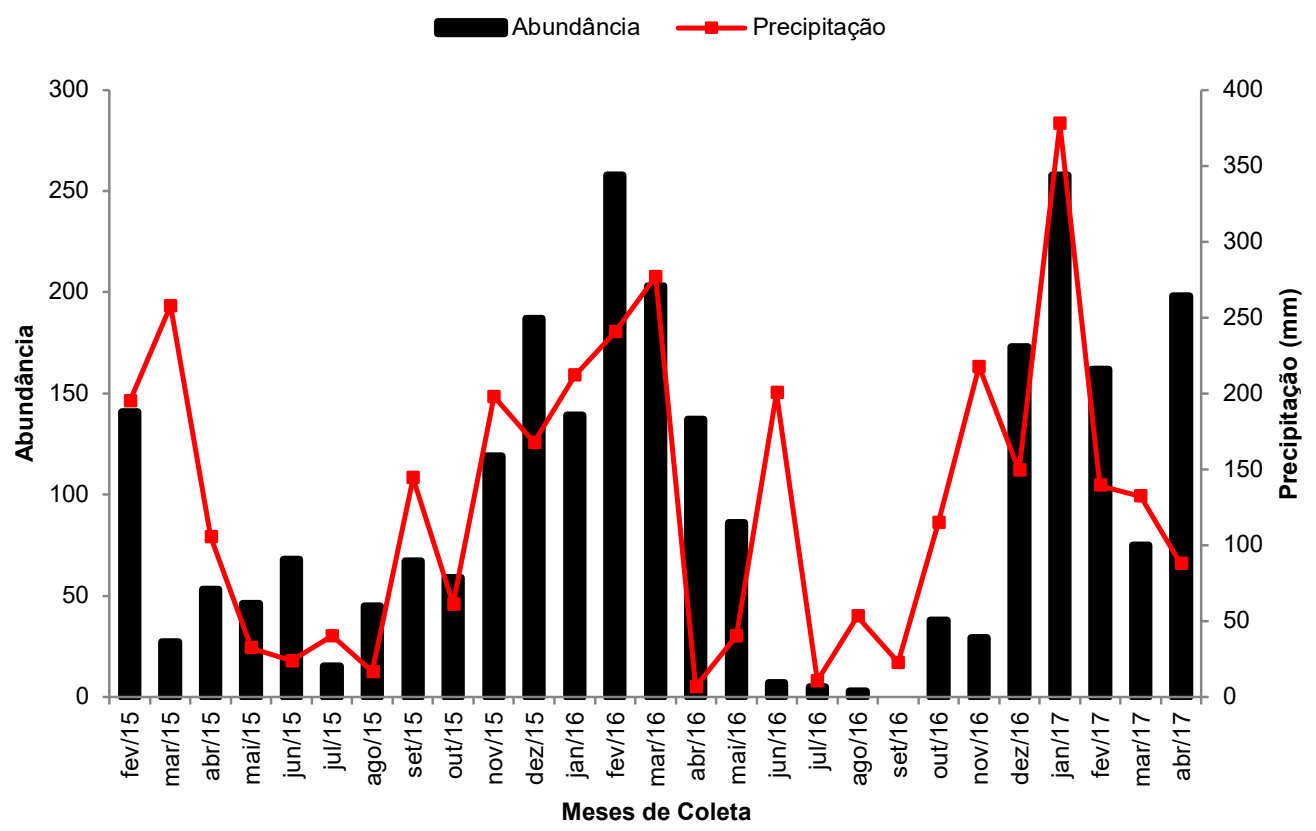

Figura 25 - Distribuição das abundâncias dos mosquitos coletados e sua relação com a precipitação acumulada de 30 dias anteriores a cada coleta, período de fevereiro de 2015 a abril de 2017, na localidade PE Cantareira.

O ambiente periurbano do PEC, no estrato solo apresentou diferença estatística significante e correlação positiva entre a variável temperatura mínima $\left(r_{s}\right.$ $=0,59895 ; p=0,003)$ e temperatura média $\left(r_{s}=0,46275 ; p=0,03\right)$. No ambiente intermediário, para o estrato solo não houve correlação significativa com nenhuma das variáveis ambientais, entretanto, o estrato copa, apresentou correlação significativa entre as variáveis ambientais de temperatura mínima $\left(r_{s}=0,54637 ; p=\right.$ $0,005)$, máxima $\left(r_{s}=0,56613 ; p=0,003\right)$ e média $\left(r_{s}=0,66281 ; p=0,0003\right)$. No ambiente silvestre da PEC, houve correlação significativa para temperatura nos dois estratos, na copa para temperatura mínima $\left(r_{s}=0,63784 ; p=0,001\right)$ máxima $\left(r_{s}=0,61874 ; p=0,001\right)$ e média $\left(r_{s}=0,6619 ; p=0,0002\right)$ e no estrato solo temperatura mínima $\left(r_{s}=0,57859 ; p=0,002\right)$ e média $\left(r_{s}=0,54555 ; p=0,004\right)$.

Das espécies mais abundantes do PEC, Wyeomyia (Prl.) confusa mostrou correlação significativa entre a copa para as variáveis ambientais, temperatura 
mínima $\left(r_{s}=0,47557 ; p=0,02\right)$ e média $\left(r_{s}=0,43636 ; p=0,04\right)$, no estrato solo apresentou correlação significativa com as variáveis, precipitação $\left(r_{s}=0,54325 ; p=\right.$ $0,01)$, temperaturas mínima $\left(r_{s}=0,8313 ; p=0,000004\right)$, máxima $\left(r_{s}=0,6589 ; p=\right.$ $0,001)$ e média $\left(r_{s}=0,76382 ; p=0,00002\right)$. Não houve correlação entre a abundância de Culex (Mel.) vaxus com nenhuma das variáveis ambientais testadas. Limatus durhamii apresentou correlação positiva entre o estrato solo e a variável temperatura média $\left(r_{s}=0,50626 ; p=0,05\right)$.

O coeficiente de correlação calculado entre a riqueza da APA e as variáveis ambientais apresentou correlação positiva com a precipitação $\left(r_{s}=0,39101 ; p=\right.$ $0,04)$ e a temperatura $\left(r_{s}=0,59535 ; p=0,001\right)$. No PEC houve correlação positiva entre a riqueza e a variável temperatura $\left(r_{s}=0,73775 ; p=0,00001\right)$.

As Figuras 26 e 27 mostram a precipitação mensal acumulada dos 30 dias anteriores às coletas, as médias das temperaturas de 30 dias anteriores às coletas e a média mensal da umidade relativa dos 30 dias anteriores às coletas. 
APA Capivari Monos

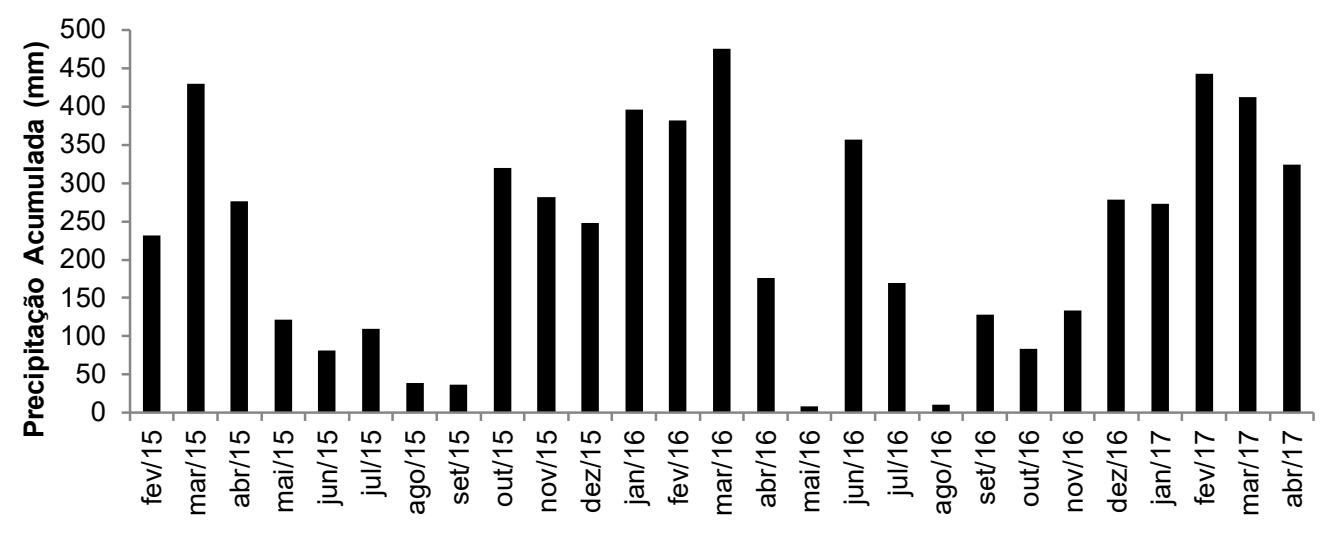

- Precipitação

APA Capivari Monos

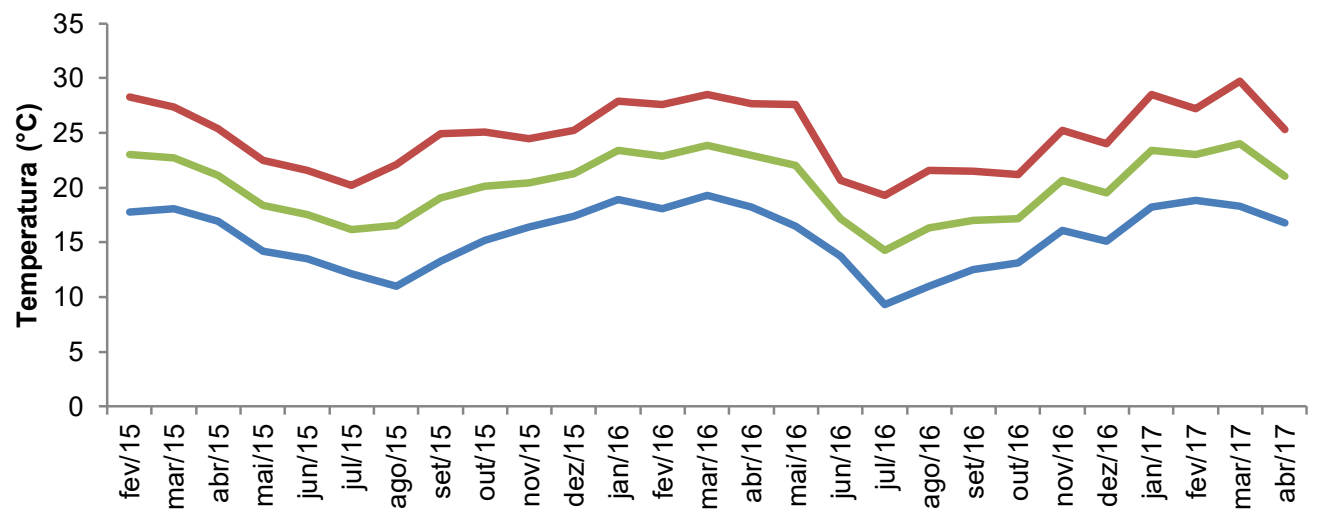

Temperatura Mínima Temperatura Máxima Temperatura Média

APA Capivari Monos

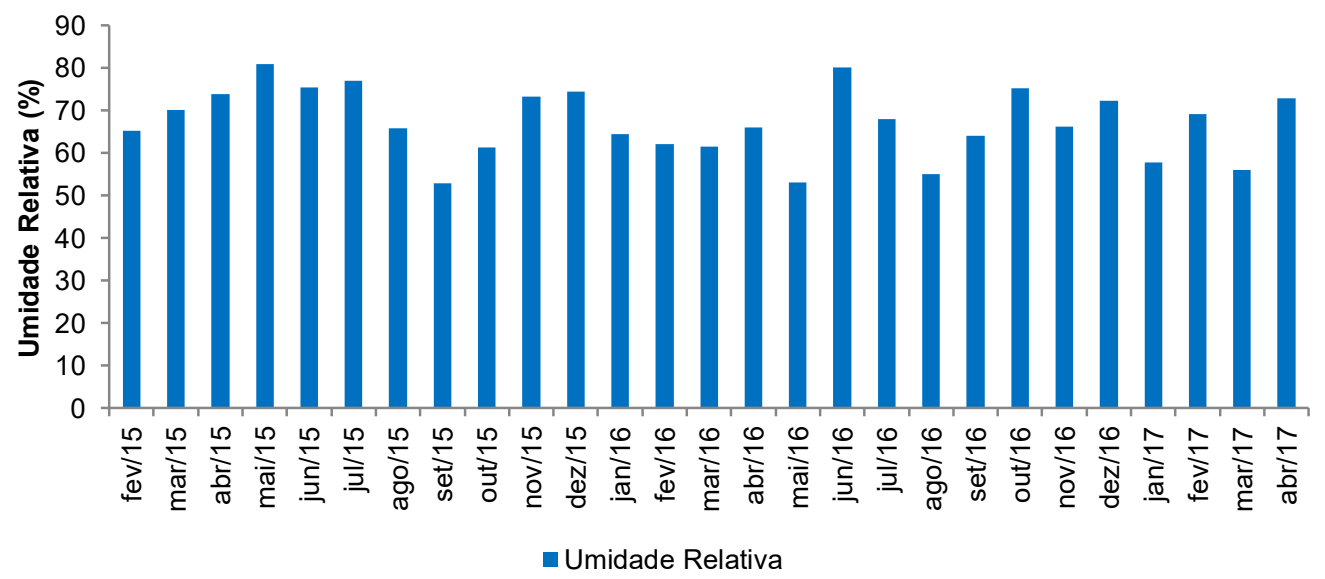

Figura 26 - Variáveis ambientais de 30 dias anteriores às coletas para APA Capivari Monos no período de fevereiro de 2015 a abril de 2017. Em A, precipitação acumulada, em $\mathrm{B}$ temperaturas e $\mathrm{C}$ umidade relativa. 


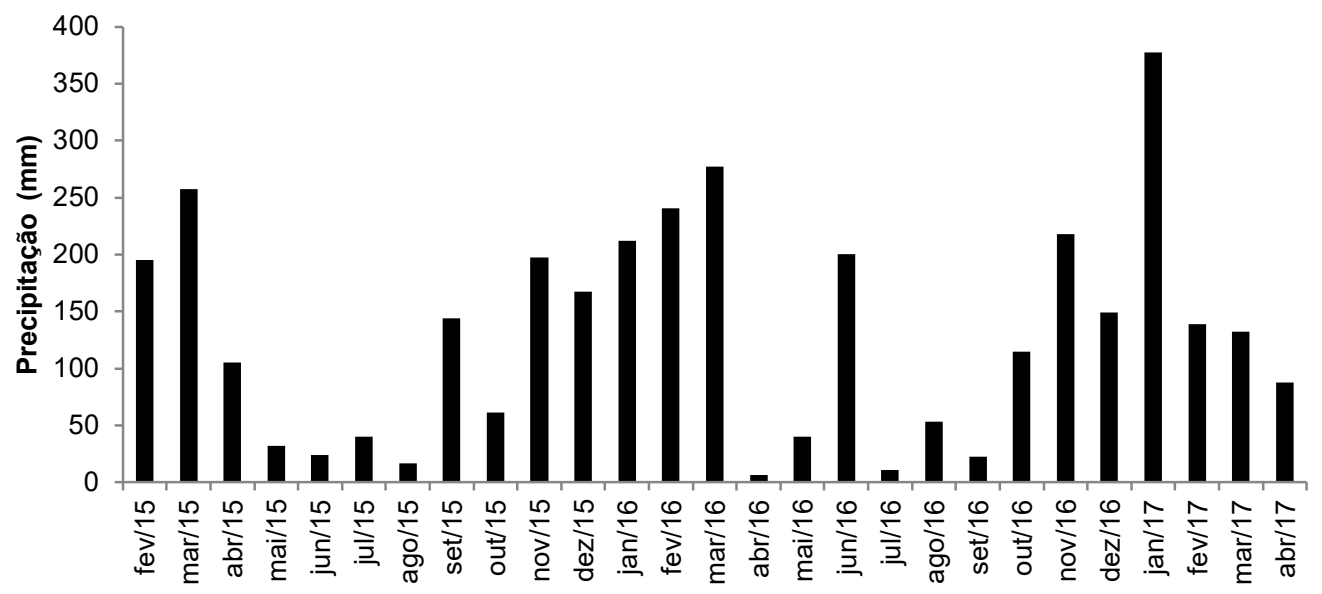

PE Cantareira

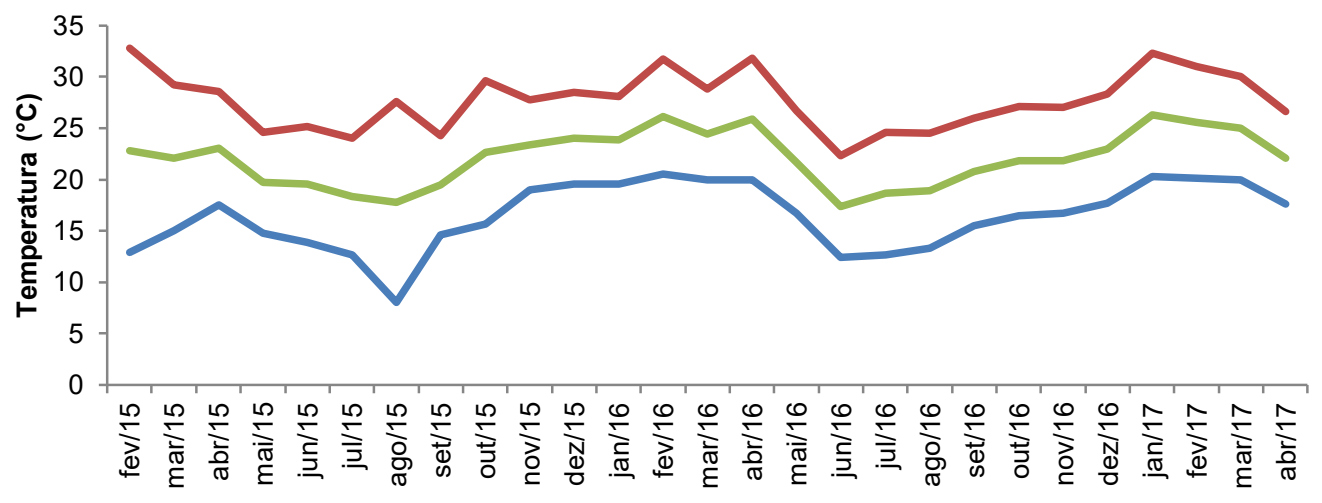

—Temperatura Mínima

Temperatura Máxima

-Temperatura Média

PE Cantareira

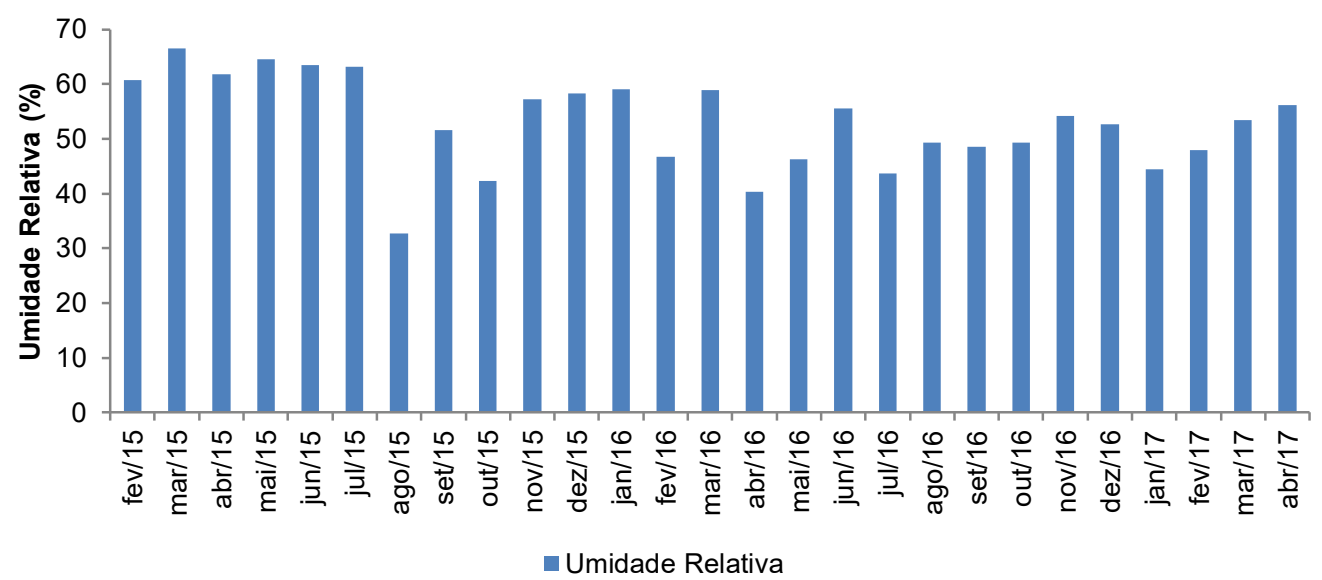

Figura 27 - Variáveis ambientais de 30 dias anteriores às coletas para PE Cantareira no período de fevereiro de 2015 a abril de 2017. Em A, precipitação acumulada, em $B$ temperaturas mínima, média e máxima. Em $C$ umidade relativa. 
As espécies mais abundantes foram verificadas quanto à distribuição de suas abundâncias e a variável precipitação que esta relacionada ao favorecimento da espécie, criando novas oportunidades de criadouros.

A sazonalidade de An. cruzii na localidade APA mostrou variação, ocorrendo três picos de abundância ao longo dos 27 meses de coleta. Observa-se que o $1^{\circ}$ pico ocorreu em fevereiro de 2015, o $2^{\circ}$ pico ocorreu em abril de 2016 e o $3^{\circ}$ ocorreu em outubro de 2016. Os dois primeiros picos ocorreram no final da estação quente e chuvosa e o terceiro pico ocorreu no início da estação quente e chuvosa ao contrário dos primeiros picos Figura 28.

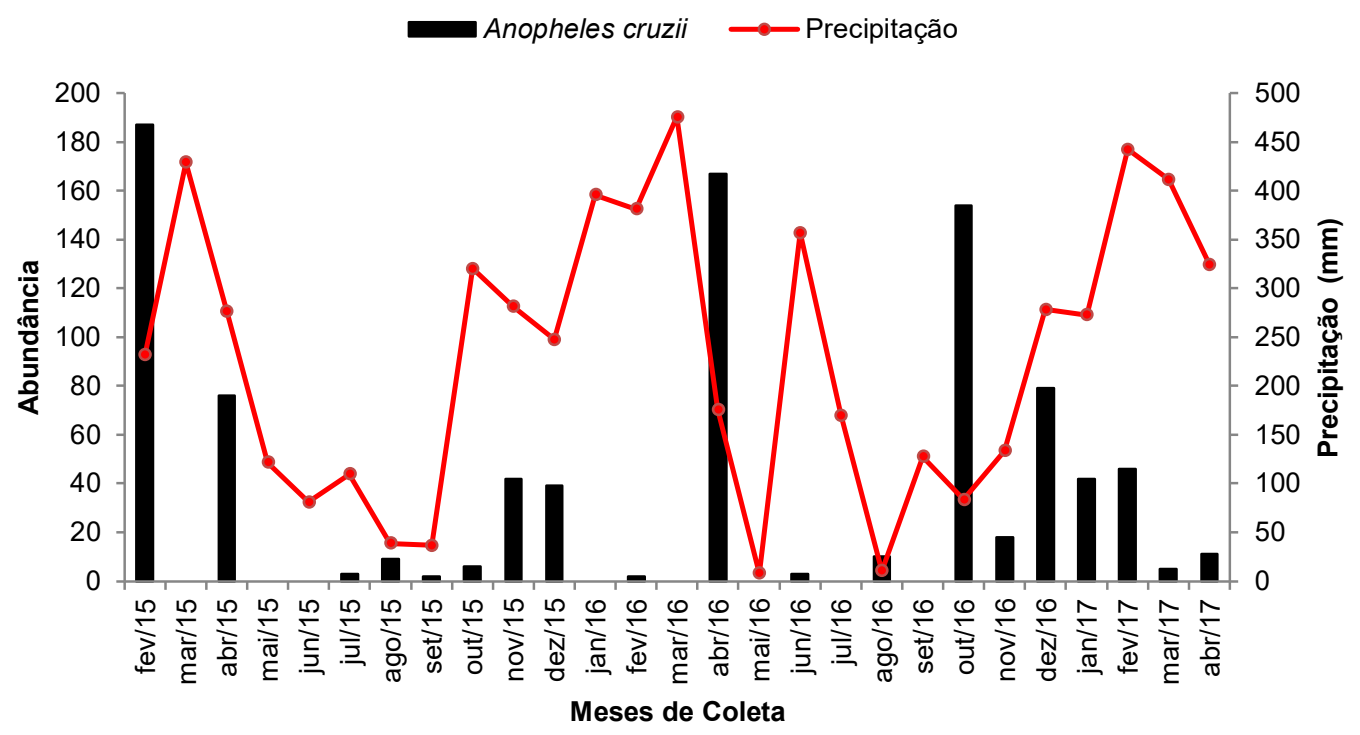

Figura 28 - Distribuição de Anopheles cruzii nos estratos verticais e volume de precipitação em 30 dias anteriores às coletas, ocorrido na APA Capivari Monos, no período de fevereiro de 2015 a abril de 2017.

Uma explicação, para essa observação pode ser razoável se observarmos os picos no período de estudo que, nesta localidade ocorrem sempre próximo ao término da estação quente e chuvosa. No caso do terceiro pico, que ocorreu no início do mês de outubro/2016, observa-se que, no mês de junho de 2016, ocorreu uma precipitação "anormal" (para os meses frios e secos) com volume de $357 \mathrm{~mm}$, 
proporcionando abastecimento de seus criadouros naturais (bromélias). Como nos meses frios e secos sua abundância é menor, devido a pouca disponibilidade de água nas bromélias, maior evapotranspiração e baixa umidade relativa ${ }^{2}$, o terceiro pico aparece com o favorecimento do inicio da estação chuvosa (outubro) e aumento das temperaturas. An. cruzii quando ocorreu no estrato vertical solo, apresentou correlação positiva com a variável temperatura máxima $\left(r_{\mathrm{s}}=0,627\right.$; $p=0,03$ ), sugerindo que a ocorrência dessa espécie nesse estrato pode depender dessa variável.

A sazonalidade de Cx. nigripalpus foi verificada quanto as variáveis ambientais mencionadas e quanto à precipitação, os dados podem ser observados na Figura 29.

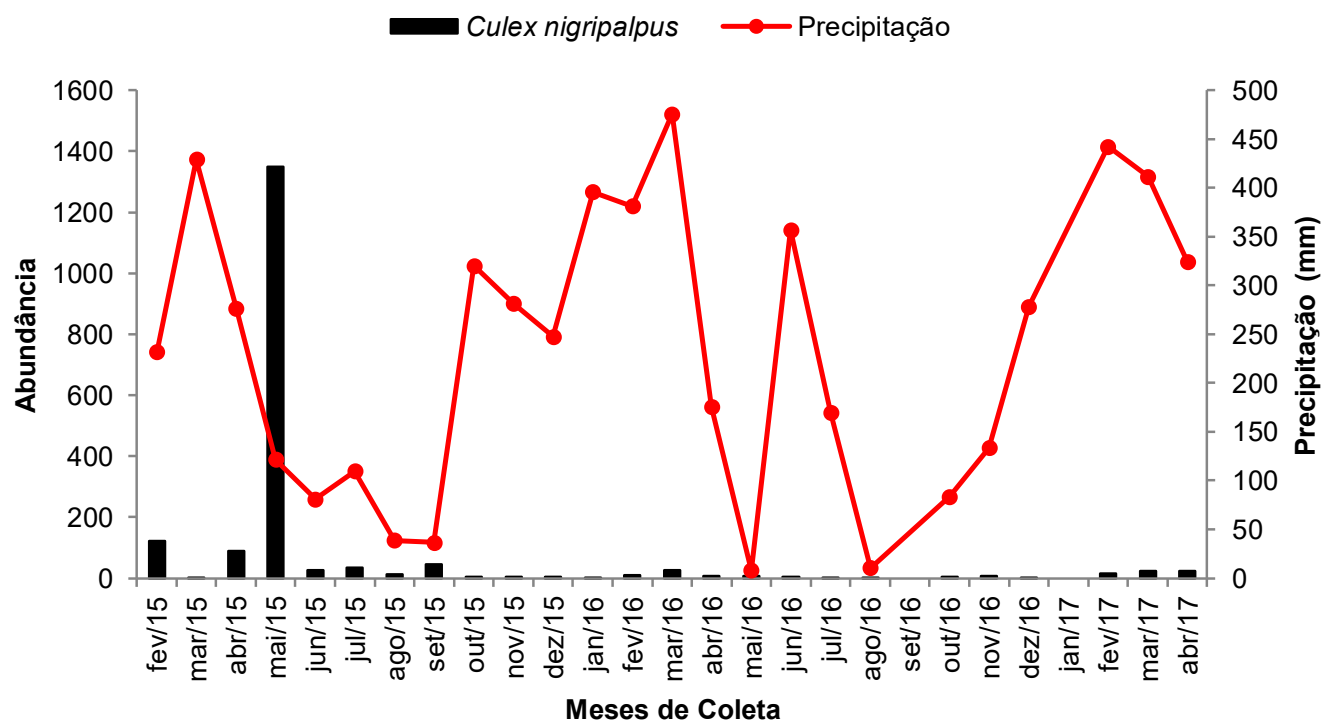

Figura 29 - Distribuição de Culex nigripalpus nos estratos verticais e volume de precipitação em 30 dias anteriores às coletas, ocorrido na APA Capivari Monos, no período de fevereiro de 2015 a abril de 2017.

Os dados desta espécie mostram apenas um pico de abundância que ocorreu em maio de 2015 contribuindo com 1348 indivíduos (apenas uma coleta), 
no final da estação quente e chuvosa, não revelando muita informação sobre sua sazonalidade.

Nos ambientes da PEC, Wyeomyia (Prl.) confusa foi a espécie mais abundante, coletada em todos os ambientes. Seus picos de abundância ocorrem coincidindo com os picos de maiores volumes de precipitação, no período quente e chuvoso Figura 30.

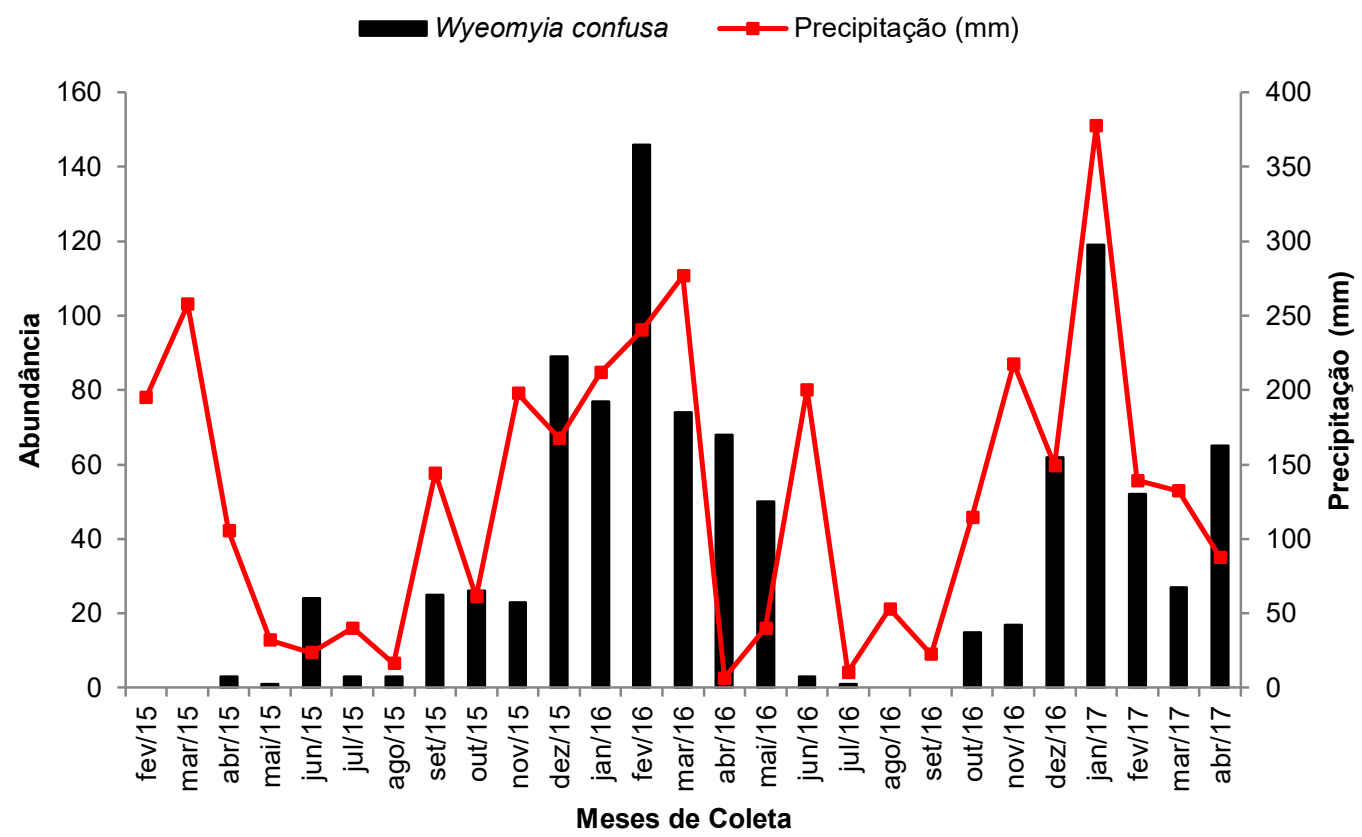

Figura 30 - Distribuição de Wyeomyia confusa nos estratos verticais e volume de precipitação em 30 dias anteriores às coletas, ocorrido no PE Cantareira, no período de fevereiro de 2015 a abril de 2017.

A segunda espécie mais abundante no PEC foi Culex (Melanoconion) vaxus que ocorreu apenas no estrato copa do ambiente intermediário. Teve sua distribuição coincidindo com o regime de chuvas Figura 31. 


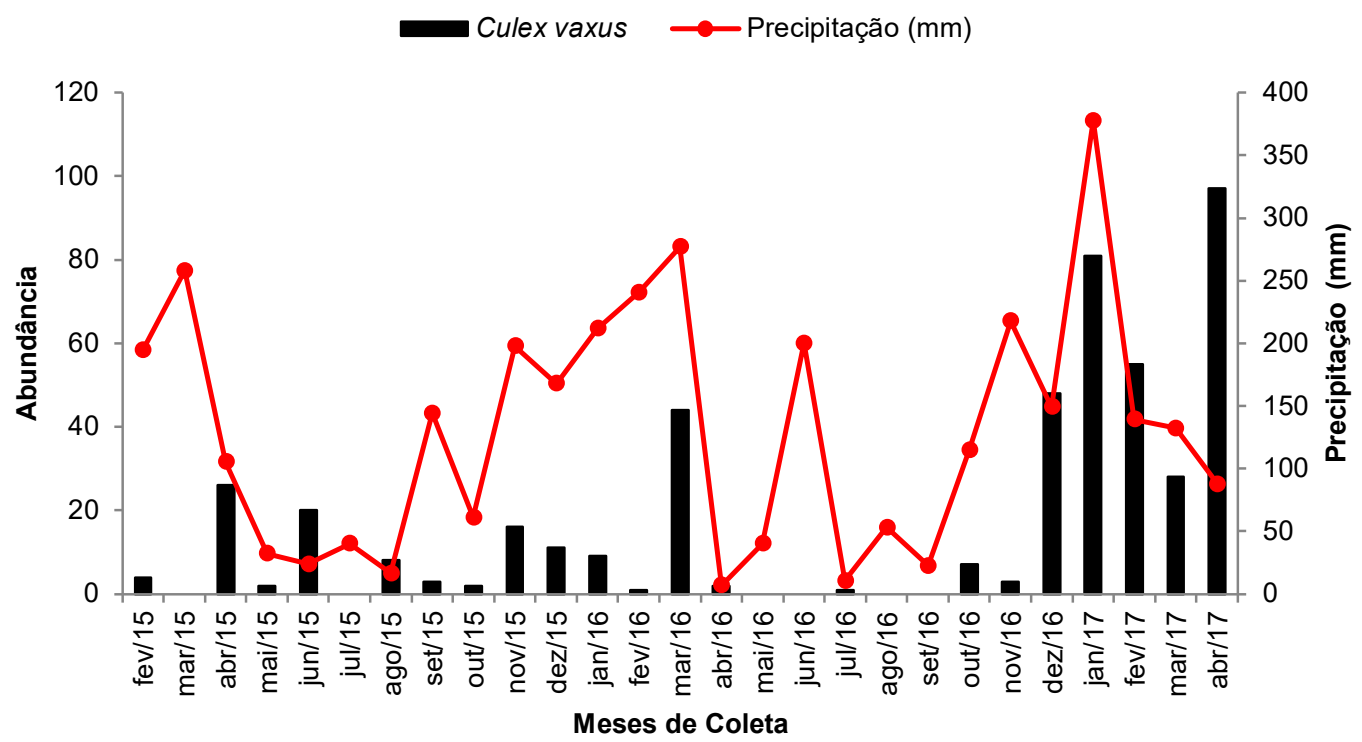

Figura 31 - Distribuição de Culex vaxus nos estratos verticais e volume de precipitação em 30 dias anteriores às coletas, ocorrido no PE Cantareira, no período de fevereiro de 2015 a abril de 2017.

Limatus durhamii habita ambientes silvestres próximos a seus limites com o peridomicílio, ocorre no estrato vertical próximo ao solo. Neste estudo apresentou distribuição coincidindo com os meses quentes e chuvosos Figura 32.

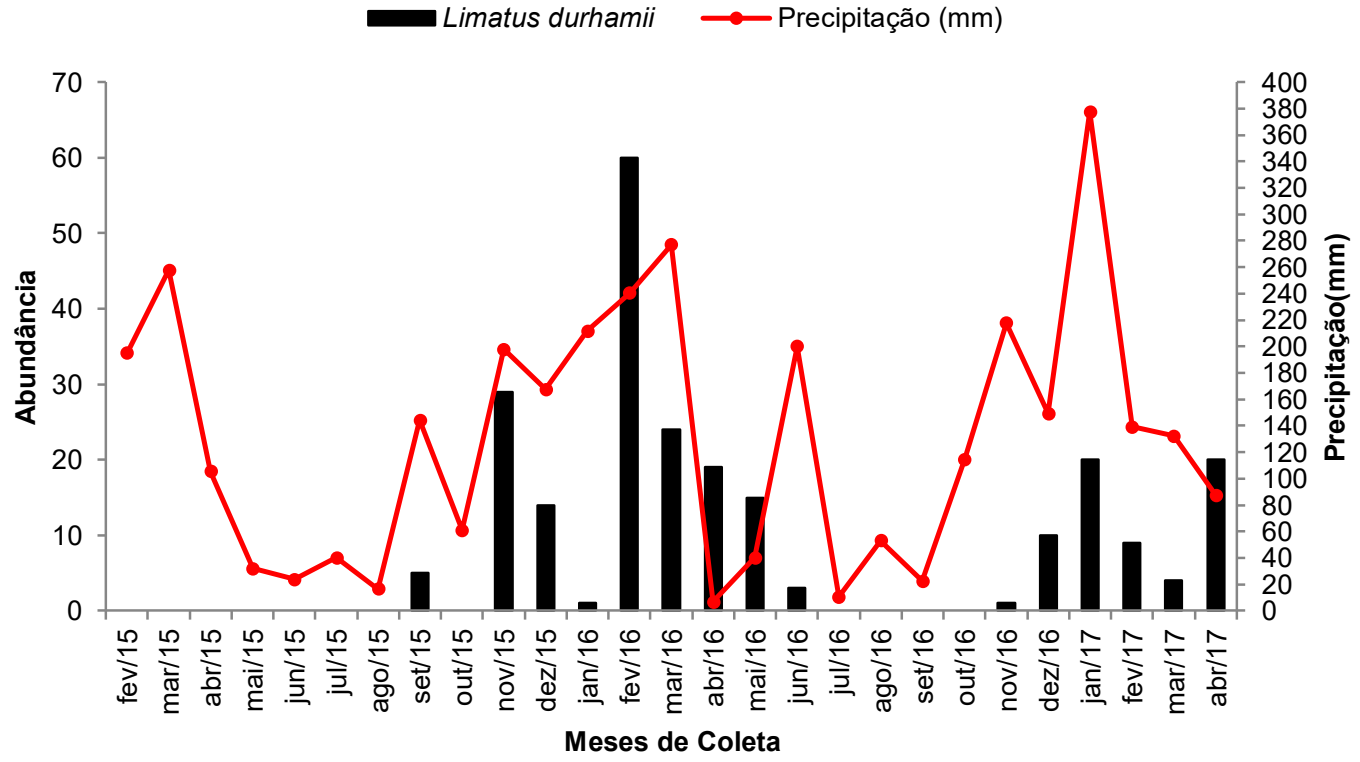

Figura 32 - Distribuição de Limatus durhamii nos estratos verticais e volume de precipitação em 30 dias anteriores às coletas, ocorrido no PE Cantareira, no período de fevereiro de 2015 a abril de 2017. 
No estudo de Lopes et al. ${ }^{117}$ a espécie Li. durhamii foi coletada em todas as alturas por eles estudadas $(0 \mathrm{~m}, 1 \mathrm{~m}, 6 \mathrm{~m}$ e $11 \mathrm{~m})$ tendo diminuição de sua abundância com a elevação da altura. Neste estudo, tanto na APA quanto na PEC esta espécie foi coletada em todos os ambientes e estratos, sendo sua estratificação vertical ocorrendo em maior proporção no solo do que na copa.

Segundo o inventário taxonômico de mosquitos ${ }^{7}$, esta espécie está distribuída na América Central e na América do Sul e no oeste da Índia, e sua presença esta mais associada aos níveis próximos ao solo. Esse sabetíneo é bastante atraído pelo homem que adentra a mata ${ }^{3}$, como observado neste estudo. Com relação à sua importância epidemiológica, estudos apontam que em um pool de espécies desse gênero já foram encontradas naturalmente infectadas com vírus Wyeomyia em Trinidad, e vírus da encefalite equina Venezuelana tem sido isolado de outra espécie desse gênero Li. flavisetosus, mas até o presente Li. durhamii não tem envolvimento em ciclos de transmissão de patógenos envolvendo humanos ou animais silvestres ou domésticos.

De maneira geral, os dados de sazonalidade mostram um cenário ideal para a existência de elevada abundância de certas espécies de mosquitos, onde o abastecimento de criadouros existentes, a geração de novos criadouros nos meses de elevada precipitação e, além disso, às temperaturas elevadas e a umidade relativa, promovem um aumento na riqueza de espécies e abundância das populações de mosquitos nessas localidades. Os dados de sazonalidade estão de acordo com Guimarães ${ }^{86}$ e Cardoso et al. ${ }^{116}$, que concluem que a temperatura e a precipitação afetam a abundância de mosquitos. 


\subsection{Hábito Alimentar}

Foram utilizadas as técnicas CDC (copa/solo), busca ativa por aspiração e Shannon na tentativa de se coletar fêmeas de mosquitos com conteúdo sanguíneo em seu abdome. Um total de 386 mosquitos ingurgitados foi coletado no período de fevereiro de 2015 a abril de 2017 nos ambientes duas localidades. Destas, 356 amostras foram coletadas na APA e apenas 30 amostras no PEC. As amostras foram submetidas à extração de DNA e após foram submetidas à amplificação por PCR com primers de trechos de mitDNA do Cyt B. Vinte e três amostras coletadas na localidade APA e 10 amostras coletadas no PEC não tiveram positividade para nenhum dos primers testados, a técnica utilizada foi sensível em detectar $92 \%$ das amostras. Não houve nenhum resultado positivo para primatas não humanos e gato nas amostras.

Anopheles cruzii foi a espécie mais coletada ingurgitada em todos os ambientes da APA, com 270 espécimes. No ambiente periurbano 1, foram coletados 2 espécimes; no ambiente periurbano 2 foram coletados 71 espécimes ingurgitados; no ambiente intermediário 83 espécimes 1 espécime em armadilhas CDC solo, 1 espécime em aspiração e 81 em armadilha de Shannon. No ambiente silvestre, 114 espécimes foram coletados, 2 espécimes em aspiração, 1 espécime em CDC copa e 111 em armadilha de Shannon. Outra espécie Mansonia (Mansonia) indubitans apresentou 22 indivíduos, todos coletados no ambiente intermediário da APA, 22 espécimes em armadilha de Shannon e 1 espécime em aspiração.

A técnica de PCR utilizando oligonucleotídeos com sequências do citocromo $\mathrm{B}$, aliadas ao sequenciamento de DNA, para análise dos hábitos alimentares de mosquitos, mostraram-se bastante adequadas e eficazes no presente estudo. 
A Tabela 10, a seguir, mostra as espécies de mosquitos coletadas ingurgitadas e fontes alimentares identificadas por técnica de PCR. Com relação às interações entre as espécies de mosquitos coletadas ingurgitadas e suas fontes de repasto sanguíneo, a Tabela 11 mostra as associações reveladas e os respectivos valores de significância encontrados. Os dados mais significativos revelados pelo teste estatístico mostraram que An. cruzii tendeu a se alimentar mais em humanos $(p=0,05)$ do que em outras fontes sanguíneas pesquisadas. 
Tabela 10 - Espécies de mosquitos coletadas ingurgitadas e fontes alimentares identificadas por técnica de PCR, no período de fevereiro de 2015 a abril de 2017, nas localidades APA Capivari Monos e PE Cantareira.

\section{Fontes - primers}

\begin{tabular}{|c|c|c|c|c|c|c|c|c|c|c|}
\hline Espécies & $\mathbf{n}$ & Aves $^{1}$ & Cão ${ }^{2}$ & Roedor $^{3}$ & Humano $^{4}$ & Bovino $^{5}$ & Equino $^{6}$ & Outros Mamiferos $^{7}$ & Fontes & Repasto Misto \\
\hline Aedes (Ochlerotatus) scapularis & 3 & 1 & 0 & 1 & 0 & 0 & 0 & 1 & $1 ; 1 ; 3$ & Sim \\
\hline Aedes (Ochlerotatus) serratus & 2 & 0 & 0 & 1 & 0 & 0 & 0 & 1 & $7 ; 3$ & Não \\
\hline Anopheles (Kerteszia) cruzii & 239 & 52 & 6 & 68 & 230 & 11 & 4 & 2 & Todas & $\operatorname{Sim}$ \\
\hline Coquillettidia (Rhynchotaenia) albifera & 4 & 0 & 0 & 0 & 2 & 1 & 1 & 0 & $4 ; 5 ; 6$ & Sim \\
\hline Culex (Culex) nigripalpus & 5 & 2 & 0 & 3 & 0 & 0 & 0 & 0 & $1 ; 3$ & Não \\
\hline Culex (Culex) quinquefasciatus & 5 & 0 & 1 & 0 & 2 & 0 & 0 & 0 & $2 ; 4$ & Sim \\
\hline Culex (Melanoconion) vaxus & 5 & 0 & 0 & 1 & 0 & 0 & 0 & 1 & $3 ; 7$ & Não \\
\hline Mansonia (Mansonia) indubitans & 22 & 1 & 0 & 9 & 14 & 4 & 2 & 1 & $1 ; 3 ; 4 ; 5 ; 6 ; 7$ & $\operatorname{Sim}$ \\
\hline Mansonia (Mansonia) titillans & 6 & 1 & 0 & 1 & 3 & 0 & 0 & 0 & $1 ; 3 ; 4$ & $\operatorname{Sim}$ \\
\hline Psorophora (Janthinosoma) ferox & 7 & 2 & 0 & 1 & 0 & 0 & 0 & 5 & $1 ; 3 ; 7$ & Sim \\
\hline Runchomyia (Runchomyia) reversa & 2 & 0 & 0 & 0 & 2 & 1 & 0 & 0 & $4 ; 5$ & Sim \\
\hline Wyeomyia (Phoniomyia) theobaldi & 10 & 0 & 0 & 1 & 3 & 1 & 0 & 3 & $3 ; 4 ; 5 ; 7$ & $\operatorname{Sim}$ \\
\hline Wyeomyia (Prosopolepis) confusa & 11 & 0 & 1 & 3 & 3 & 0 & 0 & 3 & $2 ; 3 ; 4 ; 7$ & Sim \\
\hline
\end{tabular}


Tabela 11 - Valores de $p$, entre a diferença observada e esperada da interação de mosquitos e fontes de repastos sanguíneos. Teste de permutação com 10.000 aleatorizações, no período de fevereiro de 2015 a abril de 2017, nas localidades APA Capivari Monos e PE Cantareira.

\begin{tabular}{|c|c|c|c|c|c|c|c|}
\hline \multirow[t]{2}{*}{ Mosquito } & \multicolumn{7}{|c|}{ Hospedeiro } \\
\hline & Ave & Bovino & Cão & Equino & Humano & Outros.Mam & Roedor \\
\hline Aedes (Ochlerotatus) scapularis & 0,3819 & 1,0000 & 1,0000 & 1,0000 & 1,0000 & 0,2005 & 0,4861 \\
\hline Aedes (Ochlerotatus) serratus & 1,0000 & 1,0000 & 1,0000 & 1,0000 & 1,0000 & $0,0264^{*}$ & 0,4744 \\
\hline Anopheles (Kerteszia) cruzii & 0,1618 & 0,8093 & 0,3928 & 0,5927 & $0,0494^{*}$ & 0,9829 & 0,9440 \\
\hline Coquillettidia (Rhynchotaenia) albifera & 1,0000 & 0,2586 & 1,0000 & 0,1620 & 0,5298 & 1,0000 & 1,0000 \\
\hline Culex (Culex) nigripalpus & 0,0986 & 1,0000 & 1,0000 & 1,0000 & 1,0000 & 1,0000 & 0,1631 \\
\hline Culex (Culex) quinquefasciatus & 1,0000 & 1,0000 & 0,1455 & 1,0000 & 0,3536 & 1,0000 & 1,0000 \\
\hline Culex (Melanoconion) vaxus & 1,0000 & 1,0000 & 1,0000 & 1,0000 & 1,0000 & 0,2072 & 0,1014 \\
\hline Mansonia (Mansonia) indubitans & 0,9091 & 0,0703 & 1,0000 & 0,1501 & 0,8913 & 0,6834 & 0,1180 \\
\hline Mansonia (Mansonia) titilans & 0,5279 & 1,0000 & 1,0000 & 1,0000 & 0,3960 & 1,0000 & 0,6298 \\
\hline Psorophora (Janthinosoma) ferox & 0,2481 & 1,0000 & 1,0000 & 1,0000 & 1,0000 & $0,0119 *$ & 0,7525 \\
\hline Runchomyia (Runchomyia) reversa & 1,0000 & 0,1964 & 1,0000 & 1,0000 & 0,3534 & 1,0000 & 1,0000 \\
\hline Wyeomyia (Phoniomyia) theobaldi & 1,0000 & 0,3827 & 1,0000 & 1,0000 & 0,7381 & $0,0403^{*}$ & 0,7487 \\
\hline Wyeomyia (Prosopolepis) confusa & 1,0000 & 1,0000 & 0,3078 & 1,0000 & 0,8269 & $0,0507^{*}$ & 0,2374 \\
\hline
\end{tabular}

*Significância estatística $\leq 0,05$. 


\subsection{Sequenciamento}

O sequenciamento foi realizado com o intuito de validar alguns dos primers utilizados. O resultado mostrou que os primers foram sensíveis e específicos, confirmando os resultados positivos pela técnica de PCR para os respectivos hospedeiros identificados e comparados por similaridade pela ferramenta BLAST (Tabela 12).

Tabela 12 - Resultado do sequenciamento das amostras de mosquitos ingurgitados e suas fontes alimentares identificadas por técnica de PCR, coletadas no período de fevereiro de 2015 a abril de 2017, na APA Capivari Monos e PE Cantareira.

\begin{tabular}{|c|c|c|c|c|c|c|c|}
\hline Espécies/Categorias taxonômicas & Ambientes & Técnica & Estrato & Primer & Resultado & Similaridade & Sequência BLAST \\
\hline Culex (Culex) nigripalpus & PER 1-APA & $\mathrm{CDC}$ & Copa & Aves & Cyclarhis sp & $99 \%$ & JQ239207.1 \\
\hline Anopheles (Kerteszia) cruzii & PER 2-APA & Shannon & Solo & Humano & Homo sapiens & $99 \%$ & MG244226.1 \\
\hline Anopheles (Kerteszia) cruzii & PER 2-APA & Shannon & Solo & Humano & Homo sapiens & $98 \%$ & KP240804.1 \\
\hline Anopheles (Kerteszia) cruzii & INT-APA & Shannon & Solo & Humano & Homo sapiens & $98 \%$ & MG244226 \\
\hline Anopheles (Kerteszia) cruzii & INT-APA & Shannon & Solo & Humano & Homo sapiens & $99 \%$ & GQ902958.1 \\
\hline Anopheles (Kerteszia) cruzii & SIL-APA & Shannon & Solo & Humano & Homo sapiens & $95 \%$ & KP126143 \\
\hline Wyeomyia (Phoniomyia) edwardsi & SIL-APA & Shannon & Solo & Humano & Homo sapiens & $98 \%$ & GQ902958.1 \\
\hline Anopheles (Kerteszia) cruzii & SIL-APA & Shannon & Solo & Humano & Homo sapiens & $99 \%$ & GQ902958 \\
\hline Anopheles (Kerteszia) cruzii & SIL-APA & Shannon & Solo & Humano & Homo sapiens & $99 \%$ & MG244226.1 \\
\hline Anopheles (Kerteszia) cruzii & SIL-APA & Shannon & Solo & Humano & Homo sapiens & $99 \%$ & MG244226.1 \\
\hline Anopheles (Kerteszia) cruzii & SIL-APA & Shannon & Solo & Humano & Homo sapiens & $99 \%$ & GQ902958 \\
\hline Culex (Melanoconion) sp & SIL-PEC & Aspiração & Solo & Roedor & Rattus novergicus & $100 \%$ & KP244683.1 \\
\hline Psorophora (Janthinosoma) ferox & SIL-PEC & Shannon & Solo & Roedor & Rattus novergicus & $93 \%$ & KP244683.1 \\
\hline Wyeomyia (Phoniomyia) theobaldi & SIL-APA & $\mathrm{CDC}$ & Solo & Mamíferos & Didelphis aurita & $97 \%$ & -- \\
\hline Wyeomyia (Phoniomyia) theobaldi & SIL-APA & $\mathrm{CDC}$ & Solo & Mamíferos & Didelphis aurita & $96 \%$ & -. \\
\hline
\end{tabular}




\section{DISCUSSÃO}

Os impactos das atividades humanas sobre o meio ambiente provocam distúrbios com diferentes intensidades, alterando o espaço geográfico e as comunidades naturais, intensificando a perda da biodiversidade e o surgimento de doenças $^{61,89,118}$. Em mosquitos, impactos ambientais negativos e positivos promovem alterações na composição de suas assembleias, gerando mudanças de dominância, expansão espacial de vetores (dispersão) e aumentam o risco de surgimento de novos ciclos de transmissão e o transbordamento de doenças, além dos limites de ambientes silvestres para ambientes urbanos, onde espécies amplificadoras de patógenos podem estar presentes em elevada abundância ${ }^{119}$.

Considerando que as doenças podem espalhar-se em diversas escalas, devido à proximidade e às interações humanas com o ambiente, e que a família Culicidae está amplamente distribuída geograficamente e suas espécies são conhecidas principalmente pela hematofagia das fêmeas e transmissão de patógenos aos animais silvestres, ao homem e seus animais domésticos, evidencia-se a importância de melhor conhecer as interações e a bioecologia em unidades de conservação na cidade de São Paulo.

Observando os parâmetros de diversidade, a localidade APA apresentou maiores valores de riqueza e abundância de espécies do que os valores encontrados no PEC, em esforço amostral idêntico. Apesar das coletas serem adequadas e as curvas de acúmulo de espécies mostrarem eficiência nas coletas, não foi possível acessar de maneira completa, a riqueza existente nas localidades.

Comparando as curvas de acúmulo de espécies entre as localidades (APA e PEC), em nenhum dos casos apresentados mostrou sinal de assíntota em 27 amostras, informando que a riqueza total é ainda mais elevada. Resultados semelhantes sobre a riqueza de espécies observada foram verificados por Ribeiro 
et al. $^{14}$, onde suas curvas de acúmulo de espécies não revelaram uma assíntota, sendo coletadas em ambiente silvestre 68 espécies e em ambiente antrópico 71 espécies na APA Capivari Monos, sugerindo que o ambiente antrópico por ser ambiente de transição entre a mata e o ambiente periurbano, oferece maiores oportunidades e recursos para ocorrência das espécies de mosquitos.

No PEC, Montes ${ }^{12}$ identificou apenas a presença de 21 espécies de mosquitos e ausência de anofelinos do subgênero Kerteszia, atribuindo tal fato à alterações bióticas e abióticas durante a última década, o que tornou o ambiente inadequado para o subgênero Kerteszia. Neste estudo, nos 27 meses de coleta apenas 17 indivíduos de Anopheles cruzii foram coletados e todos no estrato copa, o que afirma a presença da espécie habitando os estratos verticais mais elevados, assim como Deane et al. ${ }^{147}$ a encontraram nesta localidade.

O estimador de riqueza total Jackkinife de $1^{\text {a }}$ ordem calculado para as localidades com intervalo de confiança de 95\%, mostrou que para APA a estabilização da curva de acúmulo de espécies atingiria estabilização em torno de 91 a 114 espécies e para o PEC em torno de 67 a 93 espécies (Figura 18). Este estimador utilizado é considerado um bom estimador para riqueza total, pois considera as espécies raras presentes em apenas uma amostra uniques ${ }^{104}$.

Entre os ambientes, as curvas de acúmulo de espécies mostram a mesma situação descrita por Magurram ${ }^{104}$ e Longino et al. ${ }^{120}$, afirmando que estudos de diversidade dificilmente revelam a verdadeira riqueza, pois, nem todas as espécies poderão ser reveladas pelo emprego de poucas técnicas de amostragem e tempo de estudo, que para estudos de diversidade devem se estender até que a curva de acúmulo encontre uma estabilização. No caso desse estudo a utilização de apenas uma técnica para amostrar as espécies nos estratos (armadilha CDC) pode ter sido insuficiente para amostrar todas as espécies presentes nos ambientes, pois nem todas as espécies são atraídas por esta armadilha. 
Não só a riqueza de espécies, mas também a riqueza de gêneros deve ser considerada, pois, caracteriza a situação ambiental local ${ }^{123}$. O gênero Culex neste estudo apresentou superioridade com 20 espécies/categorias taxonômicas na APA contribuindo com $61 \%$ do total de mosquitos coletados nesta localidade. No PEC esse gênero contribuiu com 24 espécies/categorias taxonômicas e representando abundância de $39 \%$ do total de mosquitos na localidade. O gênero Culex esta distribuído amplamente em todas as regiões zoogeográficas do mundo e segundo o catálogo de mosquitos "Mosquito Taxonomy Inventory", em torno de 769 espécies são reconhecidas ${ }^{7}$. Com relação aos subgêneros revelados, na APA ocorreram Carrolia, Culex, Melanoconion, Microculex, e Phenacomyia, e no PEC dos gêneros citados, apenas Phenacomyia não foi encontrado.

Com relação à similaridade na composição de espécies compartilhadas entre os ambientes, a análise de Cluster mostrou que embora todos ambientes de coletas compartilhassem espécies de mosquitos entre si, a similaridade foi maior entre os ambientes de uma mesma localidade, do que quando comparadas as localidades APA e PEC. Esse resultado demonstra que os ambientes estudados em uma mesma localidade, embora diferentes quando se observa as feições da paisagem, possuem suas assembleias de mosquitos bastante parecidas.

O ordenamento dos ambientes, obtido nos gráficos de perfis de diversidade corroboram a semelhança entre os ambientes, pois a intersecção das curvas observadas no gráficos significam que os ambientes são não comparáveis em seus parâmetros de diversidade. Esse aspecto da relação entre as espécies de Culicidae e o ambiente foi observado por Forattini et al. ${ }^{92}$ que evidenciaram $50 \%$ de variação na similaridade entre a composição de espécies nos ecótopos estudados em ambiente intermediário e peridomiciliar.

A uniformidade, que leva em consideração a distribuição da abundância das espécies no ambiente sugere variação entre os ambientes, sendo o ambiente 
intermediário da APA o mais uniforme, seguido do ambiente silvestre e periurbano 2. O ambiente periurbano 1 foi o menos uniforme. Nos ambientes do PEC, o ambiente silvestre foi o mais uniforme, seguido pelo intermediário e periurbano, isso indica que nesses ambientes há baixa dominância de uma única espécie.

As espécies de mosquitos podem ser mais abundantes quando a temperatura e a precipitação são elevadas, pois essa característica entre outras variáveis favorece o desenvolvimento das formas imaturas, e essas características são bem definidas nos meses de outubro à março (primavera e verão) em regiões de mata atlântica ${ }^{124}$.

As duas localidades estudadas APA e PEC são bem diferentes quanto às características ambientais (relevo, altitude, vegetação, fauna, clima e regime de chuvas). A APA, que foi criada em 2001, por estar inserida no extremo sul do município de São Paulo, onde concentra patrimônio natural expressivo tem função de proteção dos recursos hídricos e da biodiversidade, possui legislação regulatória que estabelece zonas de uso sustentável dos recursos naturais da APA ${ }^{67}$. Além disso, serve como zona de amortecimento que minimiza os impactos provocados pelo uso e ocupação do solo, impedindo a expansão desordenada na região.

A proximidade com a Serra do Mar faz como que este ambiente de mata Atlântica possua forte variação climática que favorece a riqueza e abundância de mosquitos principalmente os que utilizam criadouros naturais como bromélias. Tal evidência pode explicar a menor riqueza e a baixa ocorrência de An. cruzii nos ambientes do PE Cantareira, embora exista inúmeras ilhas de bromélias distribuídas pelos ambientes estudados.

A frequência e a intensidade das chuvas pode ser um importante determinante na dinâmica das assembleias de mosquitos e taxas de transmissão de patógenos segundo observam Shaman e Day ${ }^{125}$, que o regime de precipitação tem no mínimo duas principais influências no ciclo de vida dos mosquitos, ela 
aumenta a umidade próxima da superfície alterando o comportamento dos mosquitos, principalmente na atividade de voo relacionado à busca por fontes de repasto sanguíneo; além disso, a precipitação pode alterar a abundância e os tipos de criadouros disponíveis para oviposição. Essa observação pode explicar em partes a mobilidade e a permanência de espécies de mosquitos no solo e na copa, verificada por suas frequências de coleta nesses estratos.

Nas duas localidades, a precipitação coincide com os meses mais quentes. $\mathrm{Na}$ APA essa estação se estendeu por cerca de seis meses, e a umidade relativa variou de $52,9 \%$ nos mês de menor umidade e $80,9 \%$ no mês de maior umidade. Esse fato pode explicar a maior riqueza e ocorrência das espécies nessa localidade, pois o regime de chuvas regula a disponibilidade de criadouros disponíveis ao longo do ano. O PE Cantareira, mostrou menores volumes de precipitação acumulada e temperaturas mais elevadas que os ocorridos na APA para o mesmo período de estudo. A média dos 30 dias anteriores às coletas para umidade relativa variou apresentado 32,7 no mês mais seco e $66,5 \%$ no mês mais úmido. Tal característica pode estar relacionada à proximidade dessa localidade com a pressão da urbanização da cidade de São Paulo, entre outras características bióticas e abióticas.

Segundo Souza ${ }^{126}$ variações do clima ao longo do tempo pode atingir de maneira mais ou menos homogênea as assembleias de mosquitos de ambientes verdes. Os resultados obtidos fornecem evidências de que, a variabilidade climática ao longo do tempo, promove alterações nos padrões de diversidade das assembleias de mosquitos. Assim, nos meses que tendem a ser mais quentes e chuvosos (outubro a março), há um aumento na riqueza e na abundância, em relação aos meses que tendem ser mais secos e frios (abril a setembro) ${ }^{127,128}$. Nesse estudo, verificaram-se condições de variação na abundância das espécies, próprias de cada localidade. De modo geral, a distribuição das abundâncias ao 
longo dos meses de estudo, para a localidade PE Cantareira, coincidiu com picos de maior precipitação acumulada e maiores espécimes coletadas. Na APA, a distribuição das abundâncias, ocorreu de modo mais regular, não acompanhando marcadamente as variações sazonais.

Segundo Forattini ${ }^{3}$, os representantes do gênero Culex parecem não apresentar grandes restrições em relação aos modos de vida das espécies, utilizam como criadouros coleções líquidas permanentes, criadouros tanto naturais como artificiais com águas produtivas, ricas em matéria orgânica e sob o ponto de vista epidemiológico são bem adaptados ao ambiente antrópico, o que favorece seu sucesso em colonizar praticamente qualquer tipo de ambiente ${ }^{2,129}$. São espécies de hábito predominantemente noturno e a hematofagia exercida no período crepuscular e noturno, ocorre em fontes variadas, porém, algumas têm comportamento hematofágico voltado às aves ${ }^{3}$. As espécies em sua maioria são vetores de diversos arbovírus, como West Nile Virus, encefalites e filariose bancrofitiana, além disso, são fatores de incômodo em grandes centros urbanos como acontece nas proximidades do rio Pinheiros, em São Paulo, com a espécie Cx. (Cux.) quinquefasciatus ${ }^{130-132}$.

Culex quinquefasciatus, uma das espécies importantes na região Sudeste do Brasil como fator de incômodo e em outras regiões vetor de arbovírus e filárias ${ }^{3}$, associadas à degradação ambiental e criadouros poluídos e por ter hábitos hematofágicos antropofílicos, foi coletada em todos os ambientes da APA com maior abundância no ambiente silvestre desta localidade, o que torna importante a realização de estudos futuros para investigar esse fato. Esta espécie, no PEC, em nenhum dos ambientes foi coletado em armadilha CDC, e nas duas técnicas empregadas para hábito alimentar (aspiração e armadilha de Shannon) foi coletado apenas um espécime, sem identificação do seu repasto sanguíneo. Na APA, Cx. quinquefasciatus se alimentou em hospedeiros cão e humano e um repasto misto 
nesses dois recursos, evidenciando comportamento generalista e antropofílico como descrito na literatura ${ }^{2,3}$.

Em ecologia, a riqueza entre ambientes, pode refletir o grau de distúrbios sofridos ao longo do tempo ${ }^{104}$. Entre os ambientes estudados, na APA a riqueza foi maior no ambiente periurbano 1, situado no bairro do Emburá, apresenta um mosaico de estruturas artificiais casas de alvenaria, sítios com lagos artificiais, cursos d'água naturais, piscinas circundado por ambiente de mata e influencia antrópica significativa com presença de população em expansão e animais domésticos. Essa configuração do ambiente torna possível a presença de diversidade de mosquitos bastante diferenciada, pois disponibiliza variedade de criadouros artificiais e naturais como as bromélias para manutenção das espécies.

Entre os ambientes periurbano 2 e intermediário ambos situados no bairro de Engenheiro Marsilac, a riqueza foi a mesma. O ambiente periurbano 2 apresenta em sua estrutura forte influência antrópica com muitos comércios, residências de alvenaria, uma unidade básica de saúde (UBS), posto da polícia militar, linha de ônibus e a presença da população humana em expansão, que assim como no periurbano 1 modifica a paisagem natural, e possibilita a presença de culicídeos antropofílicos pela presença de variados tipos de criadouros artificiais e naturais.

Apesar dessa modificação antrópica na paisagem, observa-se que a fauna de culicídeos é composta por diversidade considerável, com espécies silvestres como sabetíneos dos gêneros Wyeomyia, Trichoprosopon, Runchomyia, Sabethes e Limatus e espécies antrópicas como Cx. quinquefasciatus e Ae. albopictus. Li. durhamii foi uma das espécies com maior número de indivíduos nesse ambiente, devido a presença de criadouros artificiais associados a vegetação da borda de fragmentos de mata. Nesse ambiente foi coletado o único exemplar de Ae. aegypti durante o estudo. 
Outras espécies coletadas nesse ambiente como as do gênero Aedes (Ae. fluviatilis, Ae. scapularis, Ae. serratus, Ae. terrens, Ae. albopictus e Ae. aegypti) e Sabethes (Sabethes purpureus) ocupando principalmente o estrato solo, também acrescentam valor epidemiológico dado envolvimento com a transmissão de vírus da febre amarela ${ }^{79,84,121,122}$.

Espécies da tribo Mansoniini, representadas pelos gêneros Mansonia e Coquillettidia que são consideradas fator de incômodo para humanos e animais domésticos, foram coletadas em baixa abundância ocupando o estrato próximo ao solo. Segundo Dorvillé ${ }^{123}$, as espécies da tribo Mansoniini e da tribo Aedini, como a espécie Ae. scapularis, quando dominantes na assembleia de mosquitos, são consideradas como habitantes de áreas em alto grau de modificação.

Por outro lado, a presença de An. cruzii como uma das espécies mais abundantes observada nesse ambiente, sugere que embora impactos antrópicos ocorram, estes, não parecem ser intensos ao ponto de eliminar essa espécie do local. Outra característica que corrobora esse cenário é a baixa abundância de Ae. scapularis, Ae. serratus e as espécies da tribo Mansoniini.

O ambiente intermediário da APA é composto de paisagem mista formada por fragmentos de vegetação e pasto, faz divisa com os ambientes com forte influencia antrópica e o ambiente de mata. Nesse ambiente ocorre a criação de gado e possui pasto e mata em estado avançado de regeneração, lagos artificiais e cursos d'água naturais. Esse ambiente e o periurbano 2 são os mais próximos entre si em relação aos outros ambientes estudados na APA e apresentaram índice de Bray-Curtis com $79 \%$ de similaridade na composição de espécies de mosquitos.

As espécies de culicídeos mais abundantes nesse ambiente foram $C x$. nigripalpus e An. cruzii ocupando principalmente a copa, Wy. confusa e Li. durhamii ocupando principalmente o estrato solo. Todos os Aedes presentes no ambiente periurbano 2 exceto Ae. aegypti e Ae. albopictus, ocorreram no ambiente 
intermediário. A presença de Ps. ferox nesse ambiente aumenta o rol de espécies com potencial para transmissão do vírus da febre amarela.

O ambiente silvestre localizado próximo à cachoeira do Marsilac (ponto turístico de Parelheiros) foi o segundo ambiente com maior riqueza de culicídeos. É o ponto mais afastado entre os ambientes estudados, esse ambiente é mais preservado com vegetação secundária e alto grau de regeneração e com pouca interferência antrópica, apresentando poucas moradias que são esparsas. Neste local foram coletadas 47 espécies/categorias taxonômicas, sendo 37 espécies em cada um dos estratos verticais. An. cruzii foi a espécie mais abundante no ambiente e sua frequência foi de 369 espécimes na copa e 112 espécimes no solo. $C x$. nigripalpus foi a segunda espécie mais abundantes neste ambiente com frequência de 216 espécimes na copa e 23 espécimes ocorrendo ao nível do solo, um espécime ingurgitado foi coletado e identificado tendo se alimentado com sangue de roedor.

Espécies de Aedes, Psorophora, Sabethes foram identificadas no ambiente silvestre, todas elas são indicadas como potenciais transmissores do vírus da febre amarela silvestre ${ }^{37,81}$. Um dado importante para o ambiente silvestre é a presença de Cx. quinquefasciatus (138 espécimes), em relação aos outros ambientes estudados na APA, esta espécie foi mais frequente no solo (99 espécimes) e apresentou maior abundância em relação aos outros ambientes estudados. Cx. quinquefasciatus utiliza como criadouros, águas poluídas, ricas em matéria orgânica, e esta descoberta sugere que, impactos pontuais provocados pela presença humana no ambiente silvestre, mesmo em baixa aglomeração humana, favoreceu sua presença. Esta espécie foi identificada com um repasto sanguíneo misto com sangue de humano e cão e outro espécime com sangue de humano, todos no estrato solo. 
Com relação aos hábitos alimentares foram coletadas 134 fêmeas ingurgitadas, em sua grande maioria An. cruzii (114) se alimentando em humano principalmente e repastos mistos com interações entre An. cruzii, humano e aves, humano e roedor, humano e cão. Cx. (Mel.) vaxus foi coletado na copa e sua fonte alimentar foi positiva para mamíferos. Wy. confusa foi identificada se alimentando em roedor e cão e $W y$. theobaldi se alimentando em roedor ambas no estrato copa.

O ambiente silvestre é bastante rico em espécies do gênero Culex (15 espécies), o que pode ser considerado um cenário ideal para a introdução e circulação de arbovírus como West Nile Virus, caso aves migratórias infectadas vindas dos EUA utilizem esse ambiente para descanso e alimentação no percurso de suas rotas migratórias.

A presença de espécies com grande importância epidemiológica em abundância elevada, nos ambientes da APA, tais como, An. cruzii demonstrando o potencial malarígeno da região, dado o comportamento desta espécie, que foi mais presente no estrato copa e praticando a hematofagia em variadas fontes e principalmente de sangue humano no estrato solo, e além disso, o potencial para transmissão de diversas arboviroses em ciclos enzoóticos, principalmente entre $C x$. nigripalpus e aves silvestres, dada sua presença ocupando os nichos presentes na copa merecem atenção das autoridades em saúde pública.

Os dados mostram que os ambientes mais ricos em espécies podem ser considerados ambientes heterogêneos, que apresentam em sua estrutura espacial maior disponibilidade de criadouros e oferta de recursos alimentares para os mosquitos. De fato, na APA, observa-se que no ambiente periurbano 1, sendo um ambiente com diversos habitats em sua estrutura, oferece mais suporte para as espécies com tendências a comportamentos variáveis no gradiente ambiental de silvestres a antrópicos, como as espécies An. cruzii, Cx. (Cux.) sp, Cx. (Cux.) nigripalpus, Cx. (Mel.) ribeirensis e Cx. (Cux.) chidesteri ${ }^{2,3}$. 
Na localidade PE Cantareira, o ambiente mais heterogêneo foi o ambiente intermediário com a presença das espécies como, Cx. (Mel.) vaxus, Wy. (Prl.) confusa, Cx. (Cux.) nigripalpus e Li. durhamii como as mais abundantes. A presença de bromélias amplamente distribuídas pelos ambientes do PE Cantareira poderia representar uma paisagem ideal para presença de An. cruzii, no entanto, no presente estudo poucos exemplares (apenas 17 indivíduos) desta espécie foram coletados e com relação à estratificação vertical todos foram coletados no estrato copa.

Montes $^{12}$ em seu estudo não evidenciou a presença de An. cruzii e outras espécies do subgênero Kerteszia em nenhum dos ambientes pesquisados, além disso, comenta que as alterações ocorridas anteriormente ao ano de 2005, tornaram o ambiente do PEC inapropriado para permanência de espécies do gênero Kerteszia, mesmo com a ocorrência de riqueza significativa de bromélias em todos os ambientes e estratos.

O fato é que, An. cruzii ocorre nos ambientes do PEC, porém, não ficou evidentemente claro neste estudo, quais nichos são mais favoráveis para sua ocorrência e, talvez, suas exigências, como por exemplo, as variações microclimáticas sejam encontradas em habitats específicos, não explorados neste estudo, que influenciem de maneira a regular sua ocorrência nesta localidade.

Em comparação com a localidade APA, durante este estudo, An. cruzii foi coletado em todos os ambientes, e sua frequência entre os estratos verticais foi maior na copa embora tenha sido coletado também em armadilhas de solo. Gomes et al. ${ }^{146}$ verificaram comportamento diferente do observado neste estudo, eles concluíram que a presença proporcional de An. cruzii no solo e copa, sugere mobilidade desse anofelino no interior da floresta. Forattini et al. ${ }^{22}$ verificaram que An. cruzii mostrou ser indiferente aos estratos copa e solo. As observações de Gomes et al. ${ }^{146} \mathrm{e}$ Deane et al. ${ }^{147}$ mostraram resultados semelhantes aos de e 
Forattini et al. ${ }^{22}$ sobre a mobilidade de Anopheles cruzii entre a copa e o solo em uma floresta no estado de Santa Catarina. Esse comportamento sugere que esta espécie pode servir de ponte na transmissão da malária símia (copa) para humanos (solo) e vice e versa e, ainda, dependendo do local onde é coletado apresenta comportamento distinto.

Deane et $a{ }^{26}$ reconhece que a transmissão da malária para macacos que vivem no Parque Estadual da Cantareira é realizada por An. cruzii, a mesma espécie que desde 1940 é conhecida como sendo um vetor importante de malária humana no sudeste do Brasil, além disso, tem sido verificada que sua estratificação vertical varia em diferentes áreas, por exemplo, em Santa Leopoldina (Espírito Santo) e no Horto Florestal da Cantareira (São Paulo) esta espécie apresentou $99,5 \%$ e $99,3 \%$ de frequência no estrato copa.

No município de Joinville (Santa Catarina), os achados foram de $58 \%$ dessa espécie foi coletada na copa e $42 \%$ coletados no solo ${ }^{147}$. Sob os achados desta espécie, Deane ${ }^{147}$ inferiu que ela apresenta comportamento distinto em diferentes áreas, ou seja, dependendo das condições ambientais da área, ela é mais presente na copa, em outra área é coletado igual na copa e no solo, e em outros é coletado mais no solo do que na copa, ele atribuiu tal comportamento às condições ambientais. Ainda sobre os estudos de Deane et al. ${ }^{147}$, eles suspeitaram que pudesse haver um complexo de espécies crípticas de An. cruzii, com duas populações com comportamentos distintos nos estratos de um ambiente, uma picando junto à copa e transmitindo malária símia para macacos e outra picando junto ao solo e transmitindo malária para humanos, no entanto, não elucidaram tal resultado.

Os resultados deste estudo corroboram os resultados obtidos por Deane et al. ${ }^{147}$, de que dependendo do ambiente An. cruzii muda seu comportamento em relação a sua estratificação vertical. Outro fato a ser considerado, é que esta 
espécie teve correlação positiva e significância estatística com a variável temperatura máxima em estrato solo na localidade APA, sugerindo que pode haver relação desta espécie quando a temperatura está mais elevada ao nível do solo.

Souza ${ }^{126}$, em ambientes antrópico e silvestre na APA Capivari Monos, encontrou correlação positiva entre $A n$. cruzii e as variáveis ambientais pluviosidade e temperatura no ambiente antrópico, mas no ambiente silvestre essa espécie não foi associada com as variáveis ambientais.

Deane et al. ${ }^{147}$ verificaram a existência dessa espécie vivendo em mais de 99\% na copa das árvores. Neste estudo, durante as coletas no PEC, principalmente nos meses frios e secos (abril a setembro) em ambiente silvestre, observou-se que muitas bromélias, criadouros naturais de Kerteszia estavam secas e muitas bromélias epífitas encontravam-se caídas no solo. Esse achado pode explicar, em partes, a menor ocorrência e abundância dessa espécie nas coletas realizadas no PEC pelo menos no período de estudo e nos locais pesquisados dentro do ambiente silvestre, no entanto, esta espécie pode encontrar melhor refúgio em áreas não exploradas por serem de difícil acesso e não programadas para coletas.

Com relação ao hábito alimentar, An. cruzii apresentou comportamento bastante eclético, se alimentando em todos os hospedeiros testados, entretanto, os dados deste estudo mostram que houve certa atração, em se alimentar de humanos. Chaves et al. ${ }^{148}$ ao discutirem se as espécies de mosquitos se alimentam estruturadamente (em um único hospedeiro) ou aleatoriamente (diversos hospedeiros), concluíram que os mosquitos se alimentam de hospedeiros não porque são mais atraídos, mas sim, dos hospedeiros que estão mais disponíveis no ambiente. Conclusão semelhante também foi encontrada por Forattini et al. ${ }^{149} \mathrm{e}$ Molaei et al. ${ }^{100}$.

Outra espécie de importância médico entomológica, que neste estudo, teve maior abundância foi $C x$. (Cux.) nigripalpus. Esta espécie tem alto valor 
epidemiológico e vasto histórico de transmissão de diferentes patógenos em diversos países, como vírus da encefalite Saint Louis ${ }^{133,134}$, além de ser considerada espécie praga de gado em áreas rurais na Flórida, vetor de West Nile Virus em outros estados nos EUA ${ }^{135-137}$, encefalite equina venezuelana na Venezuela $^{138}$, Dirofilaria immitis em cães $^{139}$, Plasmodium hermani e Plasmodium elongatum $^{140,141}$.

Em 2014, no nordeste do Brasil, no estado do Piauí, West Nile Virus já foi isolado em humano e, mais recentemente em abril de 2018 isolado em uma epizootia em equídeos no Espírito Santo, merecendo atenção das autoridades de saúde em manter a vigilância e controle em alerta constante, dada ocorrência de Cx. nigripalpus bastante dispersa pela cidade de São Paulo ${ }^{85,142}$.

Culex nigripalpus e outras espécies desse gênero transmitem esse vírus anualmente provocando a morte de humanos e aves, elevando os gastos públicos de saúde e controle nos EUA ${ }^{143}$. Esta espécie ocorre praticamente o ano todo na APA (frequência maior que $80 \%$ das coletas) com estratificação vertical com maior frequência na copa do que no solo. Neste estudo, essa espécie tanto na localidade APA quanto na PEC não apresentou diferença estatisticamente significante entre os estratos.

Com relação aos hábitos alimentares pesquisados, as fêmeas de $C x$. nigripalpus encontradas ingurgitadas foram positivas para sangue de humano e roedor, no entanto não apresentaram significância estatística em se alimentar de nenhuma fonte específica, mostrando ser eclética na escolha de suas fontes. Associado ao fato desta espécie também não apresentar significância estatística quanto aos estratos verticais, pode-se sugerir que apresenta características potenciais para desempenhar a função como espécies ponte, na transmissão de patógenos entre os estratos e dispersá-los pelo ambiente. 
Carvalho et al. ${ }^{38}$ identificaram repasto sanguíneo por PCR em $C x$. nigripalpus sendo suas fontes identificadas como cão, humano, roedor, aves, e repastos mistos, no entanto suas análises estatísticas revelaram que esta espécie, teve uma maior predileção em se alimentar em aves como descreve a literatura. Guimarães et al. ${ }^{19}$ verificaram que esta espécie teve mais frequência de alimentação em aves e humanos. Laporta et al. ${ }^{131}$ encontrou esta espécie ingurgitada com sangue das fontes galinha, cão, humano, roedor e indivíduos com múltiplos repastos, e com maior frequência de alimentação nas fontes cão e roedores em $65 \%$ dos repastos sanguíneos, as maiores razões de repastos sanguíneos foram entre roedores e humanos. Como observado por diversos autores, esta espécie se alimenta em uma ampla variedade de hospedeiros apresentando múltiplos contatos durante a busca por fontes alimentares ${ }^{144}$, além disso, tende a se alimentar em hospedeiros mais tolerantes e pouco defensivos a exposição das picadas ${ }^{35,145}$.

A espécie Wy. confusa foi a espécie com maior ocorrência no PEC. Esse mosquito que pertencente à tribo Sabethini, ocorre em ambiente silvestre onde encontram seus criadouros naturais ${ }^{7}$. Adultos possuem hábitos diurnos e são encontrados mais no estrato ao nível do solo do que no estrato copa, se alimentam do homem quando este adentra a mata ${ }^{129,150}$. Segundo Consoli e Lourenço-deOliveira $^{2}$, as espécies conhecidas desse gênero são ecléticas quanto à sua alimentação e raramente invade as casas a procura de repastos sanguíneos. Poucos estudos são realizados com esta espécie, pois até o momento não é considerada vetor de patógenos ao homem, pelo menos no Brasil.

$\mathrm{Na}$ década de 40, após isolamento viral em uma espécie (Wy. melanocephala) na Colômbia, o vírus isolado recebeu o nome do gênero Wyeomyia $^{151}$. Em Trinidad, de um lote de mosquitos do gênero Wyeomyia, houve 
isolamento do vírus Kairi, estando entre os mosquitos mais representados na amostra Wy. aporonoma e Wy. ypsipola

No Panamá foi isolado vírus da encefalite de São Luís em espécies desse gênero ${ }^{152}$. Aitken ${ }^{153}$ também refere isolamento de vírus Tacaribe de espécies desse gênero. Há isolamentos de vírus, mas pouco se sabe sobre sua importância em ciclos de doenças silvestres atuais ${ }^{129,154}$. Os achados desta espécie neste estudo indicaram sua frequência maior no estrato solo, corroborando o descrito na literatura citada acima. Com relação aos seus hábitos alimentares, foram coletados 11 fêmeas desta espécie ingurgitadas que se alimentaram em fontes variadas: humano, cão roedor, aves e outros mamíferos que no sequenciamento revelou ser gambá Didelphis aurita. Foram identificados dois repastos sanguíneos mistos entre homem/roedor e roedor/cão. No teste estatístico de hábito as Wyeomyia encontradas indicaram com nível de significância, ter tendência a se alimentar de outros mamíferos (Tabela 11).

O gênero Limatus, representado pela espécie $L i$. durhamii bastante encontrado no estudo (>600 espécimes), ocorreu em todos os ambientes. A literatura descreve que esta espécie se cria em diversos criadouros, de naturais à artificiais, os adultos são de habito diurno e pouco agressivos ${ }^{129}$. Pouco se sabe sobre seus hábitos alimentares, mas parecem ser bastante ecléticos quanto à hematofagia $^{129}$.

Com relação à estratificação vertical, foram coletados com maior frequência ao nível do solo do que na copa. As fêmeas ingurgitadas de Li. durhamii foram coletadas nos ambientes intermediário da APA (1 indivíduo) e outro no ambiente periurbano do PEC, foi identificado repasto sanguíneo em fontes homem e outros mamíferos, e nenhum repasto misto, como esta espécie apresentou apenas dois indivíduos não foi inclusa nas análises de hábito alimentar. 
Segundo Forattini ${ }^{3}$, esta espécie parece ser entre os representantes da tribo Sabethini, os mais adaptados a permanecerem no ambiente alterado pelo homem e larvas de Li. durhamii já foram encontradas dividindo criadouros com Ae. aegypti e Ae. albopictus. Li. durhamii merece atenção, pois apresenta comportamento com tendências a domiciliação ocupando nichos nas bordas de ambientes de transição entre a mata e ambientes antrópicos podendo servir de espécie ponte.

Outras espécies como, $\mathrm{Hg}$. leucocelaenus, Ae. scapularis, Ae. fluviatilis, Ae. terrens e Ae albopictus, associadas à transmissão de febre amarela ${ }^{81}$ que compõe a fauna de mosquitos que ocorreram no PEC em baixa incidência, no entanto podem participar de ciclo de transmissão de arbovírus, sendo necessária a inclusão das áreas estudadas no PE Cantareira, na rotina de vigilância e monitoramento entomológico. Entre as espécies urbanas, Ae. aegypti foi coletado apenas um individuo no ambiente periurbano 2 da APA, Ae. albopictus foi representada por 20 indivíduos.

Os padrões de diversidade observados no estudo revelaram alta diversidade nas duas localidades, com espécies pouco restritas em apenas um ambiente. Das espécies de mosquitos encontradas em maior abundância, algumas tiveram correlações significativas estatisticamente com as variáveis ambientais estudadas, que confirmadas por alguns autores regulam sua abundância em um estrato vertical ou outro ${ }^{155}$.

Entre as localidades existe bastante diferença no padrão climático, devido às características de cada ambiente, localização geográfica (ex. proximidade com a Serra do Mar, corpos d'água, vegetação, urbanização e pressão antrópica). Essas características influenciam na dinâmica das assembleias dos mosquitos presentes em cada ambiente estudado, favorecendo sua diversidade.

O comportamento dos culicídeos de permanecer nos estratos verticais embora possa ser inerente à determinada espécie, parece sofrer forte influência 
com a variação das variáveis microclimáticas, a proporção de vegetação, estruturas antrópicas (artificiais) na paisagem e a presença de fontes alimentares, são características que estimulam tal comportamento de diferentes formas, sendo que as espécies respondem a tais estímulos de maneira diferente, variando de ambiente para ambiente.

Os resultados deste estudo contribuíram para o conhecimento da diversidade das localidades estudadas e de modo geral para biodiversidade da cidade de são Paulo. Outras espécies coletadas nas duas localidades merecem atenção por já terem sido encontradas portando arbovírus, serem transmissores comprovados de arboviroses como a febre amarela e outras por terem comportamentos e tendência a domiciliação, podendo servir de ponte entre os gradientes da vegetação expressos pela modificação de um ambiente para outro e entre os estratos verticais. 


\section{CONCLUSÕES}

a) As medidas de diversidade revelaram riqueza expressiva nas duas localidades estudadas, sendo que mais espécies podem ser reveladas tanto para APA Capivari Monos quanto para o PE Cantareira. A composição das assembleias de mosquitos foi semelhante entre os ambientes de uma mesma localidade. Variáveis ambientais podem influenciar a permanência de espécies entre os estratos verticais como sugere os dados para as espécies mais abundantes, a estratificação vertical varia entre as espécies umas tendem a frequentar mais um estrato do que o outro;

b) Anopheles (Kerteszia) cruzii apresentou frequência e significância estatística maior no estrato copa, a análise de hábito alimentar mostrou maior tendência dessa espécie em se alimentar ao nível do solo em humanos, indicando mobilidade e espécie ponte na transmissão de plasmódios entre os estratos verticais. Culex nigripalpus merece atenção das autoridades em saúde pública, pois é vetor de diversos arbovírus importantes, é eclético quanto à seus hospedeiros e sua dispersão é bastante expressiva pela cidade de São Paulo, além disso, foi a espécie mais abundante neste estudo;

c) O hábito alimentar dos mosquitos coletados ingurgitados mostra que mosquitos tendem a se alimentar de hospedeiros que estão mais disponíveis no ambiente; O comportamento de mosquitos varia de acordo com o ambiente, que apresenta características diferentes, podendo modificar seu modo de vida;

d) Considerando a importância epidemiológica das interações entre mosquitos e vertebrados e a detecção de espécies de mosquitos (como Anopheles cruzii, e outros) ingurgitados com sangue de roedores e repastos mistos, é sugerido uma melhor investigação para evidenciar ciclos silenciosos de arbovírus e plasmódios. 


\section{REFERÊNCIAS}

1 Harbach RE, Kitching IJ. Phylogeny and classification of the Culicidae (Diptera). Sys Entom. 1998;23(4):327-70.

2 Consoli RAGB, Lourenço-de-Oliveira R. Principais mosquitos de importância sanitária no Brasil. Rio de Janeiro: FIOCRUZ; 1994.

3 Forattini, OP. Culicidologia médica. São Paulo, Edusp; 2002.

4 Rueda LM. Global diversity of mosquitoes (Insecta: Diptera: Culicidae) in freshwater. Hidrobiology. Springer, Dordrecht; 2007;477-87.

5 Clements AN. The biology of mosquitoes: development, nutrition and reproduction. Wallingford: CAB International, 1992.

6 Costa C, Ide S, Simonka CE. Insetos imaturos. Metamorfose e identificação. Ribeirão Preto: Editora Holos; 2006.

7 Harbach RE. Mosquito Taxonomic Inventory. 2017. [Acessado em: 20 de Outubro de 2017]. Disponível em: http://mosquito-taxonomicinventory.info/family-culicidae-meigen-1818

8 Ward RA. Second Supplement to "A Catalog of the Mosquitoes of the World" (Diptera: Culicidae). Mosq Sys. 1984;16(3):1984.

9 Systematic catalogo of Culicidae. Washington, USA - WRBU. 2016. [Acessado em: 22 de Outubro de 2016]. Disponível em: http://www.mosquitocatalog.org/default.aspx?pglD=2

10 Urbinatti PR, Sendacz S, Natal D. Immature mosquitoes (Diptera: Culicidae) in a public city park. Rev Saúde Pública. 2001;35(5):461-6.

11 Taipe-Lagos CB, Natal D. Abundância de culicídeos em área metropolitana preservada e suas implicações epidemiológicas. Rev Saúde Pública. 2003;37(3): 275-79.

12 Montes, J. Fauna de Culicidae da Serra da Cantareira, São Paulo, Brasil. Rev Saúde Pública. 2005;39:578-84.

13 Silvério, EDC, Urbinatti, PR. The presence of mosquitoes (Diptera: Culicidae) in flood containment reservoirs in the eastern region of the City of São Paulo, Brazil. Rev Soc Bras Med Trop. 2011;44(4):504-7.

14 Ribeiro AF. Mosquitoes in degraded and preserved areas of the Atlantic Forest and potential for vector-borne disease risk in the municipality of São Paulo, Brazil. J Vec Ecol. 2012;37(2):316-324.

15 Medeiros-Sousa AR, Ceretti JR W, Urbinatti PR, Natal D, Carvalho GC, Paula MBD et al. Biodiversidade de mosquitos (Diptera: Culicidae) nos parques da cidade de São Paulo I. Biota Neotrop. 2013;13:554-560.

16 Bates M. Observations on the distribution of diurnal mosquitoes in a tropical forest. Ecology. 1944;25(2):159-170. 
17 Aragão MB. Algumas Medidas Microclimáticas, em Mata da Região" Bromélia-Malária", em Santa Catarina, Brasil. Mem Inst Oswaldo Cruz. 1958;56(2):415-452.

18 Mitchell L, Rockett L. Vertical stratification preferences of adult female mosquitoes in a sylvan habitat (Diptera: Culicidae). Great Lakes Entom. 1979;12(4):219-23.

Guimarães AE, Arlé M, Machado RNM. Mosquitos no Parque Nacional da Serra dos Órgãos, Estado do Rio de Janeiro, Brasil. II. Distribuição vertical. Mem Inst Oswaldo Cruz. 1985;80(2):171-185.

20 Laporta GZ, Sallum MAM. Coexistence mechanisms at multiple scales in mosquito assemblages. BMC Ecology. 2014;14(1):30.

21 Haddow AJ, Gillett JD, Highton RB. The mosquitoes of Bwamba county, Uganda. $V$. The vertical distribution and biting cycles of mosquitoes in rainforest, with further observations on microclimate. Bull Entom Res. 1947;37(03):301-330.

22 Forattini OP, Lopes OS, Rabello EX. Investigações sobre o comportamento de formas adultas de mosquitos silvestres. Rev Saúde Pública. 1968;2(2):111-173.

23 Love GJ, Smith WW. The stratification of mosquitoes. Mosq News. 1958; 18(4):279-288.

24 Anderson JF, Andreadis TG, Main AJ, Kline DL. Prevalence of West Nile virus in tree canopy-inhabiting Culex pipiens and associated mosquitoes. Am J Trop Med Hyg. 2004;71(1):112-9.

25 Deane LM, Deane MP, Neto JF. Studies on transmission of simian malaria and on a natural infection of man with Plasmodium simium in Brazil. Bull World Health Org. 1966;35(5):805.

26 Deane LM, Ferreira-Neto JA, Deane MP, Silveira IP. Anopheles (Kerteszia) cruzii, a natural vector of the monkey malaria parasites, Plasmodium simium and Plasmodium brasilianum. Trans Royal Society of Trop Med Hyg. 1970;64(4):647.

27 Deane LM, Deane MP, Ferreira-Neto JA, Almeida FB. On the transmission of simian malaria in Brazil. Rev Inst Med Trop São Paulo. 1971;13:311-9.

28 Deane LM, Ferreira-Neto JA, Sitonio JG. Estudo sobre a malária simiana no estado do Espirito Santo. Ver, Brasil. Biol. 1968; 28:531-6.

29 Deane LM, Ferreira-Neto JA. Malária em macacos do Estado do Rio Grande do Sul. Observações preliminares. Rev Inst Med Trop São Paulo. 1969;11:299-305.

30 Marassá AM. Identificação e diferenciação inter-específica pela subclasse IgG1 para a pesquisa de fonte sanguínea em dípteros da Família Culicidae, vetores da febre amarela silvestre. [Tese]. São Paulo: Faculdade de Saúde Pública da Universidade de São Paulo; 2008. 
31 Garcia-Rejon JEG, Blitvich BJ, Farfan-Ale JA, Loroño-Pino MA, Chi Chim WA, Flores-Flores LF et al. Host-feeding preference of the mosquito, Culex quinquefasciatus, in Yucatan State,Mexico. J Insect Science. 2010;10(32):112.

32 Tempelis $\mathrm{CH}$. Host-feeding patterns of mosquitoes, with a review of advances in analysis of blood meals by serology. J Med Entomol. 1975;11(6):635-653.

33 Heatwole $\mathrm{H}$, Shine R. Mosquitoes feeding on ectothermic vertebrates: a review and new data. Australian zoologist. 1976.

34 Edman JD, Kale HW. Host behavior: its influence on the feeding success of mosquitoes. An Entomol Soc Amer, 1971;64(2):513-6.

35 Edman JD. Host-feeding patterns of Florida mosquitoes: III. Culex (Culex) and Culex (Neoculex). J Med Entomol. 1974;11(1):95-104.

36 Klowden MJ, Lea AO. Abdominal distention terminates subsequent hostseeking behaviour of Aedes aegypti following a blood meal. J Insect Physiology. 1979;25(7):583-5.

37 Mucci LF, Junior RPC, de Paula MB, Scandar SAS, Pacchioni ML, Fernandes, et al. Feeding habits of mosquitoes (Diptera: Culicidae) in an area of sylvatic transmission of yellow fever in the state of São Paulo, Brazil. J Venom Anim Tox Trop Dis.2015;21(1):6.

38 Carvalho GC, Malafronte RS, Izumisawa CM, Teixeira RS, Natal L, Marrelli MT. Blood meal sources of mosquitoes captured in municipal parks in São Paulo, Brazil. J Vect Ecol. 2014;39(1):146-152.

39 Iversson LB. Situação atual do conhecimento ecoepidemiológico sobre arbovírus patogênicos para o homem na região da mata atlântica do Estado de São Paulo. Rev Inst Med Trop. São Paulo. 1994;36:343-353.

40 Rocco IM, Santos CL, Bisordi I, Petrella SM, Pereira LE, Souza RP, et al. Louis vírus da encefalite: Primeiro isolamento de um ser humano no estado de São Paulo, Brasil. Rev Inst Med Trop São Paulo. 2005;47(5):281-5.

41 Muriu SM, Muturi EJ, Shililu JI, Mbogo CM, Mwangangi JM, Jacob BG, et al. Host choice and multiple blood feeding behaviour of malaria vectors and other anophelines in Mwea rice scheme, Kenya. Mal J. 2008;7(1):43.

42 Takken W, Knols BG. Odor-mediated behavior of Afrotropical malaria mosquitoes. An Rev Entomol. 1999;44(1):131-157.

43 Service MW. Mosquitoes (Culicidae). Med Ins and Arac. 1993;120-240.

44 Silver JB. Mosquito ecology: field sampling methods. New York: Springer Science \& Business Media; 2007.

Wright RH. Why mosquito repellents repel. Sci Amer. 1975;233(1):104-111.

46 KHAN AA. Mosquito attractants and repellents. Texas: Agricultural Experiment Station; 1977. 
47 Price GD, Smith N, Carlson DA. The attraction of female mosquitoes (Anopheles quadrimaculatus Say) to stored human emanations in conjunction with adjusted levels of relative humidity, temperature, and carbon dioxide. J Chem Ecol. 1979;5(3):383-395.

48 Posey $\mathrm{KH}$, Schreck $\mathrm{CE}$. An airflow apparatus for selecting female mosquitoes for use in repellent and attraction studies. Mosquito News. 1981;41:566-8.

49 Chow E, Wirtz RA, Scott TW. Identification of blood meals in Aedes aegypti antibody sandwich enzyme-linked immunosorbent assay. J. Amer Mosq Control Assoc. 1993;9(2):195-205.

50 Boakye DA, Tang J, Truc P, Merriweather A, Unnasch TR. Identification of bloodmeals in haematophagous Diptera by cytochrome B heteroduplex analysis. Med Vet Entomol. 1999;13(3):282-7.

51 Deus JTD. Hábito alimentar de Aedes aegypti e Culex quinquefasciatus e sua implicação na capacidade reprodutiva. [Dissertação]. São Paulo: Faculdade de Saúde Pública da Universidade de São Paulo; 2011.

52 Logue K, Keven JB, Cannon MV, Reimer L, Siba P, Walker ED, et al. Unbiased characterization of Anopheles mosquito blood meals by targeted high-throughput sequencing. PLoS Neg Trop Dis. 2016;10(3):e0004512.

53 Haouas N, Gorcci M, Charguin AK. Leishmaniasis in central and southern Tunisia:current geographical distribution of zymodemes. Parasite. 2007;14:239-246.

54 Briegel $\mathrm{H}$. Metabolic relationship between female body size, reserves, and fecundity of Aedes aegypti. J Insect Physiol. 1990;36(3):165-172.

55 Nikbakhtzadeh MR, Buss GK, Leal WS. Toxic effect of blood feeding in male mosquitoes. Front Physiol. 2016;7:4.

56 Lehane MJ. The biology of blood-sucking in insects. England: Cambridge University Press; 2005.

57 Magnarelli LA. Diurnal nectar-feeding of Aedes cantator and A. sollicitans (Diptera: Culicidae). Env Entom. 1979;8(5):949-955.

58 Haeger JS. The non-blood feeding habits of Aedes taeniorhynchus (Diptera, Culicidae) on Sanibel Island, Florida. Mosq. News. 1955;15:21-26.

59 Farquharson CO. Harpagomyia and other Diptera fed by Crematogaster ants in S. Nigeria. Proc Entom Soc London.1918;66:29-38.

60 Stone CM, Foster WA. Plant-sugar feeding and vectorial capacity. In: Ecology of parasite-vector interactions. Wageningen Academic Publishers, Wageningen. 2013;35-79.

61 McCallum H. Landscape structure, disturbance, and disease dynamics. New Jersey, USA: Princeton University Press; 2008. Infectious disease ecology: effects of ecosystems on disease and of disease on ecosystems;100-122. 
62 Washino RK. The physiological ecology of gonotrophic dissociation and related phenomena in mosquitoes. J Med Entomol. 1977;13(4-5):381-388.

63 Roy, DN. On the role of blood in ovulation in Aedes aegypti. Linn Bull Entomol Res. 1936;27(3):423-9.

64 IBGE. Instituto Brasileiro de Geografia e Estatística. Diretoria de Pesquisas DPE - Coordenação de População e Indicadores Socias - COPIS. 2015. [Acessado em: 10 de Agosto de 2015]. Disponível em: http://www.cidades.ibge.gov.br/xtras/perfil.php?lang=\&codmun=3550308

65 Dislich, R, Cersósimo, L, Mantovani, W. Análise da estrutura de fragmentos florestais no Planalto Paulistano-SP. Rev Bras Bot. 2001;24(3):321-32.

66 São Paulo. Secretaria Municipal do Verde e Meio Ambiente. Guia dos parques Municipais de São Paulo. $4^{a}$ ed. atual. rev. São Paulo: Secretaria Municipal do Verde e Meio Ambiente; 2014. [Acessado em: 20 de Agosto 2015]. Disponível em: http://www.parqueibirapuera.org/guia-dos-parquesmunicipais-de-sao-paulo/.

67 São Paulo. Secretaria Municipal do Verde e Meio Ambiente. Plano de Manejo - APA Capivarí-Monos. 2011. [Acessado em: 21de junho de 2016]. Disponível

em: http://www.prefeitura.sp.gov.br/cidade/secretarias/meio_ambiente/publicacoe s_svma/index.php?p=26341.

68 São Paulo. Instituto Florestal. Secretaria de Estado do Meio Ambiente. Plano de Manejo do Parque Estadual da Cantareira. 2009. [Acessado em 10 agosto de 2015]. Disponível em: http://fflorestal.sp.gov.br/files/2012/01/PECantareira/Plano\%20de\%20Manejo /Plano\%20de\%20Manejo\%20Completo.pdf.

69 São Paulo. Centro de Vigilância Epidemiológica. Caso Autóctones de Malária no Estado de São Paulo. 2015 [Acessado em 24 de Julho de 2016]. Disponível em: http://www.cve.saude.sp.gov.br/htm/zoo/malaria0309_cautoctone.htm.

70 Duarte AM, Pereira DM, de Paula MB, Fernandes A, Urbinatti PR, Ribeiro $A F$, et al. Natural infection in anopheline species and its implications for autochthonous malaria in the Atlantic Forest in Brazil. Parasit Vect. 2013; $6(1)$ 50-58.

71 Deane LM. Simian malaria in Brazil. Mem Inst Oswaldo Cruz. 1992;87:1-20.

72 Duarte AMRDC. Estudo da malária em macacos silvestres brasileiros. [Dissertação]. São Paulo: Instituto de Ciências Biomédicas, Universidade de São Paulo;1998.

73 Duarte AMRC, Malafronte RS, Cerutti C, Curado I, Paiva BR, Maeda AY, et al. Natural Plasmodium infections in Brazilian wild monkeys: Reservoirs for human infections?. Acta Trop. 2008;107(2):179-185.

74 Yamasaki T, Duarte AM, Curado I, Summa ME, Neves DV, Wunderlich G, Malafronte RS. Detection of etiological agents of malaria in howler monkeys 
from Atlantic Forests, rescued in regions of São Paulo city, Brazil. J Med Primat. 2011;40(6):392-400.

75 Monath TP. Yellow fever: an update. Lancet Inf Dis. 2001;1(1):11-20.

76 Couto-Lima D, Madec Y, Bersot MI, Campos SS, de Albuquerque Motta M, Dos Santos FB, et al. Potential risk of re-emergence of urban transmission of Yellow Fever virus in Brazil facilitated by competent Aedes populations. Scientific reports. 2017;7(1):e4848.

77 Georgiev VSt. Arthropod-Borne Viral Encephalitis. In: National Institute of Allergy and Infectious Diseases, NIH. Humana Press. 2009;151-162.

78 Goddard J. Dynamics of arthropod-borne diseases. In: Infectious Diseases and Arthropods. Humana Press. 2008;19-28.

79 Vasconcelos PFC, Sperb AF, Monteiro HAO, Torres MAN, Sousal MRS, Vasconcelos $\mathrm{HB}$, et al. Isolations of yellow fever virus from Haemagogus leucocelaenus in Rio Grande do Sul State, Brazil. Trans Royal Soc Trop Med Hyg. 2003;97(1):60-62.

80 Thoisy $B$, Dussart $\mathrm{P}$, Kazanji $\mathrm{M}$. Wild terrestrial rainforest mammals as potential reservoirs for flaviviruses (yellow fever, dengue 2 and St Louis encephalitis viruses) in French Guiana. Transactions of the Royal Society of Tropical Medicine and Hygiene. 2004;98(7):409-12.

81 Mucci LF, Medeiros-Sousa AR, Ceretti-Júnior W, Fernandes A, Camargo AA, Evangelista E, et al. Haemagogus leucocelaenus and Other Mosquitoes Potentially Associated With Sylvatic Yellow Fever In Cantareira State Park In the São Paulo Metropolitan Area, Brazil. J Amer Mosq Cont Assoc. 2016;32(4):329-32.

82 Vasconcelos PFC. "Yellow fever in Brazil: thoughts and hypotheses on the emergence in previously free areas. Rev Saude Publica. 2010; 44(6):114449.

83 Auguste AJ, Lemey P, Pybus OG, Suchard MA, Salas RA, Adesiyun AA, et al. Yellow fever virus maintenance in Trinidad and its dispersal throughout the Americas. J Virol. 2010;84(19):9967-77.

84 Cardoso JC, Almeida MAB, Santos E, Fonseca DF, Sallum MAM, Noll CA, et al. Vírus da febre amarela em mosquitos Haemagogus leucocelaenus e Aedes serratus, sul do Brasil, 2008. Doen Infec Emerg. 2010;16(12):1918.

85 Brasil. Ministério da Saúde. Febre amarela sintomas transmissão e prevenção, situação epidemiológica dados. 2018. [Acessado em: 1 de Janeiro de 2018]. Disponível em: http://portalms.saude.gov.br/saude-de-az/febre-amarela-sintomas-transmissao-e-prevencao/situacaoepidemiologica-dados.

86 Guimarães AE, Gentili C, Lopes CM, Sant'Anna A, Jovita AM. Ecologia de mosquitos (Diptera: Culicidae) em áreas do Parque Nacional da Serra da Bocaina, Brasil. I-Distribuição por habitat. Rev Saúde Pública. 2000;34(3):243-50. 
Tissot AC, Navarro-Silva MA. Preferência por hospedeiro e estratificação de Culicidae (Diptera) em área de remanescente florestal do Parque Regional do Iguaçu, Curitiba, Paraná, Brasil. Rev Bras Zool. 2004;21(4):877-86.

88 Pinto CS. Ecologia de culicídeos vetores de febre amarela silvestre em relação ao microclima na floresta nacional de Caxiuanã-Melgaço-PA. [Tese]. Caxiuanã-Melgaço, Pará, Universidade Federal do Pará. 2007.

89 Myers N, Mittermeier RA, Mittermeier CG, Fonseca GAB, Kent J. Biodiversity hotspots for conservation priorities. Nature. 2000;403:853-8.

90 Altizer S, Ostfeld RS, Johnson PTJ, Kutz S, Harvell CD. Climate change and infectious diseases: from evidence to a predictive framework. Science. 2013; 341(6145):514-9.

91 WHO. World Health Organization. (2015). Dengue and severe dengue. [Acessado em: 19 de setembro de 2018]. Disponível em: http://www.who.int/en/news-room/fact-sheets/detail/dengue-and-severedengue

92 Forattini OP. Mosquitos Culicidae como vetores emergentes de infecções. Rev Saúde Pública. 1998;32(6):497-502.

93 Marques TC. Culicídeos associados às bromélias na Mata Atlântica do município de Cananéia, São Paulo, Brasil. [Dissertação]. São Paulo: Faculdade de Saúde Pública da Universidade de São Paulo; 2010.

94 Tarifa JR, Armani G. Os climas "naturais": os climas da cidade de São Paulo (JR Tarifa \& TR de Azevedo, org.). GEOUSP, FFLCH, Universidade de São Paulo, Novos Caminhos. 2001;4:34-70.

95 Nasci R.S., A lightweight battery-powered aspirator for collecting resting mosquitoes in the field. Mosq. News 1981;41:808-11.

96 Lane J. Neotropical Culicidae, Volume I. University of São Paulo, Brazil. Neotropical Culicidae. 1953;2:101-4.

97 Reinert JF. List of abbreviations for currently valid generic-level taxa in family Culicidae (Diptera). European Mosquito Bulletin. 2009;27:68-76.

98 Chang MC, Teng HJ, Chen CF, Chen YC, Jeng CR. The resting sites and bloodmeal sources of Anopheles minimus in Taiwan. Malaria Journal. 2008; 7(1): e105.

99 Ngo KA, Kramer LD. Identification of mosquito bloodmeals using polymerase chain reaction (PCR) with order-specific primers. J Med Entomol. 2003;40(2):215-22.

100 Molaei G, Andreadis TG, Armstrong PM, Diuk-Wasser M. Host-feeding patterns of potential mosquito vectors in Connecticut, USA: molecular analysis of bloodmeals from 23 species of Aedes, Anopheles, Culex, Coquillettidia, Psorophora, and Uranotaenia. J Med Entomol. 2008;45(6):1143-51.

101 Cupp EW, Zhang D, Yue X, Cupp MS, Guyer C, Sprenger TR, Unnasch TR. Identification of reptilian and amphibian blood meals from mosquitoes in an 
eastern equine encephalomyelitis virus focus in central Alabama. Amer J Trop Med Hyg. 2004;71(3):272-6.

102 Melo AS. O que ganhamos' confundindo'riqueza de espécies e equabilidade em um índice de diversidade?. Bio Neo. 2008;8(3):21-27.

103 Mclntosh RP. An index of diversity and the relation of certain concepts to diversity. Ecology. 1967;48(3):392-404.

104 Magurran AE. Medindo a Diversidade Biológica. John Wiley \& Sons, 2013.

105 Colwell RK. Biodiversity: concepts, patterns, and measurement. The Princeton guide to ecology. 2009;257-63.

106 Guedes MP. Culicidae (Diptera) no Brasil: Relações entre diversidade, distribuição e enfermidades. Oecologia Australis. 2012;16(2):283-96.

107 Whittaker RH. Evolution of species diversity in land communities. Evol. Biol. 1977;10:1-67.

108 Hurlbert SH. The nonconcept of species diversity: a critique and alternative parameters. Ecology. 1971;52(4):577-86.

109 Tóthmérész B. Comparison of different methods for diversity ordering. J Veg Science. 1995;6(2):283-90.

110 Nagendra H. (2002). Opposite trends in response for the Shannon and Simpson indices of landscape diversity. Applied Geography. 2002;22(2):17586.

111 Colwell RK, Chao A, Gotelli NJ, Lin SY, Mao CX, Chazdon RL, et al. Models and estimators linking individual-based and sample-based rarefaction, extrapolation and comparison of assemblages. J Plant Ecol. 2012;5(1):3-21.

112 Hammer $\varnothing$, Harper DAT, Ryan PD. PAST: Paleontological statistics software package for education and data analysis. Palaeontologia Electronica. 2001;4(1):e90.

113 Crawley MJ. The R book. John Wiley \& Sons; 2007.

114 Patil GP, Taillie C. Diversity as a concept and its measurement. J Amer Stat Assoc. 1982;77(379):548-61.

115 Peet RK. The measurement of species diversity: Annual review of ecology and systematics. 1974;5(1):285-307.

116 Cardoso JDC, de Paula MB, Fernandes A, dos Santos E, de Almeida MAB, da Fonseca DF, et al. Ecological aspects of mosquitoes (Diptera: Culicidae) in an Atlantic forest area on the north coast of Rio Grande do Sul State, Brazil. J Vec Ecol. 2011;36(1):175-86.

117 Lopes J, Arias JR, Yood J. Evidências preliminaries de estratificação vertical de postura de ovos por alguns Culicidae (Diptera), em florestas no municipio de manaus-Amazonas. Acta Amazonica. 1983;13(2):431-39. 
118 Myers SS, Gaffikinc L, Goldenb CD, Ostfeldd RS, Redforde KH, Rickettsf $\mathrm{TH}$, et al. Human health impacts of ecosystem alteration. Proc Nat Acad Scien. 2013;110(47):18753-60.

119 Hassell JM, Begon M, Ward MJ, Fèvre EM. Urbanization and disease emergence: Dynamics at the wildlife-livestock-human interface. T Ecol Evol. 2017; 32(1):55-67.

120 Longino JT, Coddington J, Colwell RK. The ant fauna of a tropical rain forest: estimating species richness three different ways. Ecology. 2002;83(3):689702.

121 Gratz NG. Critical review of the vector status of Aedes albopictus. Med Vet Entomol. 2004;18(3):215-27.

122 Berti J, Guzmán H, Estrada Y, Ramírez R. New records of mosquitoes (Diptera: Culicidae) from Bolívar State in South Eastern Venezuela, with 27 new species for the state and 5 of them new in the country. Fron Public Health. 2015;2:268.

123 Dorvillé LF. Mosquitoes as bioindicators of forest degradation in southeastern Brazil, a statistical evaluation of published data in the literature. Studies on Neotropical Fauna and Environment. 1996;31(2):68-78.

124 Guedes MLP, Navarro-Silva MA. Mosquito community composition in dynamic landscapes from the Atlantic Forest biome (Diptera, Culicidae). Rev Bras Entomol. 2014;58(1): 88-94.

125 Shaman J, Day JF. Reproductive phase locking of mosquito populations in response to rainfall frequency. PLoS One. 2007;2(3):e331.

126 Souza AFR. Aspectos ecológicos de mosquitos (Diptera: Culicidae) em ambientes degradados e preservados da APA Capivari-Monos no município de São Paulo. [Tese]. São Paulo: Faculdade de Saúde Pública, Universidade de São Paulo. 2014.

127 Pecoraro HL, Day HL, Reineke R, Stevens N, Withey JC, Marzluff JM, et al. Climatic and landscape correlates for potential West Nile virus mosquito vectors in the Seattle region. J Vec Ecol. 2007;32(1):22-28.

128 Chaves LF, Hamer GL, Walker ED, Brown WM, Ruiz MO, Kitron UD. Climatic variability and landscape heterogeneity impact urban mosquito diversity and vector abundance and infection. Ecosphere. 2011;2(6): 1-21.

129 Forattini OP. Entomologia médica. In: Entomologia médica. Edusp; 1965.

130 Dreyer G, Coelho G. Filariose linfática: doença potencialmente eliminável Lymphatic filariasis: a potentially eradicable disease. Cad. Saúde Públ. 1997;13(3):537-43.

131 Laporta GZ, Crivelaro TB, Vicentin EC, Amaro P, Branquinho MS, Sallum MAM. Culex nigripalpus theobald (Diptera, Culicidae) feeding habit at the parque ecologico do Tiete, Sao Paulo, Brazil. Rev Bras Entomol. 2008;52(4):663-8. 
Morais SAD, Marrelli MT, Natal D. Aspects of the distribution of Culex (Culex) quinquefasciatus Say (Diptera, Culicidae) in the region of the Pinheiros River, in the city of São Paulo, State of São Paulo, Brazil. Rev Bras Entomol. 2006;50(3):413-8.

133 Shroyer DA. The 1990 Florida epidemic of St. Louis encephalitis: virus infection rates in Culex nigripalpus. J Florida Mosq Cont Assoc (USA). 1991.

134 Chamberlain RW, Sudia WD, Coleman PH, Beadle LD. Vector studies in the St. Louis encephalitis epidemic, Tampa Bay area, Florida, 1962. Am J Trop Med Hyg. 1964;13(3):456-61.

135 Nayar JK, Rosen L, Knight JW. Experimental vertical transmission of Saint Louis encephalitis virus by Florida mosquitoes. Amer J Trop Med Hyg. 1986;35(6):1296-301.

136 Sardelis MR, Turell MJ, Dohm DJ, O'Guinn ML. Vector competence of selected North American Culex and Coquillettidia mosquitoes for West Nile virus. Emerging Infec Dis, 2001;7(6):1018.

137 Rutledge CR, Day JF, Lord CC, Stark LM, Tabachnick WJ. West Nile virus infection rates in Culex nigripalpus (Diptera: Culicidae) do not reflect transmission rates in Florida. J Med Entomol. 2003;40(3):253-8.

138 Méndez W, Liria J, Navarro JC, García CZ, Freier JE, Salas R, et al. Spatial dispersion of adult mosquitoes (Diptera: Culicidae) in a sylvatic focus of Venezuelan equine encephalitis virus. J Med Entomol. 2001;38(6):813-21.

139 Nayar JK, Knight JW. Aedes albopictus (Diptera: Culicidae): an experimental and natural host of Dirofilaria immitis (Filarioidea: Onchocercidae) in Florida, USA. J Med Entomol. 1999;36(4):441-8.

140 Nayar JK. Bionomics and physiology of Culex nigripalpus (Diptera: Culicidae) of Florida: An important vector of diseases. Florida. Agricultural Experiment Station. Bulletin (USA) 1982.

141 Nayar JK, Knight JW, Telford Jr, SR. Vector ability of mosquitoes for isolates of Plasmodium elongatum from raptors in Florida. J Parasitology. 1998;5426.

142 Vieira MA, Aguiar ADAX, Borba ADS, Guimarães HCL, Eulálio KD, Salmito MDA, et al. West nile fever in Brazil: sporadic case, silent endemic disease or epidemic in its initial stages?. Rev Inst Med Trop São Paulo. 2015;57(3):276-276.

143 CDC. Center for Disease Control and Prevention. West Nile vírus. 2018. [Acessado em: 25 de janeiro de 2018]. Disponivel em: https://www.cdc.gov/westnile/.

144 Anderson RA, Brust RA. Field evidence for multiple host contacts during blood feeding by Culex tarsalis, Cx. restuans, and Cx. nigripalpus (Diptera: Culicidae). J Med Entom. 1995;32(5):705-10.

145 Kelly DW. Why are some people bitten more than others? T Parasitology. $1981 ; 17$ (12):578-81. 
146 Gomes AC, Forattini OP, Natal D. Composição e atividade de mosquitos Culicidae. Emprego de armadilha CDC no Vale do Ribeira, Estado de São Paulo, Brasil. Rev de Saúde Pública. 1987;21:363-70.

147 Deane LM, Ferreira Neto JA, Lima MM. The vertical dispersion of Anopheles (Kerteszia) cruzi in a forest in southern Brazil suggests that human cases of malaria of simian origin might be expected. Mem Inst Oswaldo Cruz. $1984 ; 79(4): 461-3$.

148 Chaves LF, Harrington LC, Keogh CL, Nguyen AM, Kitron UD. Blood feeding patterns of mosquitoes: random or structured?. Frontiers in Zoology. 2010;7(1):3.

149 Forattini OP, Gomes ADC, Natal D, Kakitani I, Marucci D. Preferências alimentares de mosquitos Culicidae no Vale do Ribeira, São Paulo, Brasil. Rev Saúde Pública. 1987;21:171-87.

150 Galindo P, Trapido H, Carpenter SJ. Observations on Diurnal Forest Mosquitoes in Relation to Sylvan Yellow Fever in Panama1. Amer J Trop Med Hyg.1950:1(4):533-74.

151 Roca-Garcia M. The isolation of three neurotropic viruses from forest mosquitoes in eastern Colombia. J Infect Diseases. 1944;160-9.

152 Galindo P, Peralta PH, Mackenzie RB, Beye HK. St. Louis encephalitis in Panama: a review and a progress report. Amer $J$ Trop Med hyg. 1964;13(3):455-5.

153 Aitken TH. A Survey of Trinidadian Arthropods for Natural Virus Infections (August, 1953, to December, 1958). Mosquito News. 1960;20(1):1-10.

154 Hervé JDN, Travassos Rosa A, Pinheiro F, Sá Filho, G. Arboviroses. Aspectos ecológicos. Instituto Evandro Chagas. 1986;50:529-56.

155 Ueno HM, Forattini OP, Kakitani I. Distribuição vertical e sazonal de Anopheles (Kerteszia) em llha Comprida, SP. Rev Saúde Pública, 2007;41:269-75. 